UNIVERSIDADE DE SÃO PAULO

INSTITUTO DE QUÍMICA

\title{
Eletrodos Modificados por Óxido de \\ Tungstênio: Métodos de Preparação e \\ Aplicações Analíticas.
}

José Roberto Caetano da Rocha

Tese de Doutorado

Prof. Dr. Mauro Bertotti

Orientador

SÃO PAULO

23/01/2006 
"Hay hombres que luchan un día y son buenos Hay otros que luchan un año y son mejores Hay quienes luchan muchos años y son muy buenos Pero hay los que luchan toda la vida Esos son los imprescindibles." (Bertolt Brecht) 


\section{Tocando em Frente}

\section{Almir Sater e Renato Teixeira}

Ando devagar porque já tive pressa

e levo esse sorriso, porque já chorei demais

Hoje me sinto mais forte, mais feliz quem sabe

eu só levo a certeza de que muito pouco eu sei, eu nada sei

Conhecer as manhas e as manhãs,

o sabor das massas e das maçãs,

é preciso amor pra poder pulsar,

é preciso paz pra poder sorrir,

é preciso a chuva para florir.

Penso que cumprir a vida seja simplesmente

compreender a marcha, e ir tocando em frente

como um velho boiadeiro levando a boiada,

eu vou tocando os dias pela longa estrada eu vou,

de estrada eu sou

Todo mundo ama um dia, todo mundo chora,

Um dia a gente chega, no outro vai embora

Cada um de nós compõe a sua história,

e cada ser em si, carrega o dom de ser capaz,

e ser feliz

Ando devagar porque já tive pressa

e levo esse sorriso porque já chorei demais

Cada um de nós compõe a sua história,

e cada ser em si carrega o dom de ser capaz,

e ser feliz. 
Dedico este trabalho a minha querida esposa, TEREZA. A quem agradeço pelo amor, paciência e cumplicidade, que foram demonstrados a cada instante nestes 25 anos de nossa união. 


\section{À minha mãe, Mercedes, e à minha irmã, Odete, pelo constante incentivo.}

Aos meus filhos, Roberta e Leandro, em quem descobri o verdadeiro amor.

Ao Cléber a quem eu quero tanto quanto aos meus filhos. 


\section{Homenagem Póstuma}

Ao querido Prof. Antonio Machado Fonseca Neto que durante sua vida demonstrou o grande homem que era. Ético em todos os momentos. Educador ferrenho. Amado por muitos, incompreendido por poucos.

Machado onde quer que estejas quero agradecer por você ter compartilhado um pouco do seu conhecimento de vida e ter me aberto às portas da Química Analítica.

Muito obrigado. 


\section{AGRADECIMENTOS}

A Deus, eterno criador.

Ao Prof. Dr. Mauro Bertotti que teve paciência em transmitir os seus conhecimentos e me orientar durante estes quase oito anos de convívio, que incluem o período de mestrado e o de doutorado.

À Prof.a Dr.a Susana Inez Córdoba de Torresi por sugestões úteis que muito auxiliaram na conclusão desta tese.

Ao Prof. Dr. Claudimir Lucio do Lago pelo constante apoio junto à Comissão de Pós Graduação.

À Prof.a Dr.a Márcia C. A. Fantini pelo auxílio na interpretação dos espectros de raios- $\mathrm{X}$.

Aos colegas de laboratório Alexandra, Audrei, Denise, Dennys, Fernanda, Luis, Thiago, Tiago, Válber, Vânia pelos momentos bons e descontraídos que passamos juntos.

Aos professores e funcionários do Instituto de Química pelo excelente convívio.

Aos professores das Faculdades Osvaldo Cruz que, de alguma forma, me induziram para este caminho.

Aos professores, funcionários, alunos e ex-alunos da E. E. Fernão Dias Paes que muito me incentivaram neste meu projeto de vida.

Às minhas amigas - professoras do município de Ribeirão Pires Maria Clara e Sônia que além do incentivo me concederam suas amizades.

Ao Valdir, amigo e irmão, por todo o apoio.

À Célia pela amizade e conversas nos momentos bons e em momentos que não foram agradáveis.

Às funcionárias Lúcia e Luciana que sempre foram muito prestativas.

Aos funcionários da Seção de Pós Graduação pela forma eficaz e bondosa como realizam os seus trabalhos. 
A Sara, Vivente e Sueli por suas amizades.

Aos alunos Karen, Ivens e Fábio que me demonstraram muito carinho.

Aos meus familiares pelo incentivo e apoio.

Ao CNPq, CAPES e FAPESP pelo suporte financeiro.

A todas as pessoas que de alguma forma colaboraram no desenvolvimento deste trabalho, eu agradeço imensamente. 
Índice - I

\section{ÍNDICE}

Pág.

Agradecimentos

Índice

Índice das Figuras $\quad \mathrm{V}$

Índice das Tabelas $\quad$ XIII

Resumo XIV

Abstract XV

CAPÍTULO I - INTRODUÇÃO

1. INTRODUÇÃO 2

1.1. Eletrodos Quimicamente Modificados 2

1.2. Métodos de Imobilização do Agente Modificador 4

1.2.1. Adsorção ou Quimisorção 4

1.2.2. Formação de Ligação Covalente 6

1.2.3. Recobrimento com Filmes Poliméricos 7

1.2.4. Formação de Compósitos $\quad 7$

1.3. Eletrodos Modificados com Óxidos de Tungstênio 8

1.3.1. Imobilização Térmica 8

1.3.1.1. Oxidação Térmica $\quad 8$

1.3.1.2. Deposição Térmica a Pressão Reduzida 9

1.3.1.3. Spray Pirolítico 9

1.3.1.4. Eletrodo Moldado 9

1.3.1.5. Oxidação em Meio Básico 10

1.3.2. Eletrodeposição 10

1.3.2.1. Solução de Tungstato de Sódio $0,2 \mathrm{~mol}^{-1}$

1.3.2.2. Oxidação do Tungstênio Metálico 11

1.3.2.3. Método Xerogel 11

1.4. Propriedades Eletrocrômicas 12 
1.5. Aplicações Analíticas

1.6. Analitos de Interesse 13

1.6.1. Óxido Nítrico (NO) 13

1.6.2. lodato 14

1.7. Técnicas Analíticas 16

1.7.1. Amperometria 16

1.7.2. Analise por Injeção em Fluxo (FIA) 17

1.7.3. Microscopia Eletrônica de Varredura 21

1.7.4. Espectrometria Dispersiva de Energia 22

1.7.5. Espectroscopia Atômica de Raios X 24

1.7.6. Microbalança Eletroquímica de Cristal de Quartzo 25

CAPÍTULO II -OBJETIVOS 29

2. OBJETIVOS 30

CAPÍTULO III - PARTE EXPERIMENTAL 31

3. PARTE EXPERIMENTAL 32

3.1. Reagentes e Soluções 32

3.2. Aparelhagem 33

3.3. Solução Coloidal de Ácido Tungstico $\left(\mathrm{H}_{2} \mathrm{WO}_{4}\right)$

3.4. Solução $54,4 \mathrm{mmol} \mathrm{L}^{-1}$ de Ácido Perotungstico 34

3.5. Solução Carregadora pH 2,5 34

3.6. Solução Eletrólito Suporte pH 2,5 34

3.7. Esquema da Aparelhagem 35

3.8. Preparo das Amostras 36

3.9. Titulação lodométrica 36

CAPÍTULO IV - RESULTADOS E DISCUSSÃO 37

4. RESULTADOS E DISCUSSÃO 38

4.1. Estudos envolvendo a deposição de óxido de molibdênio 38

4.1.1. Modificação da superfície do eletrodo 38 
4.1.2. Verificação da estabilidade do filme formado

4.1.3. Verificação da eletrocatálise do $1 \mathrm{O}_{3}^{-}$

4.2. Estudos envolvendo a deposição de óxido de tungstênio 42

4.2.1. Eletrodeposição em solução coloidal de ácido tungstico 42

4.2.2. Eletrodeposição em solução de ácido perotungstico 46

4.2.2.1. Modificação da superfície do eletrodo 46

4.2.2.2. Verificação da estabilidade do filme formado 47

4.2.2.3. Repetibilidade na modificação dos eletrodos 50

4.2.2.4. Resposta Eletroquímica em função da Quantidade de Material Depositado 51

4.2.2.5. Estudo da permeabilidade dos filmes de óxidos de tungstênio 52

4.2.2.6. Aquisição de Imagem da Superfície do Eletrodo de Carbono Vítreo Modificado

4.2.2.7. Composição da Superfície Modificada 63

4.2.2.8. Eletrocatálise do lodato em Eletrodo Modificado com $\mathrm{WO}_{3} \quad 66$

4.3. Comparação dos Resultados da Eletrocatálise do $\mathrm{IO}_{3}{ }^{-} \mathrm{em}$ Eletrodos Modificados com $\mathrm{MoO}_{3}$ ou $\mathrm{WO}_{3}$

4.4. Estudos de $\mathrm{IO}_{3}^{-}$em Eletrodos Modificados com $\mathrm{WO}_{3}$

4.4.1. Resposta Eletroquímica de $\mathrm{IO}_{3}{ }^{-}$em função da Quantidade de Material Depositado

70

4.4.2. Estudo do processo de transferência de elétrons de $\mathrm{IO}_{3}{ }^{-}$em eletrodo modificado com óxidos de tungstênio

4.4.3. Estudo da permeabilidade dos filmes de óxidos de tungstênio (Parte II)

4.4.4. Quantificação do íon $1 \mathrm{O}_{3}^{-}$

4.4.4.1. Parâmetros do Sistema FIA 78

4.4.4.2.. Resultados Analíticos $\quad 80$

4.4.5. Ensaios com Microbalança Eletroquímica de Cristal de Quartzo (MECQ) 
4.4.5.1. Modificação do Eletrodo de Ouro

4.4.5.2. Determinação da Quantidade de Material Depositado $(I)$ de

Filmes de Óxidos de Tungstênio

4.4.5.3. Influência do pH na Solubilização de Filmes de Óxidos de

Tungstênio

90

4.4.5.4. Estabilidade dos filmes $\mathrm{WO}_{3}$ em presença de $\mathrm{IO}_{3}{ }^{-} \quad 91$

4.5. Estudos eletroquímicos envolvendo outras espécies químicas 93

4.5.1. Bromato e Clorato

93

4.5.1.1. Redução Catódica de $\mathrm{IO}_{3}^{-}, \mathrm{BrO}_{3}^{-}$e $\mathrm{ClO}_{3}^{-}$em Eletrodos Modificados com $\mathrm{WO}_{3}$ e com Eletrodos Modificados com $\mathrm{MoO}_{3}$.

93

4.5.2. Nitrito e Óxido Nítrito

98

CAPÍTULO V - CONCLUSÕES

102

5. CONCLUSÕES

103

CAPÍTULO VI - PERSPECTIVAS FUTURAS

105

6. PERSPECTIVAS FUTURAS

106

CAPITULO VII - REFERÊNCIAS BIBLIOGRÁFICAS

107

7. REFERÊNCIAS BIBLIOGRÁFICAS

108

CAPÍTULO VIII - CURRICULUM VITAE

118

8. CURRICULUM VITAE

119

8.1. Dados Pessoais

119

8.2. Endereço profissional

119

8.3. Formação Acadêmica

8.4 Experiência Profissional

120

8.5. Participação em Congressos

121

8.6. Publicações 


\section{ÍNDICE DAS FIGURAS}

Figura

Pág.

1 Esquema dos planos basal e vertical de superfícies de eletrodos de carbono.

2 Representação esquemática do processo de recepção do elemento iodo pela glândula tireóide.

3 Esquema básico de um sistema de análise por injeção em fluxo (FIA) com detecção amperométrica, cujo registro típico apresenta proporcionalidade direta entre a altura ou área com a concentração da amostra.

4 Comparação da mistura e condição de dispersão em sistema estacionário e em sistema de injeção em fluxo.

5 Controle da dispersão do constituinte de interesse em função do tempo. $\mathrm{C}_{0}$ é a concentração do constituinte de interesse antes da injeção no sistema em fluxo. C são as diversas concentrações do constituinte de interesse ao longo do tempo após a injeção na solução carregadora. S é o constituinte de interesse sendo injetado no tempo inicial $\left(\mathrm{t}_{\mathrm{o}}\right) . \mathrm{C}_{\max }$ é a concentração máxima obtida após a injeção do constituinte de interesse no sistema em fluxo e D é o coeficiente de dispersão do constituinte de interesse.

6 Representação esquemática da microscopia eletrônica de varredura, onde se percebe que a amostra é varrida com um feixe de elétrons energéticos e vários tipos de sinais são produzidos.

7 Foto do microscópio eletrônico de varredura, LEO 440, com detectores de elétrons secundários e retroespalhados, catodoluminescência e corrente de amostra. Laboratório de 
Caracterização Tecnológica (LCT) da Esc. Politécnica da USP.

8 Modelos de eletrodos de cristal de quartzo.

9 Esquema de um sistema de microbalança eletroquímica de cristal de quartzo (MECQ).

10 Esquema para otimização do Sistema FIA e quantificação de iodato, utilizando potenciostato PAR - 273 EG\&G. Solução carregadora $50 \mathrm{mmol} \mathrm{L}^{-1}$ de sulfato de sódio $+0,7 \mathrm{~mol} \mathrm{~L}^{-1}$ de $\mathrm{NaCl}(\mathrm{pH}=2,5)$. $\mathrm{E}=-200 \mathrm{mV}$.

11 Voltamogramas cíclicos sucessivos ( $\mathrm{n}=10$ ciclos) obtidos durante a modificação da superfície de eletrodo de carbono vítreo, quando se varia o potencial aplicado eletrodo de carbono vítreo de $200 \mathrm{mV}$ a - $800 \mathrm{mV}$ versus eletrodo de referência $\mathrm{Ag} / \mathrm{AgCl}$ saturado em solução de molibdato de sódio $1 \mathrm{mmol} \mathrm{L}^{-1} \mathrm{e} \mathrm{Na}_{2} \mathrm{SO}_{4} 50 \mathrm{mmol} \mathrm{L}^{-1}(\mathrm{pH} 3,0) . \mathrm{V}=50 \mathrm{mV} \mathrm{s}^{-1}$.

12 Voltamogramas cíclicos sucessivos ( $\mathrm{n}=10$ ciclos) obtidos quando se varia o potencial aplicado eletrodo de trabalho de $200 \mathrm{mV}$ a $-800 \mathrm{mV}$ versus eletrodo de referência $\mathrm{Ag} / \mathrm{AgCl}$ saturado em solução sulfato de sódio $50 \mathrm{mmol} \mathrm{L}^{-1}(\mathrm{pH} \mathrm{2,5)}$. Eletrodo de trabalho = eletrodo modificado com óxido de molibdênio (Figura 11). $\mathrm{V}=50 \mathrm{mV} \mathrm{s}^{-1}$.

13 Voltamogramas cíclicos obtidos variando o potencial de aplicado eletrodo de trabalho na faixa de $-800 \mathrm{mV}$ a $700 \mathrm{mV}$ versus eletrodo de $\mathrm{Ag} / \mathrm{AgCl}$ : $(\mathrm{A})$ em solução de sulfato de sódio $50 \mathrm{mmol} \mathrm{L} \mathrm{L}^{-1}(\mathrm{pH}$ 3) utilizando eletrodo de trabalho polido, (B) em solução de sulfato de sódio $50 \mathrm{mmol} \mathrm{L}^{-1}(\mathrm{pH} 2,5)$ utilizando eletrodo de trabalho modificado e (C) em solução de sulfato de sódio $50 \mathrm{mmol} \mathrm{L}^{-1}$ com $10 \mathrm{mmol} \mathrm{L}^{-1}$ de iodato de sódio $(\mathrm{pH} 2,5)$ utilizando eletrodo de trabalho modificado com óxido de molibdênio. $\mathrm{V}=50 \mathrm{mV} \mathrm{s}^{-1}$.

14 Voltamogramas cíclicos sucessivos obtidos durante a modificação do eletrodo de carbono vítreo quando se variou o 
potencial do eletrodo de trabalho de $800 \mathrm{mV}$ a $-300 \mathrm{mV}$ versus $\mathrm{Ag} / \mathrm{AgCl}$ ( $\mathrm{n}=80$ ciclos) com tempo aproximado de 60 minutos. Variação realizada em solução coloidal de tungstato de sódio $0,2 \mathrm{~mol} \mathrm{~L}^{-1} \mathrm{e}$ ácido sulfúrico $2 \mathrm{~mol} \mathrm{~L}^{-1} . \mathrm{V}=50 \mathrm{mV} \mathrm{s}^{-1}$.

15 Voltamogramas cíclicos sucessivos obtidos durante a verificação da estabilidade do filme de óxido de tungstênio $(n=$ 80 ciclos) com tempo aproximado de 60 minutos. Variação realizada em solução de ácido sulfúrico $2 \mathrm{~mol} / \mathrm{L}$. $\mathrm{V}=50 \mathrm{mV} \mathrm{s}^{-1}$.

16 Voltamogramas cíclicos sucessivos ( $\mathrm{n}=17$ ciclos) obtidos durante a modificação do eletrodo de trabalho em solução 54,4 mmol L ${ }^{-1}$ ac. perotungstico $(\mathrm{pH}=1,5) . \mathrm{V}=50 \mathrm{mV} \mathrm{s}^{-1}$.

17 Voltamogramas cíclicos sucessivos obtidos com eletrodo modificado com filme de óxido de tungstênio em solução de $\mathrm{SO}_{4}{ }^{2-} 50 \mathrm{mmol} \mathrm{L}^{-1}$ em diferentes valores de $\mathrm{pH} . \mathrm{V}=50 \mathrm{mV} \mathrm{s}^{-1}$.

18 Voltamogramas cíclicos sucessivos obtidos com eletrodo modificado com filme de óxido de tungstênio em solução de $\mathrm{SO}_{4}{ }^{2-} 50 \mathrm{mmol} \mathrm{L}^{-1}(\mathrm{pH} 2,5) . \quad \mathrm{V}=50 \mathrm{mV} \mathrm{s}^{-1}$.

19 Voltamogramas cíclicos obtidos com seis diferentes eletrodos modificados com filme de óxido de tungstênio em solução de $\mathrm{SO}_{4}{ }^{2-} 50 \mathrm{mmol} \mathrm{L}^{-1}(\mathrm{pH}=2,5) . \mathrm{V}=50 \mathrm{mV} \mathrm{s}^{-1}$.

20 Voltamogramas cíclicos referentes aos eletrodos modificados com 17 (B), 34 (C), 68 (D), 136 (E) ciclos de potencial e o voltamograma cíclico obtido com eletrodo de trabalho polido (A) em solução $\mathrm{SO}_{4}{ }^{2-} 50 \mathrm{mmol} \mathrm{L}^{-1}(\mathrm{pH} 2,5) . \mathrm{V}=50 \mathrm{mV} \mathrm{s}^{-1}$.

21 Voltamogramas cíclicos obtidos em diferentes velocidades de rotação $(100,400,900,1600,2500,3600$ e 4900 rpm) em solução $50 \mathrm{mmol} \mathrm{L}^{-1}$ de $\mathrm{SO}_{4}{ }^{2-}$ contendo $0,1 \mathrm{mmol} \mathrm{L}^{-1}$ de

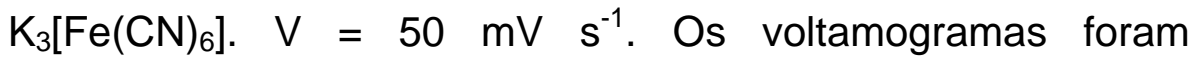
registrados com eletrodos de carbono vítreo modificados com diferentes quantidades de óxidos de tungstênio $(1,2,3,4,5,8$, 17, 34, 51 e 68 ciclos durante a modificação). 
22 Voltamogramas cíclicos obtidos em diferentes velocidades de rotação $(100,400,900,1600,2500,3600$ e 4900 rpm) em solução $50 \mathrm{mmol} \mathrm{L}^{-1}$ de $\mathrm{SO}_{4}{ }^{2-}$ contendo $1 \mathrm{mmol} \mathrm{L}^{-1}$ de

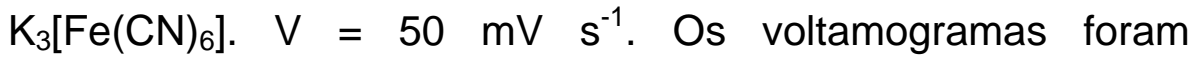
registrados com eletrodos de carbono vítreo modificados com diferentes quantidades de óxidos de tungstênio $(1,2,3,4,5,8$, 17, 34, 51 e 68 ciclos durante a modificação).

23 Voltamogramas cíclicos obtidos com eletrodo de carbono vítreo modificado com óxidos de tungstênio em diferentes velocidades de rotação $(100,400,900,1600,2500,3600$ e 4900 rpm) em solução $50 \mathrm{mmol} \mathrm{L}^{-1}$ de $\mathrm{SO}_{4}{ }^{2-}$ contendo $10 \mathrm{mmol} \mathrm{L}^{-1}$ de

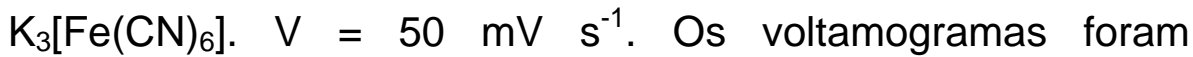
registrados com eletrodos de carbono vítreo modificados com diferentes quantidades de óxidos de tungstênio $(1,2,3,4,5,8$, 17, 34, 51 e 68 ciclos durante a modificação).

24 Gráficos de $\Delta \mathrm{I}_{\mathrm{L}}$ vs. $\omega^{1 / 2}$ construídos a partir de dados dos voltamogramas cíclicos registrados com eletrodo modificados com óxido de tungstênio $(100,400,900,1600,2500,3600$ e $4900 \mathrm{rpm})$ em solução de $\mathrm{SO}_{4}{ }^{2-} 50 \mathrm{mmol} \mathrm{L}^{-1}(\mathrm{pH} 2,5)$ contendo respectivamente soluções de $\left[\mathrm{Fe}(\mathrm{CN})_{6}\right]^{3-}(\mathrm{pH} 2,5) . \quad \mathrm{V}=50 \mathrm{mV}$ $\mathrm{S}^{-1} . \Delta \mathrm{L}$ L medidos em $0 \mathrm{~V}$.

25 Imagem obtida utilizando a câmera de vídeo colorida CCD-IRIS SONY da superfície do eletrodo de carbono vítreo modificado com 34 ciclos de potencial em solução de tungstênio $(\mathrm{VI})$ 54,4 $\mathrm{mmol} \mathrm{L} \mathrm{L}^{-1}$.

26 Imagem da superfície do eletrodo de carbono vítreo modificado com óxidos de tungstênio (15 minutos de modificação) utilizando a técnica microscopia eletrônica de varredura.

27 Espectro de dispersão do eletrodo modificado com óxidos de tungstênio. Espectro obtido no Laboratório de Caracterização Tecnológica (LCT) da Escola Politécnica da USP. 
28 Espectros de absorção de raios $X$. O primeiro refere-se a um padrão de $\mathrm{WO}_{3}$ e o segundo a superfície modificada com óxido de tungstênio.

29 Voltamogramas cíclicos obtidos utilizando eletrodo de carbono vítreo polido em sol. $\mathrm{SO}_{4}{ }^{2-} 50 \mathrm{mmol} \mathrm{L}^{-1}(\mathrm{pH} 2,5)$ e em sol. $\mathrm{SO}_{4}{ }^{2-}$ $50 \mathrm{mmol} \mathrm{L}^{-1}$ contendo $7 \mathrm{mmol} \mathrm{L}^{-1}{\mathrm{de} \mathrm{IO}_{3}}^{-1}(\mathrm{pH} \mathrm{2,5)}$. Velocidade de varredura $=50 \mathrm{mV} \mathrm{s}^{-1}$.

30 Voltamogramas cíclicos obtidos utilizando eletrodo de carbono vítreo modificado (A) com óxidos de tungstênio e (B) com óxidos de molibdênio. Os voltamogramas foram obtidos variando o potencial aplicado ao sistema em solução $50 \mathrm{mmol}$ $\mathrm{L}^{-1}$ de $\mathrm{SO}_{4}{ }^{2-}$ contendo $1 \mathrm{mmol} \mathrm{L}^{-1}$ de $\mathrm{IO}_{3}{ }^{-}(\mathrm{pH} 2,5)$.

31 Voltamogramas obtidos subtraindo os voltamogramas registrados em solução $50 \mathrm{mmol} \mathrm{L}^{-1}$ de $\mathrm{SO}_{4}{ }^{2-}$ daqueles registrados em solução $50 \mathrm{mmol} \mathrm{L}^{-1}$ de $\mathrm{SO}_{4}{ }^{2-}$ contendo $1 \mathrm{mmol}$ $\mathrm{L}^{-1}$ de $\mathrm{IO}_{3}^{-}(\mathrm{pH} 2,5)$. Em (A) foi utilizado eletrodo de carbono vítreo modificado com óxidos de tungstênio e em (B) eletrodo de carbono vítreo modificado com óxidos de molibdênio.

32 Dependência de $\Delta I_{L}\left(I_{k}-I_{d}\right)$ em função do número de ciclos utilizados durante o procedimento de deposição do óxido de tungstênio. $I_{k}$ e $I_{d}$ correspondem a valores de intensidade de corrente da onda catódica em presença e ausência de substrato $\left(0,1 ; 0,5 ; 1 ; 5\right.$ e $\left.10 \mathrm{mmol} / \mathrm{L} \mathrm{IO}_{3}{ }^{-}\right) . \mathrm{V}=50 \mathrm{mV} \mathrm{s}^{-1}$.

33 Gráficos de $\Delta \mathrm{I}_{\mathrm{L}}$ vs. $\omega^{1 / 2}$ obtidos de voltamogramas cíclicos registrados com eletrodo modificado com óxido de tungstênio $(100,400,900,1600,2500,3600$ e 4900 rpm) em sol. de $\mathrm{SO}_{4}{ }^{2-} 50 \mathrm{mmol} / \mathrm{L}(\mathrm{pH} 2,5)$ contendo de $\mathrm{IO}_{3}^{-} . \mathrm{V}=50 \mathrm{mV} \mathrm{s}^{-1} . \mathrm{I}_{\mathrm{L}}$ medidos em $-800 \mathrm{mV}$.

34 Gráficos de $\Delta \mathrm{I}_{\mathrm{L}}$ vs. $\omega^{1 / 2}$ em função da espessura dos filmes de óxido de tungstênio. Dados obtidos de voltamogramas cíclicos registrados em diferentes velocidades de rotação $(100,400$, 
$900,1600,2500,3600$ e $4900 \mathrm{rpm})$ em sol. de $\mathrm{SO}_{4}{ }^{2-} 50 \mathrm{mmol}$ $\mathrm{L}^{-1}(\mathrm{pH} 2,5)$ contendo $\mathrm{IO}_{3}^{-} . \mathrm{V}=50 \mathrm{mV} \mathrm{s}^{-1}$. $\mathrm{I}_{\mathrm{L}}=-800 \mathrm{mV}$.

35 Esquema do processo eletrocatalítico do iodato na superfície modificada com óxidos de tungstênio.

36 Gráficos de $\Delta \mathrm{I}_{\mathrm{L}}$ versus $\mathrm{n}^{0}$ de ciclos utilizados durante a modificação do eletrodo rotativo de carbono vítreo com óxido de tungstênio $(1 ; 2 ; 3 ; 4 ; 5 ; 8 ; 17 ; 34 ; 51$ e 68 ciclos de potencial). Voltamogramas cíclicos registrados em solução 50 mmol L ${ }^{-1}$ de $\mathrm{SO}_{4}{ }^{2-}(\mathrm{pH} 2,5)$ contendo $\mathrm{IO}_{3}{ }^{-} . \mathrm{V}=50 \mathrm{mV} \mathrm{s}^{-1}$. IL medido em $-800 \mathrm{mV}$.

37 Influência da vazão da solução carregadora nos sinais de corrente para iodato. Sinais de corrente medidos após injeções de solução $50 \mathrm{mmol} \mathrm{L}^{-1}$ de sulfato contendo $1 \mathrm{mmol} \mathrm{L}^{-1}$ de iodato. $\mathrm{E}=-200 \mathrm{mV}$.

38 Influência do volume da alça de amostragem nos sinais de corrente para iodato. Sinais de corrente medidos após injeções de solução $50 \mathrm{mmol} \mathrm{L}^{-1}$ de sulfato contendo $1 \mathrm{mmol} \mathrm{L}^{-1}$ de iodato. $\mathrm{E}=-200 \mathrm{mV}$.

39 Resposta amperométrica em fluxo utilizando eletrodo de carbono vítreo modificado com óxido de tungstênio, $\mathrm{E}=$ $200 \mathrm{mV}$ versus $\mathrm{Ag} \mid \mathrm{AgCl}$. Solução carregadora $50 \mathrm{mmol} \mathrm{L}^{-1} \mathrm{SO}_{4}{ }^{2-}$ $(\mathrm{pH} 2,5)$. Vazão da solução carregadora $=2,4 \mathrm{~cm}^{3} \mathrm{~min}^{-1}$. Volume da amostra de $\mathrm{IO}_{3}{ }^{-}=150 \mu \mathrm{L}$. (A) 20, (B) 40, (C) 60, (D) 80 e (E) $100 \mu \mathrm{mol} \mathrm{L}$.

40 Curva analítica para iodato obtida com os dados da Figura 39.

41 Fiagrama obtido durante injeções de solução $80 \mu \mathrm{mol} \mathrm{L^{-1 }}$ de iodato $(150 \mu \mathrm{L})$ à solução carregadora sulfato de sódio 50 $\mathrm{mmol} \mathrm{L}^{-1}(\mathrm{pH}=2,5)$. Potencial aplicado: $-0,2 \mathrm{~V}$.

42 Fiagrama obtido a partir da injeção de alíquotas de $150 \mu \mathrm{L}$ de amostras de solução de sal de cozinha. (A) refere se à amostra 1, (B) amostra 2, (C) amostra 3 e (D) amostra 4. 
43 (A) Voltamogramas cíclicos consecutivos obtidos com eletrodo de ouro $\left(A=0,31 \mathrm{~cm}^{2}\right)$ em solução $54 \mathrm{mmol} \mathrm{L}^{-1}$ de ácido perotungstico. $V=50 \mathrm{mV} \mathrm{s}^{-1}$. Em (B) observa-se a variação de massa durante o experimento voltamétrico.

44 Variação da freqüência do cristal de quartzo em função do tempo durante o processo de deposição do óxido de tungstênio (polarização do eletrodo entre 0,5 e -0,8 $\vee \mathrm{a} \vee=50 \mathrm{mV} \mathrm{s}^{-1}$ ) em solução $54 \mathrm{mmol} \mathrm{L}^{-1}$ de ácido perotungstico.

45 Variação da massa do cristal de quartzo em função do tempo durante o processo de deposição do óxido de tungstênio (polarização do eletrodo entre 0,5 e -0,8 $\vee \mathrm{a} \vee=50 \mathrm{mV} \mathrm{s}^{-1}$ ) em solução $54 \mathrm{mmol} \mathrm{L}^{-1}$ de ácido perotungstico.

46 Variação da massa do eletrodo modificado com filme de $\mathrm{WO}_{3}$ durante a polarização entre 0,5 e $-0,8 \mathrm{~V}$, com $\mathrm{V}=50 \mathrm{mV} \mathrm{s}^{-1} \mathrm{em}$ solução de $\mathrm{Na}_{2} \mathrm{SO}_{4} 50 \mathrm{mM}$ em diferentes valores de $\mathrm{pH}$.

47 Variação da freqüência do cristal de quartzo em função do tempo durante o período em que foi verificada a estabilidade do filme de óxidos de tungstênio em diferentes situações.

48 Voltamogramas cíclicos obtidos com eletrodo de carbono vítreo modificado com óxidos de tungstênio (A) em solução $50 \mathrm{mmol}$ $\mathrm{L}^{-1}$ de $\mathrm{SO}_{4}{ }^{2-}$, (B) em solução $50 \mathrm{mmol} \mathrm{L}^{-1}$ de $\mathrm{SO}_{4}{ }^{2-}$ contendo 2 mmol L'-1 de $\mathrm{ClO}_{3}^{-}$, (C) em solução $50 \mathrm{mmol} \mathrm{L}^{-1}$ de $\mathrm{SO}_{4}{ }^{2-}$ contendo $2 \mathrm{mmol} \mathrm{L}^{-1}$ de $\mathrm{BrO}_{3}{ }^{-}$e (D) em solução $50 \mathrm{mmol} \mathrm{L}^{-1}$ de $\mathrm{SO}_{4}{ }^{2-}$ contendo $2 \mathrm{mmol} \mathrm{L}^{-1}$ de $\mathrm{IO}_{3}{ }^{-}$. Soluções com $\mathrm{pH}=2,5 . \mathrm{V}=$ $50 \mathrm{mV} \mathrm{s}^{-1}$.

49 Voltamogramas cíclicos obtidos com eletrodo de carbono vítreo modificado com óxidos de molibdênio (A) em solução $50 \mathrm{mmol}$ $\mathrm{L}^{-1}$ de $\mathrm{SO}_{4}{ }^{2-}$, (B) em solução $50 \mathrm{mmol} \mathrm{L}^{-1}$ de $\mathrm{SO}_{4}{ }^{2-}$ contendo 2 mmol L'-1 de $\mathrm{ClO}_{3}^{-}$, (C) em solução $50 \mathrm{mmol} \mathrm{L}^{-1}$ de $\mathrm{SO}_{4}{ }^{2-}$ contendo $2 \mathrm{mmol} \mathrm{L}^{-1}$ de $\mathrm{BrO}_{3}^{-}$e (D) em solução $50 \mathrm{mmol} \mathrm{L}^{-1}$ de $\mathrm{SO}_{4}{ }^{2-}$ contendo $2 \mathrm{mmol} \mathrm{L}^{-1}$ de $\mathrm{IO}_{3}^{-}$. Todas as soluções com $\mathrm{pH}$ 
$=2,5$. Velocidade de varredura $=50 \mathrm{mV} \mathrm{s}^{-1}$.

50 Voltamogramas cíclicos obtidos com eletrodo de carbono vítreo modificado com óxidos de tungstênio: (A) solução $50 \mathrm{mmol} \mathrm{L}^{-1}$ de $\mathrm{SO}_{4}{ }^{2-}$; (B) solução $50 \mathrm{mmol} \mathrm{L}^{-1}$ de $\mathrm{SO}_{4}{ }^{2-}$ contendo $1 \mathrm{mmol} \mathrm{L}^{-1}$ de $\mathrm{IO}_{3}^{-}$e (C) solução $50 \mathrm{mmol} \mathrm{L}^{-1}$ contendo $7 \mathrm{mmol} \mathrm{L}^{-1}$ de $1 \mathrm{O}_{3}^{-}$. Todas as soluções com $\mathrm{pH}=2,5 . \mathrm{V}=50 \mathrm{mV} \mathrm{s}^{-1}$.

51 Voltamogramas cíclicos obtidos em solução $2 \mathrm{mmol} \mathrm{L}^{-1}$ de (A) óxido nítrico (Velocidade de varredura $=100 \mathrm{mV} / \mathrm{s}$ ) e $1 \mathrm{mmol}$ $\mathrm{L}^{-1}$ de (B) nitrito (Velocidade de varredura $=50 \mathrm{mV} \mathrm{s}^{-1}$ ). Eletrodo de trabalho carbono vítreo polido $(\mathrm{d}=3 \mathrm{~mm})$.

52 Voltamogramas cíclicos obtidos em solução $50 \mathrm{mmol} \mathrm{L}^{-1}$ de sulfato contendo $1 \mathrm{mmol} \mathrm{L}^{-1}$ de nitrito $(\mathrm{pH}=2,5)$ com eletrodo de carbono vítreo polido $(-)$ e eletrodo de carbono vítreo modificado com óxido de tungstênio (-). Voltamograma cíclico obtido com eletrodo de carbono vítreo modificado (-) imerso em solução $50 \mathrm{mmol} \mathrm{L} \mathrm{L}^{-1}$ de sulfato $(\mathrm{pH}=2,5)$. Velocidade de varredura $50 \mathrm{mV} \mathrm{s}^{-1}$.

53 Voltamogramas cíclicos referentes ao sinal anódico de NO obtidos em solução $50 \mathrm{mmol} \mathrm{L}^{-1}$ de sulfato contendo $2 \mathrm{mmol} \mathrm{L}^{-1}$ de $\mathrm{NO}(\mathrm{pH}=2,5)$ com eletrodo de carbono vítreo polido $(-)$ e eletrodo de carbono vítreo modificado com óxido de tungstênio $(-) . \vee=50 \mathrm{mV} \mathrm{s}^{-1}$. 


\section{ÍNDICE DAS TABELAS}

Tabela

Pág.

1 Valores obtidos por EDS referente à amostra de óxido de 64 tungstênio depositado em eletrodo de carbono vítreo em porcentagem em massa.

2 Valores da concentração de iodato obtidos por meio de ensaios amperométricos e iodométricos em amostras de sal de cozinha.

3 Comparação dos valores de $\Delta l_{\mathrm{pc}}$ (diferença entre o valor de corrente catódica na presença e na ausência do oxiânion) obtidos com eletrodo de carbono vítreo modificado com $\mathrm{WO}_{3}$ ou $\mathrm{MoO}_{3}$. 


\section{RESUMO}

Neste trabalho são apresentados resultados da eletrodeposição de $\mathrm{MoO}_{\mathrm{x}}$ e de $\mathrm{WO}_{\mathrm{x}}$ em eletrodos de carbono vítreo e em eletrodos de ouro. A estabilidade de filmes de $\mathrm{WO}_{\mathrm{x}}$ foi investigada em diferentes valores de $\mathrm{pH}$ utilizando voltametria cíclica e microbalança eletroquímica de cristal de quartzo e observou-se que estes filmes são estáveis em soluções com valores de $\mathrm{pH}$ inferiores a 3.

O processo eletrocatalítico envolvendo a redução de $\mathrm{IO}_{3}^{-}$em superfícies recobertas com $\mathrm{WO}_{\mathrm{x}}$ foi comparado com aquele observado em eletrodo modificado com $\mathrm{MoO}_{\mathrm{x}}$, observando-se as vantagens deste processo em superfícies modificadas com $\mathrm{WO}_{\mathrm{x}}$. Discutiram-se ainda os resultados obtidos do processo da oxidação de óxido nítrico na superfície eletródica polida e modificada com $\mathrm{WO}_{\mathrm{x}}$. Também são apresentados resultados de estudos comparativos sobre a redução do $\mathrm{IO}_{3}{ }^{-}, \mathrm{BrO}_{3}{ }^{-}$e $\mathrm{ClO}_{3}{ }^{-}$ na superfície modificada, concluindo-se que no caso do $\mathrm{IO}_{3}^{-}$obtêm-se maiores valores de corrente devido à maior polarizabilidade do átomo de iodo em relação aos outros dois halogênios.

Estudos envolvendo a permeabilidade de íons $\mathrm{IO}_{3}{ }^{-}$e $\mathrm{Fe}(\mathrm{CN})_{6}{ }^{3-}$ em filmes de $\mathrm{WO}_{\mathrm{x}}$ foram realizados por voltametria com eletrodos rotativos percebendo-se que filmes mais espessos apresentam pouca permeabilidade.

Eletrodos recobertos por filmes de $W_{x}$ foram utilizados como sensores amperométricos para iodato. Para tanto, desenvolveu-se método em fluxo para $\mathrm{IO}_{3}{ }^{-}$em uma faixa de concentração de 5 a $5000 \mu \mathrm{mol} / \mathrm{L}$, com limite de detecção estimado em $210 \mathrm{nmol} / \mathrm{L}$. A repetibilidade do método para 41 injeções de solução $80 \mu \mathrm{mol} / \mathrm{L}$ de $\mathrm{IO}_{3}{ }^{-}$foi de $98,3 \%$. Também foram realizados ensaios para determinar o analito em amostras de sal de cozinha e os dados obtidos foram concordantes com os resultados oriundos do uso de método oficial. 


\section{ABSTRACT}

Thin films of non-stoichiometric tungsten oxides have been deposited onto glassy carbon surfaces by electrodeposition from acidic $\mathrm{W}$ (VI) solutions. At these modified surfaces, rotating disc electrode voltammetric experiments indicated that iodate is electrocatalytically reduced in a masstransport controlled process. The influence of the film thickness on the response to iodate was investigated and the results suggested a reaction occurring at the film/solution interface. The modified electrode was employed successfully as an amperometric sensor for iodate in a flow injection apparatus. The linear response of the developed method is extended from a $5 \mu \mathrm{mol} \mathrm{L}{ }^{-1}$ to $5 \mathrm{mmol} \mathrm{L}^{-1}$ iodate with a limit of detection (signal-to-noise $=3$ ) of $210 \mathrm{nmol} \mathrm{L} \mathrm{L}^{-1}$. The repeatability of the method for 41 injections of an 80 $\mu \mathrm{mol} \mathrm{L}{ }^{-1}$ iodate solution was $98,3 \%$ and the throughput was determined as 123 injections $\mathrm{h}^{-1}$. Interference from other oxidant anions such as nitrate and nitrite was not noticeable, whereas bromate and chlorate interfere at slight levels. The method was used in the determination of the iodate content in commercial salt samples. 


\section{Capítulo I}

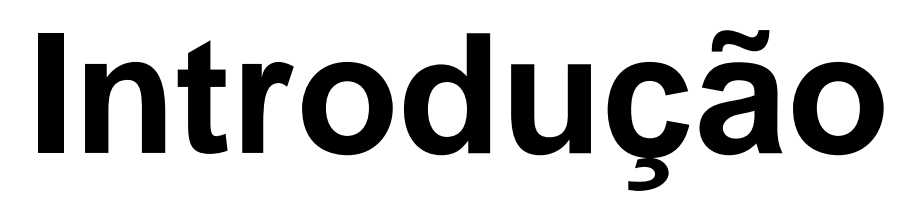




\section{1 - INTRODUCCÃO}

Neste capítulo são apresentados os vários tópicos abordados durante todo o trabalho de doutoramento. Embora muitos destes tópicos sejam discutidos de forma mais profunda em livros-texto, optou-se por apresentálos de forma resumida com o intuito de facilitar a interpretação dos resultados obtidos. Também são relatadas diferentes formas de modificação da superfície de eletrodos com óxidos de tungstênio e suas aplicações analíticas.

\subsection{Eletrodos Quimicamente Modificados}

Fred Anson, na década de 60 e início da década de 70, trabalhou intensamente para entender as propriedades de processos de adsorção na superfície de eletrodos. A importância particular de seus estudos reside no fato de que muitos deles envolviam compostos de coordenação e destes estudos surgiram regras relativamente simples que descrevem as propriedades de uma ampla série de adsorventes [1].

Os primeiros trabalhos envolvendo a preparação de eletrodos com superfícies modificadas surgiram no início da década de 70. Até então somente eram utilizados eletrodos de materiais como ouro, platina, carbono e mercúrio. Nestes trabalhos, Lane e Hubbard [2,3] modificaram deliberadamente a superfície de eletrodos de platina com várias olefinas funcionalizadas e desta forma exploraram a propensão de grupos alcenos adsorverem quimicamente sobre a superfície do eletrodo. Nestes trabalhos pioneiros foram realizadas observações importantes. Entre elas, foi verificada a capacidade do eletrodo de platina modificado com ácido 3-alilsalicílico aumentar o sinal da oxidação de $\mathrm{Fe}^{2+}$ e da redução de $\mathrm{Fe}^{3+}$. Este fato possivelmente tenha sido a primeira indicação da utilidade analítica dos eletrodos quimicamente modificados, pois demonstrou a capacidade de um 
grupo imobilizado complexar um íon metálico e também a possibilidade de se direcionar a coordenação através da escolha do potencial aplicado.

Em 1975, Murray e colaboradores descreveram a modificação química da superfície de eletrodos de $\mathrm{SnO}_{2}$ com organosilanos e introduziram o termo eletrodos quimicamente modificados [4]. O termo é designado para eletrodos que apresentam suas superfícies modificadas após a imobilização de espécies que permanecem quimicamente ativas, com o objetivo de controlar a natureza físico-química da interface eletrodo/solução. A modificação deliberada da superfície do eletrodo é uma forma de impor e controlar sua reatividade e/ou seletividade. Este processo possibilita o desenvolvimento de eletrodos para várias aplicações, entre elas biossensores.

A partir destes trabalhos pioneiros, a preparação e utilização de eletrodos quimicamente modificados têm se expandido de forma acentuada, como pode ser verificado pelo expressivo número de trabalhos publicados sobre o tema nos últimos anos. Além da eletroanálise, que tem se destacado como uma das áreas mais ativas neste campo, os eletrodos quimicamente modificados têm sido utilizados para outros fins que não analíticos, incluindo estudos básicos de eletrocatálise, de cinética de transferência eletrônica, de permeação de membranas, síntese eletroorgânica e fotoeletroquímica. Uma análise mais profunda e detalhada sobre a área de pesquisa envolvendo o termo eletrodos quimicamente modificados pode ser obtida em diversos trabalhos disponíveis na literatura [5-12].

Percebe-se o crescente uso de estratégias para a modificação da superfície de eletrodos. A alteração intencional das características da superfície de um eletrodo, pela imobilização de um agente adequado - por adsorção, formação de compósitos ou formação de ligação covalente - faz com que este sensor ofereça maiores recursos para determinações 
eletroanalíticas. Um dos resultados desejado com a técnica de modificação do eletrodo consiste em bloquear o acesso direto do substrato ao eletrodo inibindo alguns processos e promovendo outros [13]. A habilidade de manipular as propriedades dos eletrodos pode levar a uma variedade de efeitos atrativos dentre os quais a eletrocatálise, a prevenção de envenenamento da superfície do eletrodo, a seletividade e a préconcentração [14, 15].

\subsection{Métodos de Imobilização do Agente Modificador}

Devido às diversas tecnologias existentes atualmente, a modificação da superfície de eletrodos é um campo muito amplo. Para a modificação da superfície de eletrodo podem ser usados metais eletrodepositados [16], óxidos [17-20], espécies orgânicas que são adsorvidas [21], metaloporfirinas [22-24], enzimas [25], DNA [26, 27], filmes poliméricos [28-29] entre uma infinidade de substâncias.

Segundo vários autores as formas de modificar quimicamente as superfícies de eletrodos podem ser explicadas por uma das quatro aproximações descritas a seguir [5, 7, 9, 12, 30].

\subsubsection{Adsorção ou Quimisorção}

Este foi o processo pioneiro e é a maneira mais simples de fixar o agente modificador ao substrato do eletrodo base. Consiste na dissolução do agente modificador em um solvente apropriado, com posterior exposição do eletrodo a esta solução. Em geral este processo é realizado pela imersão do eletrodo na solução modificadora, seguida da evaporação do solvente. Outro processo de modificação consiste na deposição de uma quantidade específica de solução modificadora com o auxílio de uma micro-pipeta sobre a superfície do eletrodo e a evaporação do solvente. A maioria dos trabalhos de eletrodos quimicamente modificados foi realizada utilizando 
eletrodos de grafite ou de carbono vítreo. Esta preferência se deu devido à capacidade particular destes eletrodos quimisorverem reagentes que possuam sistemas de elétrons $\pi$ estendidos, como por exemplo, compostos orgânicos aromáticos. Esta adsorção ocorre pela forte interação entre o plano basal (Figura 1) do eletrodo de carbono e o sistema de elétrons $\pi$ da molécula aromática.
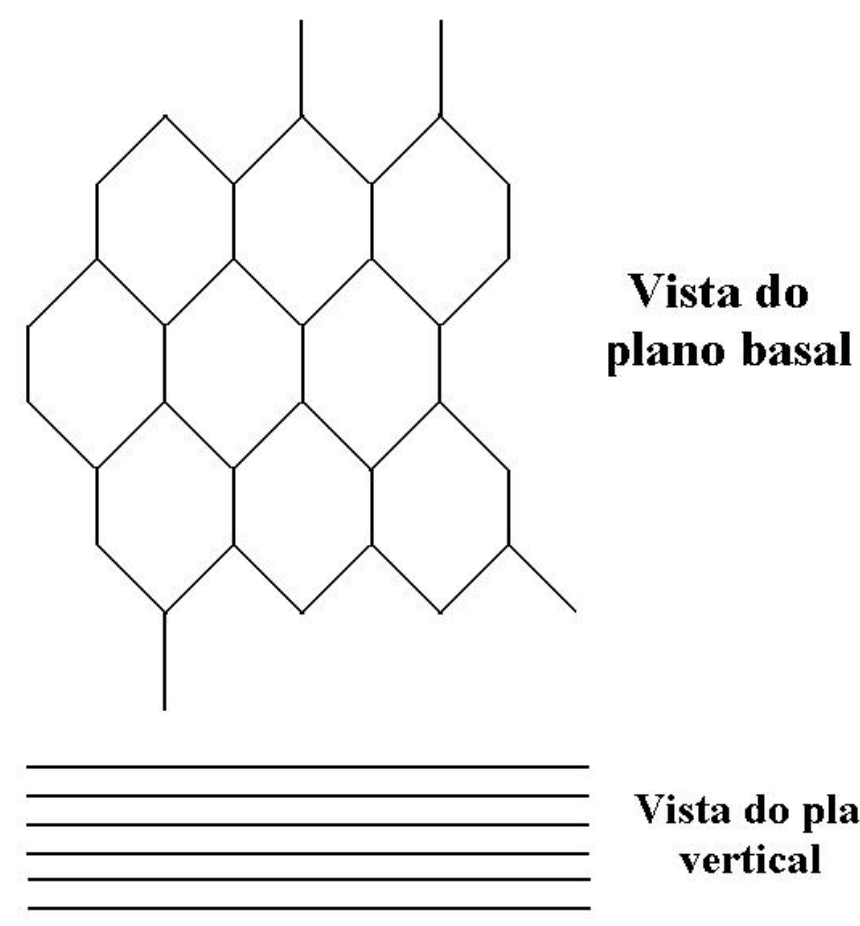

Vista do plano

vertical

Figura 1 - Esquema dos planos basal (plano da folha) e vertical (plano perpendicular à folha) de superfícies de eletrodos de carbono.

Embora simples, esta técnica apresenta a desvantagem da inevitável dessorção do agente modificador para o meio. Desta forma, ocorre diminuição na reprodutibilidade e repetibilidade dos resultados. Este fato se dá pois o fenômeno de dessorção também é um processo de equilíbrio, e como tal pode ser minimizado de várias formas entre elas pela adição de um contra-íon à solução modificadora. 


\subsubsection{Formação de Ligação Covalente}

O modificador pode também ser ligado covalentemente ao substrato do eletrodo. Por exemplo, são empregadas reações de silanização, envolvendo organosilanos e óxidos presentes na superfície do eletrodo. A maioria dos eletrodos metálicos, quando oxidados em meio ácido, são recobertos com uma fina camada de óxido, muito reativa em relação a silanos. Portanto, um metal após ser oxidado pode ser silanizado e posteriormente reagir com outra molécula, contendo o grupo funcional que se queira imobilizar. O silano atuará como uma "ponte" para fixar um grupo funcional à superfície do eletrodo.

Superfícies de carbono apresentam grupos óxidos funcionais tais como álcoois ou fenóis, cetonas ou quinonas, ácidos carboxílicos e anidridos, resultantes da oxigenação de átomos de carbono do plano vertical, contendo ligações incompletas. A concentração destas funções pode ser aumentada através de reações de oxidação, sendo inclusive passíveis de derivatização. Portanto, a modificação de superfície de eletrodos de carbono, via ligação covalente do agente modificador, é em grande parte baseada na manipulação da reatividade destes grupos funcionais, frente a reagentes como aminas, organosilanos, cloreto de tionila entre outros. Também é explorada a possibilidade de modificar covalentemente superfícies de eletrodos de carbono livres de óxidos. Nestes casos as reações envolvem os próprios átomos de carbono do plano vertical. Tratamentos como abrasão mecânica ou fratura sob atmosfera inerte, "decapagem" por plasma de argônio ou termólise sob vácuo são capazes de gerar superfícies livres de óxidos com grande reatividade quando expostos a uma variedade de reagentes.

Os eletrodos modificados via ligação covalente são mais estáveis do que aqueles obtidos pelos demais métodos, entretanto são mais difíceis de preparar. 


\subsubsection{Recobrimento com Filmes Poliméricos}

Esta técnica é bastante atrativa para a preparação de eletrodos modificados. Para isso as membranas devem ser boas condutoras ou então permeáveis ao eletrólito suporte e à espécie de interesse. Dependendo da aplicação pode ser escolhido um polímero eletroativo (quando o objetivo for uma eletrocatálise), quimicamente ativo (para propriedades ligantes ou de troca iônica para pré-concentração) ou inerte (quando se quer apenas exclusão de interferentes). Os filmes eletroativos se subdividem em duas categorias principais que dependem de como o centro redox é imobilizado: polímero redox se o centro redox é parte do esqueleto polimérico; polímeros de troca iônica se o componente redox ativo é um contra-íon de um filme poli-iônico, como polivinilpiridina ou Nafion.

A cobertura polimérica pode ser obtida a partir de soluções de polímeros pré-formados, ou através de polimerização in situ a partir de unidades monoméricas. Neste último caso o recobrimento polimérico pode ser obtido via eletropolimerização ou por meio de métodos não eletroquímicos como, por exemplo: polimerização ativada por plasma, fotoindução por UV ou polimerização de organosilanos.

\subsubsection{Formação de Compósitos}

Um compósito é uma mistura de componentes, portanto outra forma de preparar um "eletrodo quimicamente modificado" é simplesmente misturar o agente modificador com o substrato do eletrodo. Esta técnica é adequada para modificar eletrodos à base de grafite em pó, tais como: eletrodos de pasta de carbono, de grafite-epóxi, "screen-printed" e pastilhas. Quando possível preferencialmente utiliza-se um método derivado daquele que foi descrito anteriormente, que consiste em misturar a grafite em pó a uma solução adequada de agente modificador. Após a evaporação do solvente as partículas de grafite ficam recobertas pelo modificador e isto 
resulta numa distribuição mais homogênea deste último. Em ambos os casos também podem ocorrer perda gradual do agente modificador para a solução prejudicando a reprodutibilidade. Para minimizar o problema 0 eletrodo pode ser recoberto com algum filme polimérico e desta forma diminuir ainda mais a perda do agente modificador para a solução.

\subsection{Eletrodos Modificados com Óxido de Tungstênio}

Dentre as possibilidades de modificação da superfície de eletrodos, aquela que será tratada em detalhes é a deposição de óxido de tungstênio não estequiométrico, que segundo as aproximações citadas acima é a formação de ligações covalente entre a superfície do eletrodo e o filme. Do ponto de vista experimental pode-se afirmar que esta modificação ocorre basicamente por duas técnicas, imobilização térmica e deposição eletroquímica. A seguir são detalhadas estas técnicas mostrando exemplos de imobilização de óxido de tungstênio por diferentes métodos.

\subsubsection{Imobilizacão Térmica}

Este tipo de imobilização resume-se no aquecimento do eletrodo e/ou da solução modificadora, com deposição ou formação do óxido de tungstênio na superfície do eletrodo. Assim, serão citados alguns métodos de modificação utilizando esta técnica, os quais são relatados na literatura.

\subsubsection{Oxidação Térmica}

Por este processo, a imobilização de óxido de tungstênio é obtida aquecendo discos ou ainda filamentos de tungstênio à temperatura de $750^{\circ} \mathrm{C}$ por um período de 30 minutos em presença de gás oxigênio. Desta forma, uma fina camada de óxido de tungstênio é formada para posterior caracterização [31]. 


\subsubsection{Deposição Térmica a Pressão Reduzida}

Neste caso, filmes finos de óxido de tungstênio são preparados por evaporação a baixa pressão utilizando óxido de tungstênio em pó. Durante o processo de evaporação o óxido de tungstênio é depositado sobre $\alpha$ $\mathrm{Al}_{2} \mathrm{O}_{3}$, sílica ou tântalo. No período de evaporação mantém-se a temperatura do substrato e do agente modificador em $300^{\circ} \mathrm{C}$ com pressão residual de aproximadamente $10^{-5}$ Torr $[32,33]$.

\subsubsection{Spray Pirolítico}

A preparação de filmes finos transparentes de óxido de tungstênio, por este processo, é realizada em duas etapas. Na primeira etapa preparase uma solução de cloreto de tungstênio ( $\mathrm{VI})$ 0,01 $\mathrm{mol} \mathrm{L}^{-1}$, dissolvendo este sal em uma mistura de álcool etílico (50\% v/v) e água destilada (50\% v/v). A solução preparada é então transportada até a superfície do eletrodo utilizando uma bomba peristáltica que regula o jato da solução. A solução é borrifada em pequenas gotas sobre o substrato de vidro aquecido à temperatura que varia entre 200 e $400^{\circ} \mathrm{C}$. Com isso, obtém-se um filme escuro e homogêneo que fica aderido à superfície do substrato. A segunda etapa consiste na fixação da temperatura do eletrodo em $500^{\circ} \mathrm{C}$ pelo período de 1 hora, obtendo-se assim o referido filme de óxido de tungstênio [34].

\subsubsection{Eletrodo Moldado}

Este eletrodo é preparado pela mistura de proporções adequadas de pó de grafite, Teflon ${ }^{\circledR}$ e óxido de tungstênio. Em seguida, esta mistura é prensada a $345^{\circ} \mathrm{C}$, moldando assim o eletrodo do tamanho e formato desejado [35]. 


\subsubsection{Oxidação em Meio Básico}

Barras de tungstênio são polidas com lixa 400 mesh e posteriormente lavadas com acetona. Em seguida, estas barras são aquecidas a temperaturas acima de $500^{\circ} \mathrm{C}$ pelo período de uma hora em presença do ar atmosférico. O eletrodo é então colocado em solução de hidróxido de sódio $1 \mathrm{mmol} \mathrm{L}{ }^{-1}$ por 24 horas. Antes do uso o eletrodo é limpo com água destilada para retirar o excesso de hidróxido de sódio [36].

\subsubsection{Eletrodeposição}

Para os três processos de eletrodeposição citados abaixo se prepara uma solução em que será imerso o sistema de três eletrodos. Ao eletrodo de trabalho aplica-se potencial conveniente para a eletrodeposição de óxido de tungstênio em sua superfície. O processo de deposição pode ser amperométrico, quando se aplica um valor fixo de potencial ao eletrodo de trabalho, ou ainda voltamétrico, quando se varia o potencial aplicado ao eletrodo de trabalho em uma faixa pré-estabelecida, sendo que no último caso é possível perceber a contínua formação do filme em função do número de ciclos realizados.

\subsubsection{Solução de Tungstato de Sódio $0,2 \mathrm{~mol} L^{-1}$}

Por este processo, Kulesza e Faulkner [21] e posteriormente seus colaboradores preparam uma solução coloidal amarela pálida misturando, sob agitação constante e gota a gota, $5 \mathrm{~mL}$ de solução de $\mathrm{Na}_{2} \mathrm{WO}_{4} \cdot 2 \mathrm{H}_{2} \mathrm{O}$ $0,2 \mathrm{~mol} \mathrm{~L}^{-1}$ em $45 \mathrm{~mL}$ de solução de ácido sulfúrico $2,2 \mathrm{~mol} \mathrm{~L}^{-1}$. A eletrodeposição ocorre quando se varia o potencial aplicado ao eletrodo de trabalho, pelo período de 4 horas, entre $-0,4 \mathrm{~V}$ e $0,8 \mathrm{~V}$ na mistura coloidal formada de $\mathrm{WO}_{3} \cdot 2 \mathrm{H}_{2} \mathrm{O}$ e $\mathrm{WO}_{3} \cdot \mathrm{H}_{2} \mathrm{O}$ [37-39]. 


\subsubsection{Oxidação do Tungstênio Metálico}

Guerfi e Dao [40] propuseram, em seu trabalho, a obtenção de óxidos de metais de transição usando-se como precursor uma solução preparada pela oxidação do metal por ação de peróxido de hidrogênio. Após este trabalho, vários outros surgiram empregaram procedimento similar [20, 4145]. A concentração da solução de tungstênio, nesses trabalhos, variou de 50 a $125 \mathrm{mmol} \mathrm{L}^{-1}$.

O procedimento, em linhas gerais, consiste em pesar certa massa de tungstênio em pó e oxidar o metal com peróxido de hidrogênio. Após o término da reação, que é extremamente exotérmica, coloca-se um eletrodo de platina platinizada na solução para catalisar a decomposição de $\mathrm{H}_{2} \mathrm{O}_{2} \mathrm{e}$ desta forma eliminá-lo, este fato é perceptível com o final da efervescência da solução. Após este procedimento a solução é utilizada no processo de eletrodeposição do óxido de tungstênio (VI, V).

\subsubsection{Método Xerogel}

Uma das possíveis formas de obtenção de uma mistura xerogel, em que se insere o eletrodo de trabalho para sofrer modificação, é percolar uma solução de tungstato de sódio em uma coluna de troca iônica, obtendo-se a solução de $\mathrm{H}_{2} \mathrm{WO}_{4}$, cujo $\mathrm{pH}$ situa-se próximo de 1,2.

A solução de $\mathrm{H}_{2} \mathrm{WO}_{4}$ não é estável em presença de ar, por isso é necessário que se adicione peróxido de hidrogênio $\left(\left[\mathrm{H}_{2} \mathrm{WO}_{4}\right]:\left[\mathrm{H}_{2} \mathrm{O}_{2}\right]=\right.$ 1:0,03) à solução. Esta fica estável por um longo período de tempo em presença de ar e à temperatura ambiente.

O processo de eletrodeposição do óxido de tungstênio $(\mathrm{VI}, \mathrm{V})$ pode ser realizado logo após a obtenção desta solução [46-47]. 
1 - Introdução - 12

\subsection{Propriedades Eletrocrômicas}

Os filmes de óxido de tungstênio apresentam características eletrocrômicas, ou seja, há mudança de cor quando estes são polarizados em diferentes potenciais [48]. A característica eletrocrômica deste filme vem sendo descrita por vários modelos, porém o mais aceito é o de dupla injeção no qual ocorre o processo de intercalação de prótons e a incorporação de moléculas de água durante a formação do filme. A equação 1 resume o processo eletrocrômico com a inserção de íons monovalentes no interior da matriz do filme:

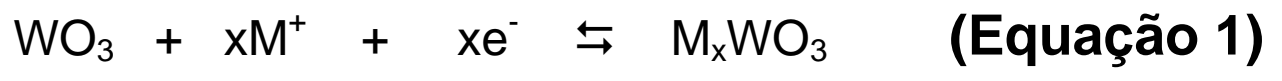
Incolor

Azul

onde $\mathrm{M}^{+}$é o íon monovalente $\left(\mathrm{H}^{+}, \mathrm{Li}^{+}, \mathrm{Na}^{+}\right)$e x pode variar entre 0 e 1 [20].

As propriedades eletrocrômicas dos materiais modificados com óxidos de tungstênio foram exploradas extensivamente ao longo do tempo, todavia poucas são as publicações que relatam alguma aplicação analítica destes eletrodos modificados.

\subsection{Aplicações Analíticas}

Faulkner e colaboradores verificaram a reatividade e a transferência de carga na interface dos filmes de óxido de tungstênio em meio fortemente ácido. Para tanto, foram estudados os processos de eletrorredução de oxianions como bromato $\left(\mathrm{BrO}_{3}^{-}\right)$e clorato $\left(\mathrm{ClO}_{3}^{-}\right)$[49]. Este mesmo grupo de trabalho também incorporou micro-partículas de metais como platina em filmes de óxidos de tungstênio e analisou o aumento do efeito catalítico do sensor eletroquímico se comparado ao sistema sem as micro-partículas [50-52].

Bock e MacDougall, usando principio semelhante ao de Faulkner, estudaram a oxidação de compostos orgânicos, tais como metanol $\left(\mathrm{H}_{3} \mathrm{COH}\right)$, 
ácido metanóico $(\mathrm{HCOOH})$, ácido etanóico $\left(\mathrm{H}_{3} \mathrm{CCOOH}\right)$ e ácido etanodióico $(\mathrm{COOH})_{2}$ [44-45]. Procedimento similar baseou os trabalhos de Chen e Alexander, que quantificaram potenciometricamente ácidos carboxílicos, tais como ácido metanóico e ácido propanóico, e aminas como a metilamina e a propilamina, usando um sistema de análise por injeção em fluxo (FIA) [36].

\subsection{Analitos de Interesse}

\subsection{1. Óxido Nítrico (NO)}

Até meados da década de 1980, o óxido nítrico era considerado apenas membro de uma família de poluentes ambientais indesejáveis, pois era e continua sendo um dos precursores da chuva ácida e destruidor da camada de ozônio. Este gás também era conhecido como um carcinógeno potencial [53].

Em 1987, com a descoberta por Ignarro, Moncada e outros pesquisadores de que o óxido nítrico (NO) era o gás vasodilatador responsável direto pelo controle da pressão sanguínea, esta pequena molécula, diatômica, escapou das mãos e mentes dos químicos de coordenação, químicos da atmosfera e engenheiros químicos e, veloz e vigorosamente, inundou, abalou e alicerçou as bases da Medicina moderna. Nos cinco anos seguintes, o Web of Science (Institute for Scientific Information) registrou a publicação de mais de seis mil artigos sobre o NO, dezessete mil no qüinqüênio seguinte e mais de vinte mil nos últimos cinco anos [54].

Devido a todos estes fatos, em 1992, a American Association for the Advancement of Science elegeu o NO como a molécula do ano [55].

Em 1998 os cientistas norte-americanos Robert Furchgott, Ferid Murad e Louis Ignarro receberam o Prêmio Nobel de Medicina e Fisiologia pela descoberta do papel do óxido nítrico no organismo.

A partir deste momento, o óxido nítrico (NO) ficou também conhecido como uma das menores e mais versáteis moléculas produzidas pelo 
organismo pois desempenha uma série de funções fisiológicas no organismo de mamíferos.

Entre suas propriedades está a de controlar a pressão arterial, contribuindo para aumentar a eficácia de tratamentos contra arteriosclerose e em caso de crises de hipertensão e angina, por exemplo.

Também é uma molécula utilizada pelo sistema imunológico, nos processos de defesa do organismo contra agentes patológicos - e, entre eles, o protozoário causador da leishmaniose. Nestes casos, os agentes invasores são bombardeados pelas células de defesa com uma mistura letal de NO e superóxido, um poderoso agente oxidante, formando outros produtos que possuem forte ação bactericida e de combate a tumores.

No sistema cardiovascular ele é um neurotransmissor potente em conseqüência da sua difusão muito rápida através das membranas celulares.

O uso mais popular decorrente da pesquisa com o óxido nítrico são os medicamentos que combatem a impotência sexual masculina. Estes inibem uma enzima (a fosfodiesterase tipo 5) que leva ao aumento da produção de óxido nítrico no tecido muscular do corpo cavernoso do pênis. O óxido nítrico causa o relaxamento desse tecido, permitindo a passagem de sangue, condição essencial para que haja a ereção peniana [56].

\subsection{2. lodato}

A glândula tireóide produz hormônios que são responsáveis pelo bom funcionamento da maioria dos órgãos do organismo humano. Quando o organismo apresenta deficiência do elemento iodo, aumenta a probabilidade de desenvolvimento do hipertiroidismo. Uma das conseqüências desta disfunção orgânica é o crescimento elevado da glândula devido à produção acelerada de hormônios (Figura 2). 


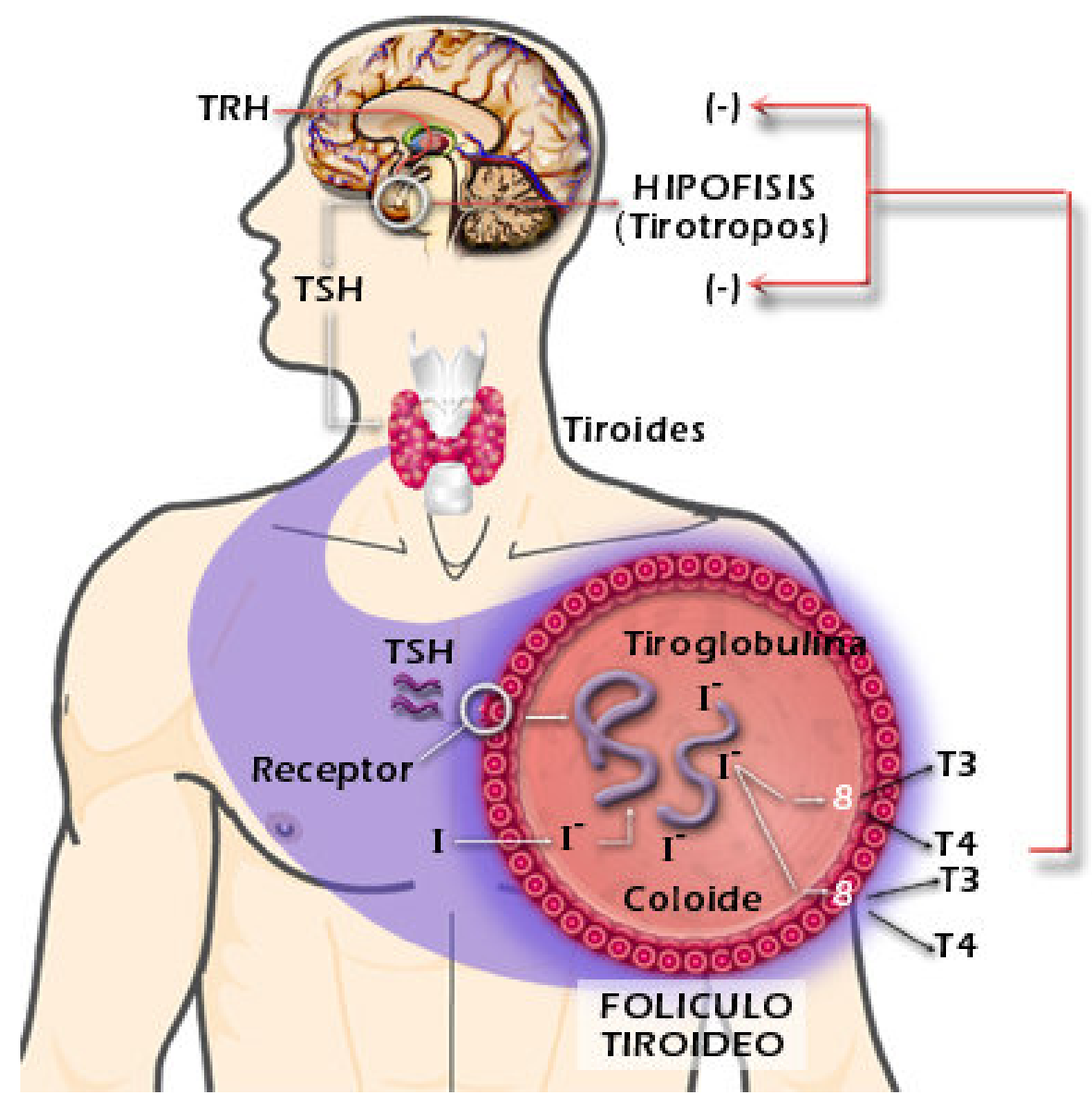

Figura 2 - Representação esquemática do processo de recepção do elemento iodo pela glândula tireóide.

Por este motivo, no Brasil o sal de cozinha - um dos alimentos mais barato e mais utilizado pela população brasileira - deve ser comercializado com a presença de íons $\mathrm{IO}_{3}^{-}$para evitar o desenvolvimento da doença. Segundo a legislação instituída pela Agência Nacional de Vigilância Sanitária, o sal de cozinha deve conter de 40 a 100 mg de iodo por quilo do produto [57]. Visto que eletrodos modificados com óxidos metálicos são eficientes sensores para oxiânions como o iodato, pretende-se desenvolver metodologia amperométrica para quantificar o íon $\mathrm{IO}_{3}{ }^{-}$em amostras de sal de cozinha. 


\subsection{Técnicas Analíticas}

Em seguida são descritos resumos das técnicas analíticas que foram utilizadas para obter os resultados apresentados neste trabalho.

\subsubsection{Amperometria}

Esta técnica analítica é fundamentalmente muito simples porém apresenta excelente potencial analítico. O fluxo de corrente existente entre o eletrodo de trabalho e o eletrodo de referência é monitorado em função do tempo enquanto a diferença de voltagem entre estes eletrodos é mantida constante. Em outros casos, a corrente é monitorada em função da adição de alíquotas do titulante, por exemplo. A principal característica desta técnica é que a medida de intensidade de corrente é proporcional à concentração do analito contanto que a concentração do analito seja mantida constante nas proximidades da superfície do eletrodo. Desta forma, ao medir a intensidade de corrente do sistema obtêm-se informações sobre a quantidade do constituinte em análise. Uma importante aplicação desta técnica está relacionada à utilização de sensores eletroquímicos [58].

Um sensor voltamétrico registra vários pontos no perfil de correntepotencial, ou ainda numa região escolhida desta curva. Um sensor amperométrico nada mais é do que um sensor voltamétrico mantido em um potencial fixo [59].

Os eletrodos hidrodinâmicos aumentam a sensibilidade, melhoram a repetibilidade e desta forma diminuem os limites de detecção. Por estes fatores torna-se vantajoso acoplar os sensores amperométricos em sistemas em fluxo, ganhando-se em sensibilidade, aumentando-se a repetibilidade dos resultados e a freqüência analítica das determinações [60]. 


\subsubsection{Análise por Injecão em Fluxo (FIA)}

O procedimento de análise por injeção em fluxo (FIA, proveniente do inglês Flow Injection Analysis) baseia-se na introdução de uma amostra líquida em uma solução carregadora [61]. Este procedimento analítico apresenta várias vantagens e dentre elas destacam-se a repetibilidade dos resultados e minimização do consumo de amostras e de reagentes. Além disso, a freqüência analítica é muito maior do que os métodos manuais, ou seja, uma maior quantidade de análises pode ser realizada no mesmo período de tempo. Além disso, procedimentos como pré-separação, préconcentração, precipitações, entre outros podem ser realizados "on line", evitando assim erros operacionais [62].

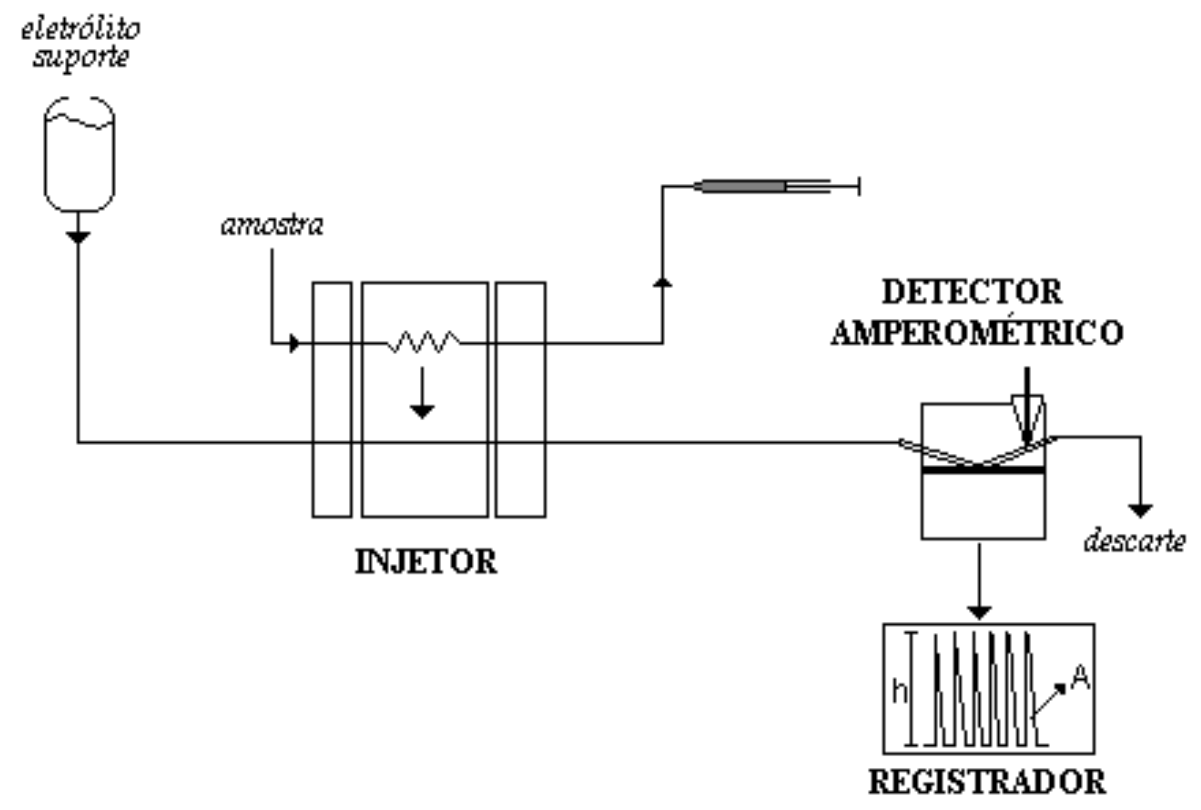

Figura 3 - Esquema básico de um sistema de análise por injeção em fluxo (FIA) com detecção amperométrica, cujo registro típico apresenta proporcionalidade direta entre a altura(h) ou área $(A)$ com a concentração da amostra.

O esquema de um sistema de análise por injeção em fluxo (FIA) com detecção amperométrica pode ser observado na Figura 3. A solução 
carregadora passa pelo detector impulsionada por gravidade ou, ainda, utilizando uma bomba peristáltica. A amostra é introduzida na solução carregadora pelo injetor, que tem uma alça de amostragem a ser preenchida pela sucção da amostra com uma seringa hipodérmica ou sistema similar.

A representação gráfica típica é denominada de fiagrama e este apresenta proporcionalidade direta entre a altura $(h)$ ou área $(A)$ dos picos e a concentração da amostra [63]. Devido à facilidade, praticidade e comodidade, prefere-se trabalhar com a altura do pico.

Quando se injeta uma amostra ao fluxo carregador, ocorre formação de uma zona que é transportada para um detector. Este mede continuamente a absorbância, corrente em um eletrodo ou outros parâmetros físicos que sofrem alteração quando da passagem desta zona de amostragem pelo detector no sistema em fluxo [64].

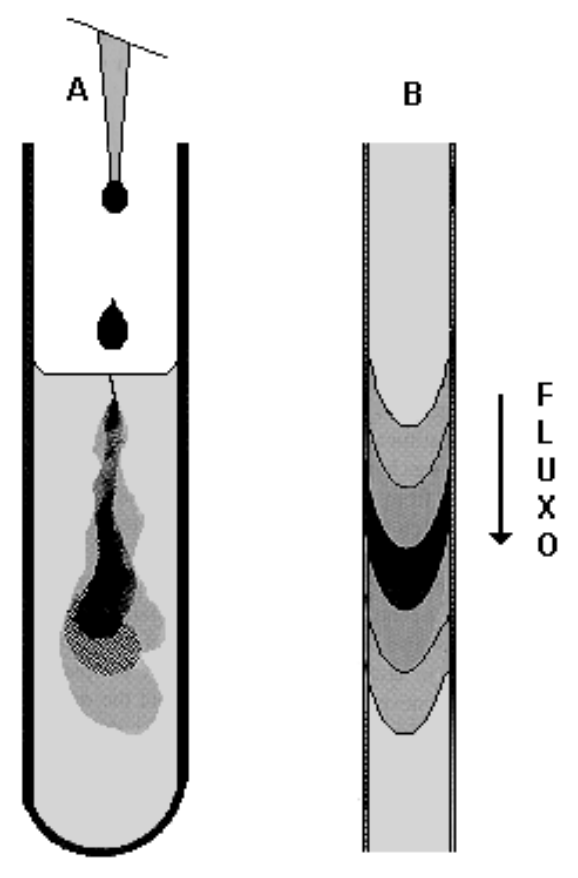

Figura 4 - Comparação da mistura e condição de dispersão em (A) sistema estacionário e (B) em sistema de injeção em fluxo [65]. 
O mais importante fenômeno físico na manipulação da amostra, ou zona de reagente em um fluxo contínuo não segmentado, é a dispersão e, nestes sistemas, a amostra ou zona de reagente pode ser manipulada para se obter um requerido grau de dispersão. A dispersão da amostra é, por isso, controlada para satisfazer diferentes objetivos analíticos. A dispersão da amostra, no reagente ou solvente, não é um processo exclusivo para o processo ou sistema FIA. Em processos analíticos por batelada ou outros métodos de análise em fluxo existe a dispersão, porém pode-se perceber pela Figura 4 que no sistema FIA a dispersão é reprodutiva e controlada. Tal fato não ocorre em um sistema estacionário, onde a dispersão é caótica, ou seja sem direção definida [65].

Segundo Ruzicka e Hansen, o coeficiente de dispersão pode ser calculado através da Equação 2, onde D é o coeficiente de dispersão, $C_{0}$ é a concentração original do constituinte de interesse e C é a concentração do mesmo constituinte após a injeção, ou seja, após a dispersão do constituinte no fluxo carregador.

$$
\mathrm{D}=\mathrm{C}_{0} / \mathrm{C}
$$

(Equação 2)

Por conveniência, a dispersão da amostra é considerada limitada ou pequena quando o valor do coeficiente de dispersão (D) estiver entre 1 e 3 , média quando o valor do coeficiente de dispersão (D) estiver entre 3 e 10 ou grande quando o valor do coeficiente de dispersão (D) for maior do que 10 [66] e estes dados podem ser entendidos observando a Figura 5. 


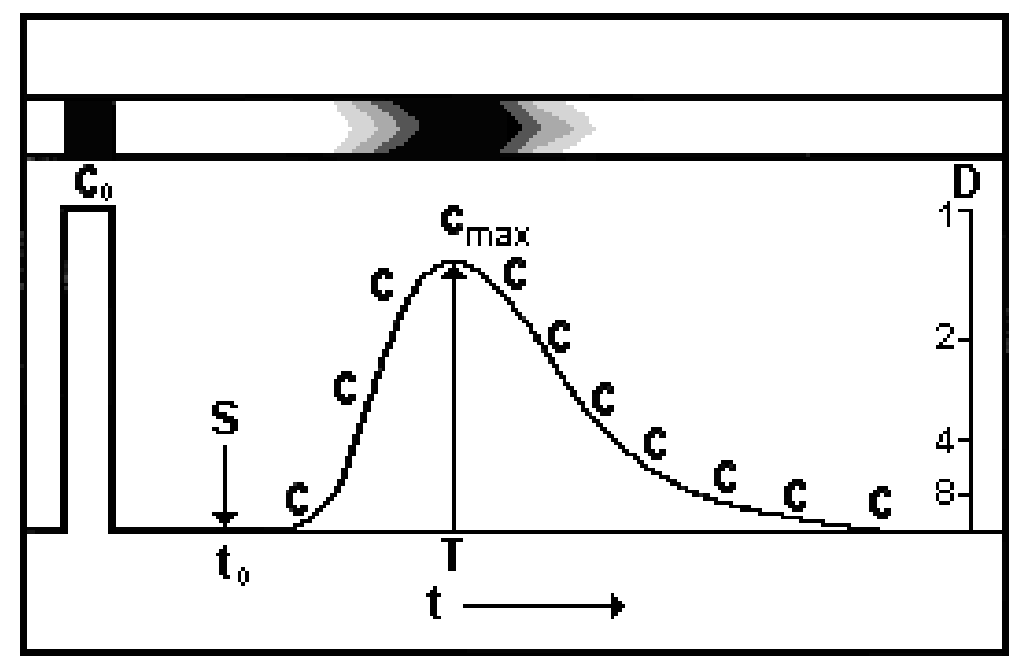

Figura 5 - Controle da dispersão do constituinte de interesse em função do tempo. Co é a concentração do constituinte de interesse antes da injeção no sistema em fluxo. C são as diversas concentrações do constituinte de interesse ao longo do tempo após a injeção na solução carregadora. S é o constituinte de interesse sendo injetado no tempo inicial $\left(t_{0}\right)$. $C_{\max }$ é a concentração máxima obtida após a injeção do constituinte de interesse no sistema em fluxo e $D$ é o coeficiente de dispersão do constituinte de interesse [67].

Quando o coeficiente de dispersão é menor do que 3, percebe-se que a relação entre a altura do pico e a base do mesmo é alta, desta forma fica nítida a visualização e determinação da concentração do constituinte na amostra.

Caso o coeficiente de dispersão esteja entre 3 e 10, a relação entre a altura do pico e a base do mesmo é baixa, embora seja possível ainda determinar a concentração do constituinte na amostra. Coeficientes de dispersão acima de 10 inviabilizam a determinação da concentração de qualquer constituinte.

A dispersão ocorre por vários fatores, sendo os principais: volume da amostra, velocidade do fluxo carregador, proporção da velocidade do fluxo 
existente entre a solução carregadora e a amostra, dimensões geométricas e configuração dos diferentes componentes do sistema, viscosidade dos líquidos utilizados e temperatura.

O controle destes parâmetros faz com que o sistema apresente picos mais definidos e desta forma exista a possibilidade de quantificar 0 constituinte de interesse em concentrações cada vez menores, principalmente quando se empregam outras técnicas acopladas ao sistema [65-68].

\subsubsection{Microscopia Eletrônica de Varredura}

Esta técnica é utilizada para detalhar a natureza física de superfícies sólidas, como por exemplo, eletrodos modificados. Para vários campos da química, da ciência de materiais, da geologia e da biologia estas informações são importantíssimas.

Nesta técnica a superfície de uma amostra sólida é varrida utilizando um padrão de rastreamento com um feixe de elétrons. Vários tipos de sinais são produzidos por uma superfície neste processo, incluindo elétrons espalhados, elétrons secundários, elétrons Auger, fótons de fluorescência de raios $X$ e fótons de várias energias (Figura 6).

$\mathrm{Na}$ microscopia eletrônica de varredura, os sinais de maior interesse são os elétrons secundários e os espalhados, considerando que estes variam de acordo com diferenças topográficas da superfície quando o feixe de elétrons varre a superfície em estudo. A emissão de elétrons secundários é limitada à área próxima onde ocorreu o impacto do feixe de elétrons, permitindo assim obter imagens de boa resolução. Desta forma, a microscopia eletrônica fornece informação morfológica e topográfica sobre as superfícies de sólidos. Fato este muito importante como o primeiro passo no estudo das propriedades da superfície de um sólido [69]. 


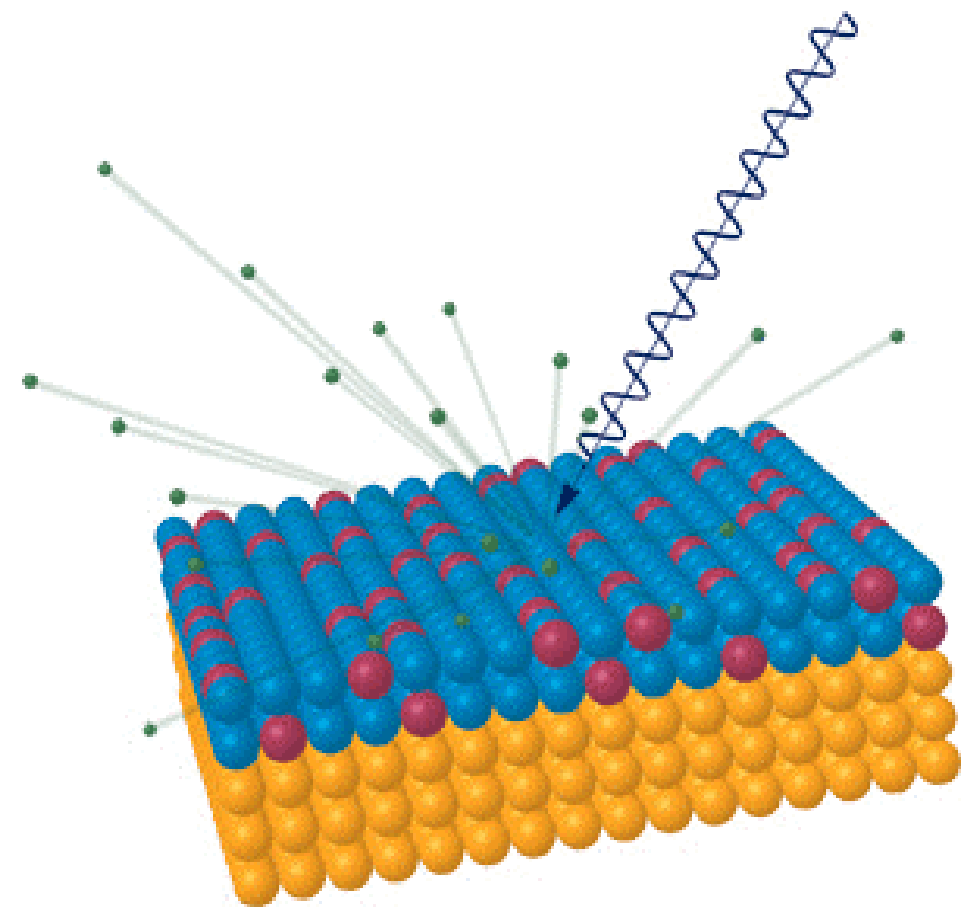

Figura 6 - Representação esquemática da microscopia eletrônica de varredura, onde se percebe que a amostra é varrida com um feixe de elétrons energéticos e vários tipos de sinais são produzidos.

\subsubsection{Espectrometria de Fluorescência Dispersiva de Energia}

A espectrometria de fluorescência dispersiva de energia é um tipo específico de fluorescência de raios $X$. Este método analítico é um dos mais utilizados para identificar qualitativamente elementos que apresentem números atômicos maiores do que o oxigênio; além disso, esta técnica é freqüentemente empregada na análise elementar semiquantitativa ou quantitativa.

Um espectrômetro dispersivo de energia consiste em uma fonte policromática, que pode ser tanto um tubo de raios $X$ como um material radioativo, um porta-amostras, um detector de semicondutor e vários componentes eletrônicos requeridos para a discriminação da energia. 


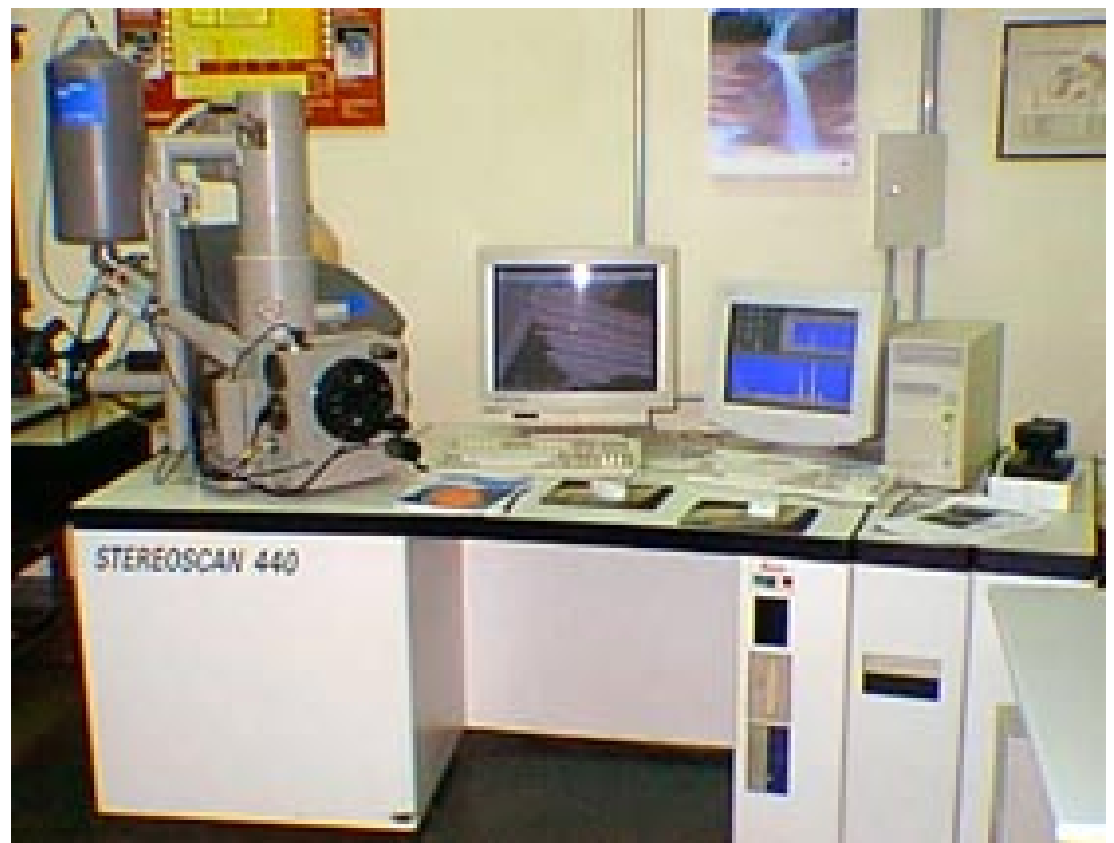

Figura 7 - Foto do microscópio eletrônico de varredura, LEO 440, com detectores de elétrons secundários e retroespalhados, catodoluminescência e corrente de amostra. Acoplado a sistemas de microanálise química por EDS e WDS, OXFORD Isis (EDS) integrado com Microspec 600i (WDS). Laboratório de Caracterização Tecnológica (LCT) da Escola Politécnica da USP.

Uma vantagem dos sistemas dispersivos de energia é a simplicidade e inexistência de partes móveis nos componentes de excitação e detecção do espectrômetro. Além disso, a ausência de colimadores e de um cristal difrator, como também a proximidade entre o detector e a amostra, resulta em um aumento de 100 vezes ou mais na energia que chega no detector. Essas características permitem que seja usada uma fonte mais fraca, tal como um material radioativo ou tubos de raios $X$ de baixa potência, que causa menos danos à amostra [70]. 


\subsubsection{Espectroscopia Atômica de Raios X}

A espectroscopia atômica de raios $X$ para análise química fornece informação qualitativa e quantitativa sobre a composição elementar da matéria, particularmente de superfícies sólidas.

Esta técnica é uma ferramenta poderosa para a identificação de todos os elementos da tabela periódica, com exceção de hidrogênio e hélio. Mais importante ainda, o método permite a determinação do estado de oxidação do elemento e o tipo de espécie a qual ele está ligado. Utiliza-se esta técnica para estudar a estrutura eletrônica e geométrica dos materiais através da fotoabsorção de raios-X. Finalmente, a técnica fornece informações úteis sobre as estruturas eletrônicas das moléculas.

No caso, os raios $X$ constituem uma radiação eletromagnética de comprimento de onda curto produzida pela aceleração ou desaceleração de elétrons de alta energia ou pelas transições de elétrons dos orbitais internos dos átomos.

Para propósitos analíticos, os raios X são obtidos de quatro formas:

1) pelo bombardeamento de um alvo metálico com um feixe de alta energia,

2) pela exposição de uma substância a um feixe primário de raios $X$ de forma a gerar um feixe secundário de fluorescência de raios $X$,

3) pelo uso de fontes radioativas artificiais cujo processo de decaimento resulta na emissão de raios $X$,

4) por uma fonte de radiação síncroton [71]. Luz síncrotron é a intensa radiação eletromagnética produzida por elétrons de alta energia num acelerador de partículas. A luz síncrotron é emitida pela fonte que abrange uma ampla faixa do espectro eletromagnético: Raios-X, Luz Ultravioleta e Infravermelha, além da Luz Visível, que sensibiliza o olho humano [72]. 
Quando um feixe de raios $X$ passa através de uma camada fina de matéria, sua intensidade geralmente diminui em conseqüência da absorção e do espalhamento. O efeito do espalhamento para todos os elementos, menos os mais leves, é normalmente pequeno e pode ser desprezado nas regiões de comprimento de onda onde ocorre uma absorção apreciável. O espectro de absorção de um elemento, assim como o espectro de emissão, é simples e consiste em poucos picos bem-resolvidos de absorção. Os comprimentos de onda dos picos são característicos dos elementos e são praticamente independentes do seu estado químico.

Uma peculiaridade dos espectros de absorção é o aparecimento de descontinuidades pronunciadas, denominadas arestas de absorção, nos comprimentos de onda imediatamente além dos máximos de absorção.

A absorção de um quantum de raios $X$ provoca a ejeção de um dos elétrons mais internos de um átomo e conseqüentemente produção de um íon excitado. Nesse processo, toda a energia $h v$ da radiação é dividida entre a energia cinética do elétron (o fotoelétron) e a energia potencial do íon excitado. A maior probabilidade de absorção aparece quando o quantum de energia é exatamente igual à energia necessária para remover o elétron até exatamente a periferia do átomo, isto é, quando a energia cinética do elétron ejetado tende a zero [73].

\subsubsection{Microbalanca Eletroquímica de Cristal de Quartzo}

Quando uma reação química acontece na superfície de um sensor não ocorre simplesmente troca de calor mas também variação de massa. Esta variação de massa é obviamente muito pequena, porém se a balança utilizada for sensível o suficiente, ela pode detectar e quantificar a massa de 
analito que reagiu com a superfície do sensor. Desta forma esta superfície é considerada um transdutor para um sensor químico que se baseia na variação de massa. A microbalança eletroquímica de cristal de quartzo é um exemplo de um detector extremamente sensível de variação de massa que se baseia no efeito piezelétrico reverso. Este efeito tem sido usado geralmente em sensores sensíveis de massa para quantificar diversos analitos [74].

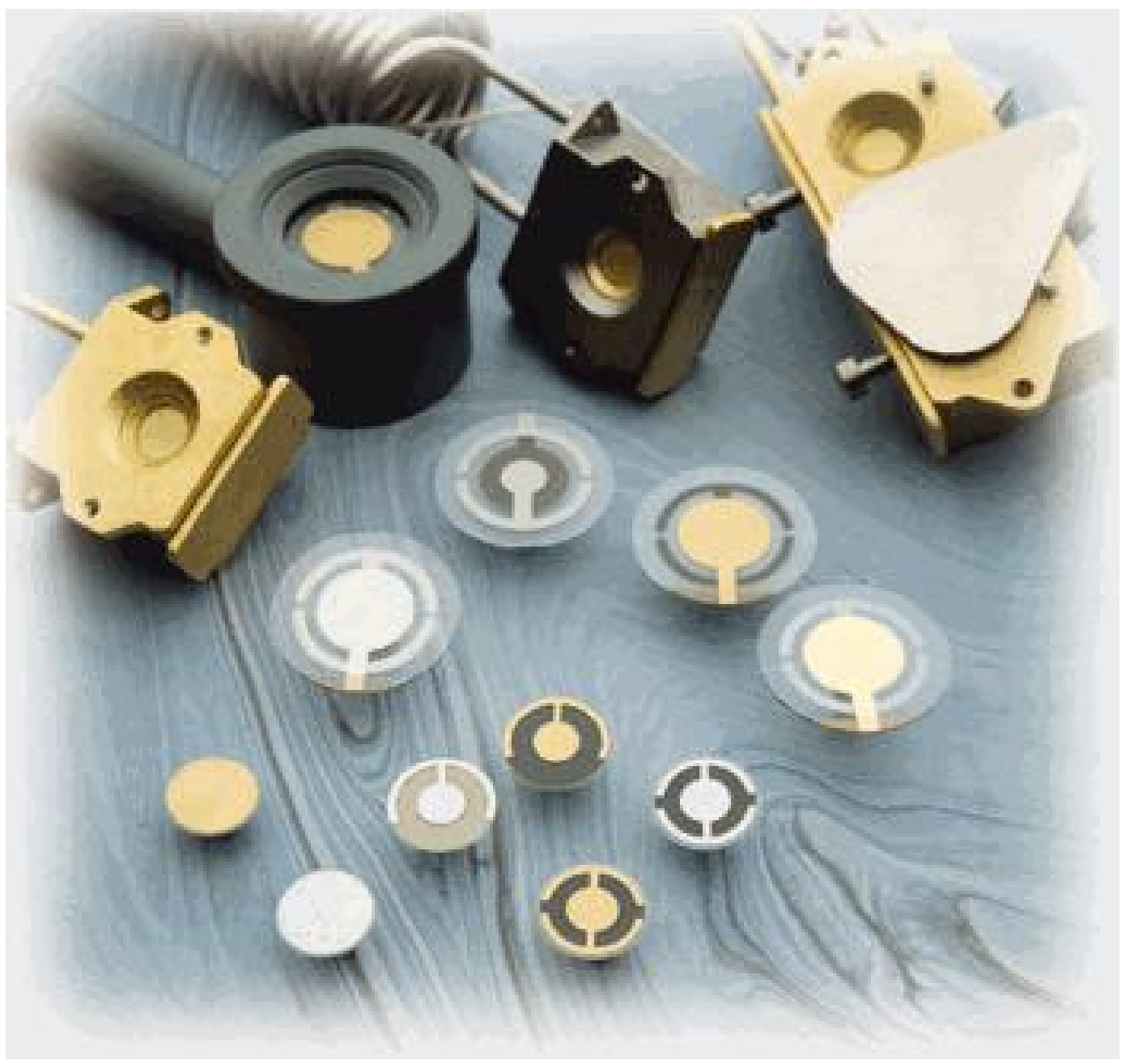

Figura 8 - Modelos de eletrodos de cristal de quartzo. 
Para que seja possível entender o funcionamento de uma microbalança eletroquímica de cristal de quartzo (MECQ) é necessário que se conheça o efeito piezelétrico. Os primeiros cientistas a estudarem este efeito foram Jacques e Pierre Curie. Em 1880, eles verificaram que ao se deformar mecanicamente a superfície de vários cristais - entre eles quartzo, sal de Rochelle ( $\left.\mathrm{NaKC}_{4} \mathrm{H}_{4} \mathrm{O}_{6} \cdot 4 \mathrm{H}_{2} \mathrm{O}\right)$ e turmalina - aparecia como resposta um potencial elétrico cuja magnitude era proporcional à tensão mecânica aplicada [75]. Quando se aplica uma variação de potencial elétrico adequado sobre uma rede de cristal, esta é então deformada oscilando em uma freqüência característica. Quando ocorre uma variação de massa na superfície do cristal a freqüência de oscilação do cristal muda. Este efeito é usado como parâmetro de medida no desenvolvimento de sensores químico piezelétricos ou sensores de massa [74].

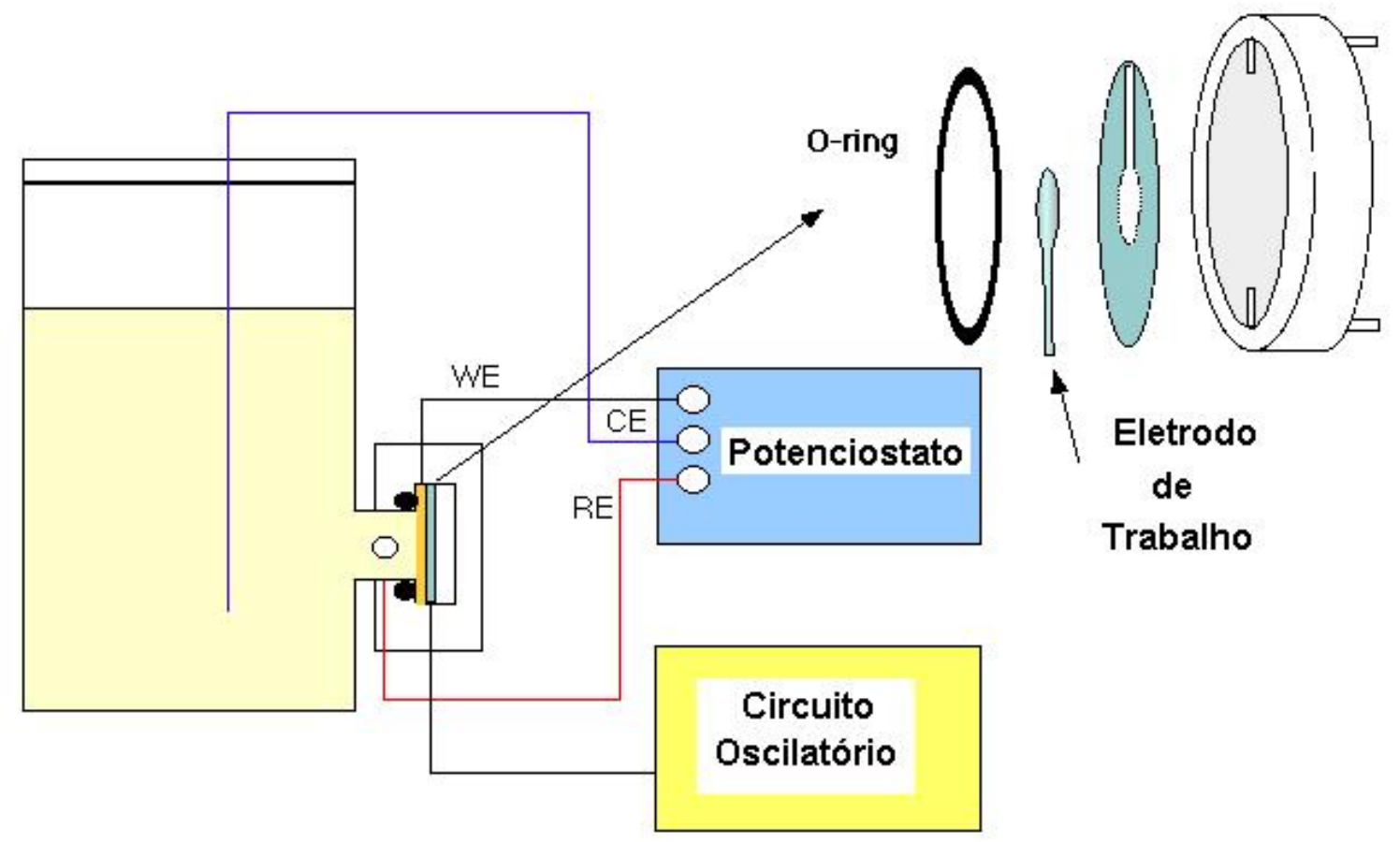

Figura 9 - Esquema de um sistema de microbalança eletroquímica de cristal de quartzo (MECQ). 
Para operar um sensor piezelétrico, uma diferença de potencial alternada é aplicada ao cristal de quartzo e esta causa oscilação mecânica na freqüência de ressonância natural do cristal. A freqüência ressonante depende das dimensões físicas do cristal e também da quantidade de material que for depositado em sua superfície. Normalmente os sensores piezoelétricos apresentam o formato de discos de 1,5 cm de diâmetro e 0,2 $\mathrm{mm}$ de espessura. Eletrodos metálicos condutores (p. ex. ouro) são presos à superfície como apresentado na Figura 8. Um disco de cristal de quartzo do tipo indicado anteriormente com freqüência oscilando em cerca de 9 $\mathrm{MHz}$ é conectado a um freqüencímetro devidamente acoplado a um circuito oscilatório (Figura 9).

A deposição do filme metálico, ou de outra substância, na superfície do cristal de quartzo altera a freqüência de oscilação conforme a equação de Sauerbrey (Equação 3).

\section{$\Delta \mathrm{F}=-\mathrm{C}_{\mathrm{f}} \Delta \mathrm{m}$}

(Equação 3)

Onde $\Delta \mathrm{F}=$ variação de freqüência $(\mathrm{Hz}) ; \mathrm{C}_{\mathrm{f}}=$ constante integral de sensibilidade; $\Delta \mathrm{M}=$ variação de massa do material depositado [76-77]. 
2- OBJETIVOS - 29

\section{Capítulo II}

\section{Objetivos}




\section{OBJETIVOS}

Realizar pesquisas no sentido de desenvolver eletrodo modificado pela eletrodeposição de óxidos de vanádio, de molibdênio e/ou de tungstênio.

Avaliar as potencialidades destes eletrodos modificados para a análise de óxido nítrico (NO) e/ou iodato em amostras sintéticas.

Elucidar, utilizando eletrodo rotativo, o mecanismo envolvendo o processo catalítico do analito de interesse na superfície modificada.

Avaliar a estabilidade química de filmes destes óxidos em diferentes valores de $\mathrm{pH}$ utilizando microbalança eletroquímica de cristal de quartzo.

Desenvolver um sensor amperométrico em fluxo utilizando estes eletrodos modificados para a determinação quantitativa do analito de interesse em amostras sintéticas e reais. 
3 - Parte Experimental - 31

\section{Capítulo III}

\section{Parte Experimental}




\section{3 - PARTE EXPERIMENTAL}

\subsection{Reagentes e Soluções}

- Molibdato de Sódio - Merck.

- Tungstato de Sódio - Merck.

- Microfibras de carbono $-r=2 \mu \mathrm{m}$.

- Microfios de platina $-r=12,5 \mu \mathrm{m}$.

- Pontas de pipeta de $400 \mu \mathrm{L}$.

- Cola Araldite ${ }^{\circledR}$.

- Cola de Prata.

- Lixa d'água 600.

- Lixa d'água 1200.

- Sulfato de Sódio - Merck.

- Ácido Sulfúrico - Merck.

- Ferricianeto de Potássio - Merck.

- Peróxido de Hidrogênio - Merck.

- Tungstênio Metálico - Acros Organics.

- Cloreto de Potássio - Merck.

- Iodato de Sódio - Merck.

- Óxido Nítrico - White Martins.

- Água previamente destilada e desionizada (18M $\Omega$ ) utilizando equipamento da Nanopure Infinity - Barnstead/Thermolyne.

- Eletrodo de carbono vítreo $-r=1,5 \mathrm{~mm}$.

- Eletrodo de referência - $\mathrm{Ag} / \mathrm{AgCl}$ [78]

- Eletrodo de Platina.

- Microbalança de Cristal de Quartzo com eletrodo de ouro.

- Alumina 0,1 $\mu \mathrm{m}$.

- Alumina $1 \mu \mathrm{m}$. 


\subsection{Aparelhagem}

- Potenciostato PAR-273 - EG\&G Princeton Applied Research.

- Sistema de aquisição de dados - Avolm - versão 3 - Prof. Dr. Luiz Henrique Mazo - Instituto de Química São Carlos - São Carlos.

- pHmetro 713 Metrohm

- Bipotenciostato com eletrodo rotativo modelo AFCBP1 - Pine Instrument Company

- Microscópio Infinity Photo-Optical Company acoplado a câmera de vídeo colorida CCD-IRIS SONY

- Software VidCap32 da Microsoft

- Microscópio Eletrônico de Varredura WDX 600 e espectrômetro Oxford Link ISIS 440. (Laboratório de Caracterização Técnica - Escola Politécnica da USP).

- Espectrômetro de Absorção de Raios X do Laboratório Nacional de Luz Síncroton (LNLS) - Campinas - São Paulo - Brasil.

- Potenciostato modelo PG3901 da Omnimeta.

- Freqüencímetro Stardford Research System modelo SR620 devidamente conectado a um circuito oscilatório.

\subsection{Solução Coloidal de Ácido Tungstico $\left(\mathrm{H}_{2} \mathrm{WO}_{4}\right)$ [21]}

A suspensão coloidal é produzida pela mistura de $3 \mathrm{~mL}$ de solução de tungstato de sódio $0,2 \mathrm{~mol} \mathrm{~L}^{-1}$ em $27 \mathrm{~mL}$ de solução de ácido sulfúrico $2 \mathrm{~mol}$ $\mathrm{L}^{-1}$. Na solução de ácido sulfúrico borbulhou-se $\mathrm{N}_{2}$ em constante agitação mecânica por 10 minutos, visando eliminar o $\mathrm{O}_{2}$ dissolvido, antes da adição da solução de tungstato de sódio.

Outro cuidado adotado durante a preparação da solução coloidal de $\mathrm{Na}_{2} \mathrm{WO}_{4} .2 \mathrm{H}_{2} \mathrm{O}$ em $\mathrm{H}_{2} \mathrm{SO}_{4}$ foi a adição da solução de tungstato de sódio 0,2 
mol L $\mathrm{L}^{-1}$ gota a gota à solução de ácido sulfúrico $2 \mathrm{~mol} \mathrm{~L}^{-1}$ para a efetiva reação de formação do ácido tungstíco $\left(\mathrm{H}_{2} \mathrm{WO}_{4}\right)$.

\subsection{Solução $54,4 \mathrm{mmol} \mathrm{L}^{-1}$ de Ácido Perotungstico [20]}

Pesam-se 0,5 g de tungstênio metálico e se oxida o metal adicionando-se $5 \mathrm{~mL}$ de solução de peróxido de hidrogênio $30 \%$. Em seguida transfere-se a solução quantitativamente para um balão volumétrico de $50 \mathrm{ml}$, avolumando a mesma com água desionizada até o menisco $(\mathrm{pH}=$ 1,5). O excesso de peróxido de hidrogênio é eliminado deixando a solução em repouso por uma semana em sistema aberto.

\subsection{Solução Carregadora pH 2,5}

Pesam-se 3,551 $\mathrm{g}$ de $\mathrm{Na}_{2} \mathrm{SO}_{4}$ e $20,5 \mathrm{~g}$ de $\mathrm{NaCl}$. Estes sais são transferidos quantitativamente para balão volumétrico de $500 \mathrm{~mL}$, completando o volume com água desionizada até o menisco. Para o acerto prévio do pH das soluções, utiliza-se solução de ácido sulfúrico e as medições são realizadas usando o pHmetro 713 Metrohm.

\subsection{Solução Eletrólito Suporte pH 2,5}

Pesam-se 7,102 g de $\mathrm{Na}_{2} \mathrm{SO}_{4}$ e se transfere este sal quantitativamente para um balão volumétrico de $1000 \mathrm{~mL}$. Completa-se o volume com água desionizada até o menisco para se preparar a solução de eletrólito suporte $\left(\mathrm{SO}_{4}{ }^{2-} 50 \mathrm{mmol} \mathrm{L}{ }^{-1} \mathrm{pH} 2,5\right)$. O acerto do $\mathrm{pH}$ da solução é executado utilizando solução de ácido sulfúrico, e as medições são realizadas usando o pHmetro 713 Metrohm. 


\subsection{Esquema da Aparelhagem}

Para realizar os ensaios amperométricos utilizou-se o esquema apresentado na figura 10 , onde se observa que o a solução carregadora é constituído de solução $50 \mathrm{mmol} \mathrm{L}^{-1}$ de sulfato $(\mathrm{pH}=2,5)$ com velocidade igual a 2,4 $\mathrm{mL} \mathrm{min}^{-1}$. O potencial aplicado à célula eletroquímica foi de $-0,2 \mathrm{~V}$, suficiente para reduzir o íon iodato que chega à superfície do eletrodo modificado.

No potenciostato PAR-273 - EG\&G Princeton Applied Research é conectado o sistema de três eletrodos, sendo que o eletrodo de referência é de $\mathrm{Ag} \mid \mathrm{AgCl}$ saturado. O contra-eletrodo é de platina. O eletrodo de trabalho é de carbono vítreo modificado com óxido de tungstênio quando se variou o potencial aplicado à célula eletroquímica na faixa de $+500 \mathrm{mV}$ a $-800 \mathrm{mV}$, por 15 minutos, em solução de tungstênio (VI) $54,4 \mathrm{mmol} \mathrm{L}^{-1}$.

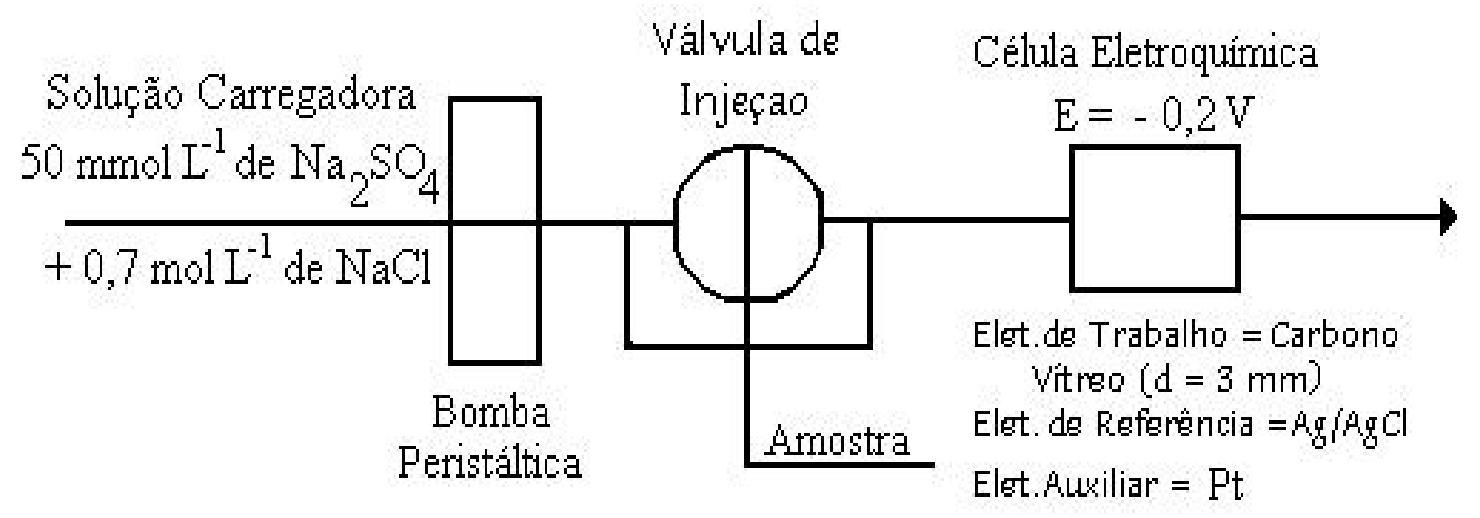

Figura 10 - Esquema para otimização do Sistema FIA e quantificação de iodato, utilizando potenciostato PAR - 273 EG\&G. Solução carregadora $50 \mathrm{mmol} L^{-1}$ de sulfato de sódio $+0,7 \mathrm{~mol} \mathrm{~L}^{-1}$ de $\mathrm{NaCl}(p H=2,5) . E=-200 m \mathrm{~V}$. 


\subsection{Preparo das amostras}

Preparou-se a solução de cada uma das amostras de sal de cozinha em estudo pesando $3 \mathrm{~g}$ destas amostras. Em seguida transferiu-se quantitativamente para balões volumétricos de $50 \mathrm{~mL}$, completando o volume com solução $50 \mathrm{mmol} \mathrm{L}^{-1}$ de sulfato de sódio $(\mathrm{pH} \mathrm{2,5)}$.

\subsection{Titulação iodométrica}

Pesaram-se aproximadamente $55 \mathrm{~g}$ da amostra de um dos sais de cozinha. Em seguida esta quantidade de sal foi dissolvida em água desionizada recém fervida. Adicionaram-se a esta solução $2 \mathrm{~g}$ iodeto de potássio e $5 \mathrm{~mL}$ de ácido sulfúrico $1 \mathrm{~mol} \mathrm{~L}^{-1}$. O triiodeto liberado durante a reação foi titulado até amarelo pálido com solução de tiossulfato de sódio 0,02002 $\mathrm{mol} \mathrm{L}^{-1}$ e empregou-se solução de amido como indicador do ponto final [79]. 


\section{Capítulo IV}

\section{Resultados}

e

Discussão 


\section{4 -RESULTADOS E DISCUSSÃO}

\subsection{Estudos envolvendo a deposição de óxido de molibdênio}

Foram realizados ensaios para verificar a deposição de óxidos de molibdênio em eletrodo de carbono vítreo, bem como a potencialidade destes eletrodos na catálise dos processos de transferência de elétrons para certos substratos de interesse. Estes estudos foram realizados para posterior comparação com os resultados obtidos com eletrodos de carbono vítreo modificados com óxidos de tungstênio.

Estes ensaios basearam-se nos trabalhos de Bertotti et al. [19, 80], os quais relatam a possibilidade de deposição eletroquímica de óxidos de molibdênio não-estequiométricos na superfície de eletrodo de carbono vítreo.

\subsubsection{Modificação da Superfície do Eletrodo}

O procedimento usado para a modificação da superfície do eletrodo baseou-se na variação do potencial aplicado ao eletrodo de carbono vítreo, de $200 \mathrm{mV}$ a $-800 \mathrm{mV}$ versus eletrodo de referência de $\mathrm{Ag} / \mathrm{AgCl}$ saturado em solução de molibdato de sódio $1 \mathrm{mmol} \mathrm{L}^{-1}$ e sulfato de sódio $50 \mathrm{mmol} \mathrm{L}^{-1}$ $(\mathrm{pH} 3,0)$ previamente desareada com $\mathrm{N}_{2}$. Na Figura 11 são apresentados os voltamogramas cíclicos do processo de modificação do eletrodo. Nesta Figura pode ser observado o aumento da intensidade de corrente do componente catódico, e do componente anódico indícios do aumento da área superficial do agente modificador. 


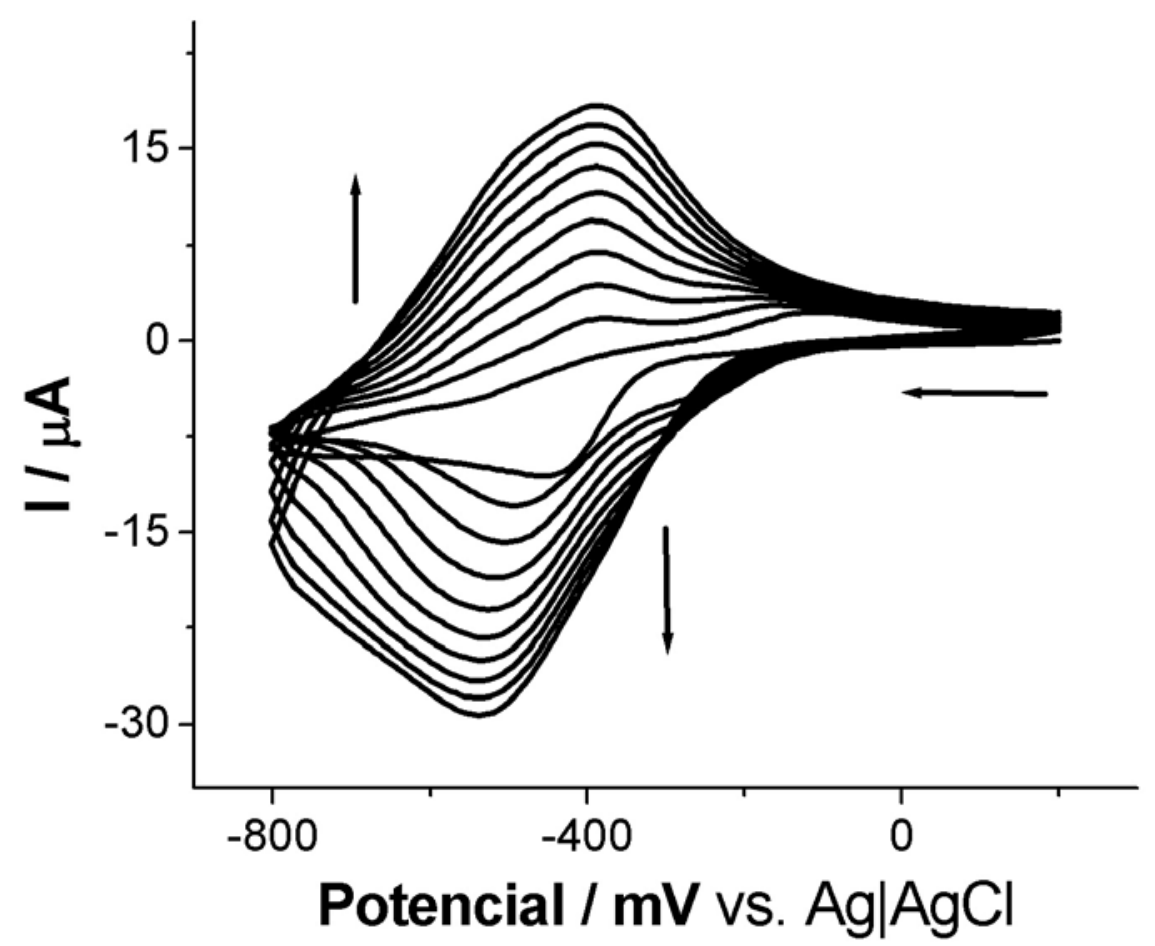

Figura 11 - Voltamogramas cíclicos sucessivos ( $n=10$ ciclos) obtidos durante a modificação da superfície de eletrodo de carbono vítreo, quando se varia o potencial aplicado ao eletrodo de carbono vítreo de $200 \mathrm{mV} \mathrm{a}-$ $800 \mathrm{mV}$ versus eletrodo de referência $\mathrm{Ag} / \mathrm{AgCl}$ saturado em solução de

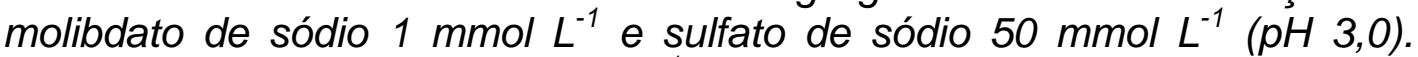
Velocidade de varredura $=50 \mathrm{mV} \mathrm{s}^{-1}$.

\subsubsection{Verificação da Estabilidade do Filme Formado}

Para confirmar a eletrodeposição do filme de óxido de molibdênio e verificar a estabilidade do filme formado sobre a superfície eletródica foram registrados 10 voltamogramas cíclicos sucessivos em solução de sulfato de sódio $50 \mathrm{mmol} \mathrm{L}^{-1}(\mathrm{pH} 2,5)$. O resultado pode ser observado na Figura 12, onde se percebe que tanto a intensidade de corrente do componente catódico como do anódico atingem um valor estável, demonstrando assim que neste meio o filme depositado é estável. 


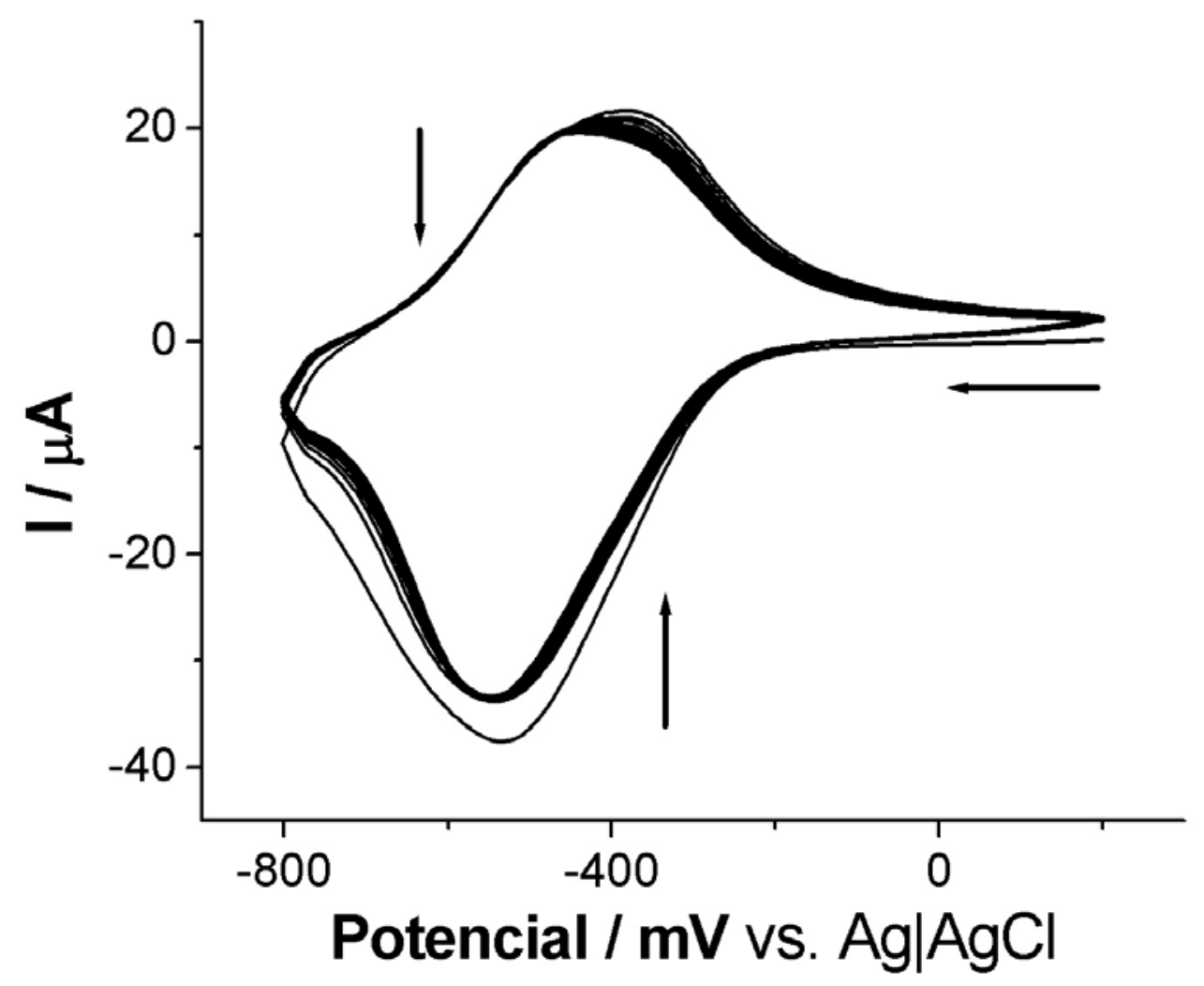

Figura 12 - Voltamogramas cíclicos sucessivos ( $n=10$ ciclos) obtidos quando se varia o potencial aplicado ao eletrodo de trabalho $200 \mathrm{mV} \mathrm{a}-800$ $\mathrm{mV}$ versus eletrodo de referência $\mathrm{Ag} / \mathrm{AgCl}$ saturado em solução sulfato de sódio $50 \mathrm{mmol}^{-1}(\mathrm{pH} \mathrm{2,5)}$. Eletrodo de trabalho = eletrodo modificado com óxido de molibdênio (Figura 11). Velocidade de varredura $=50 \mathrm{mV} \mathrm{s}^{-1}$.

\subsubsection{Verificação da Eletrocatálise do $1 \mathrm{O}_{3}{ }^{-}$}

Nos ensaios realizados por Bertotti et al. [80] foi verificada a potencialidade destes eletrodos modificados na quantificação de $\mathrm{IO}_{3}{ }^{-}$, conforme pode ser observado na Figura 13. Neste caso, os ensaios foram realizados variando o potencial aplicado eletrodo de trabalho de $-800 \mathrm{mV}$ a $700 \mathrm{mV}$ versus eletrodo de $\mathrm{Ag} / \mathrm{AgCl}$ saturado: em (A) é apresentado o voltamograma cíclico obtido em solução de sulfato de sódio $50 \mathrm{mmol} \mathrm{L}^{-1}(\mathrm{pH} 2,5)$ com o eletrodo de carbono vítreo polido, em (B) é apresentado o voltamograma cíclico obtido em solução de sulfato 
de sódio $50 \mathrm{mmol} \mathrm{L}^{-1}(\mathrm{pH}$ 2,5) com eletrodo de carbono vítreo modificado com óxidos de molibdênio e em (C) é apresentado o voltamograma cíclico obtido em solução de sulfato de sódio $50 \mathrm{mmol} \mathrm{L}^{-1}$ com $10 \mathrm{mmol} \mathrm{L}^{-1}$ de iodato de sódio $(\mathrm{pH}$ $2,5)$ utilizando eletrodo de carbono vítreo modificado com óxidos de molibdênio. No voltamograma cíclico $C$ da Figura 13 percebe-se um aumento significativo do pico catódico - referente à redução de $\mathrm{IO}_{3}{ }^{-}$- em relação ao pico catódico registrado no voltamograma cíclico $\mathrm{B}$ da mesma figura, obtido em meio sem $\mathrm{IO}_{3}{ }^{-}$. Demonstra-se assim a potencialidade do eletrodo modificado em catalisar o processo de redução do iodato. No voltamograma cíclico $\mathrm{C}$ se percebe ainda 0 sinal do par $\mathrm{I}_{2} / \mathrm{l}^{-}$em torno de $500 \mathrm{mV}$ levando a conclusão que iodeto é um dos produtos da redução do iodato na superfície modificada.

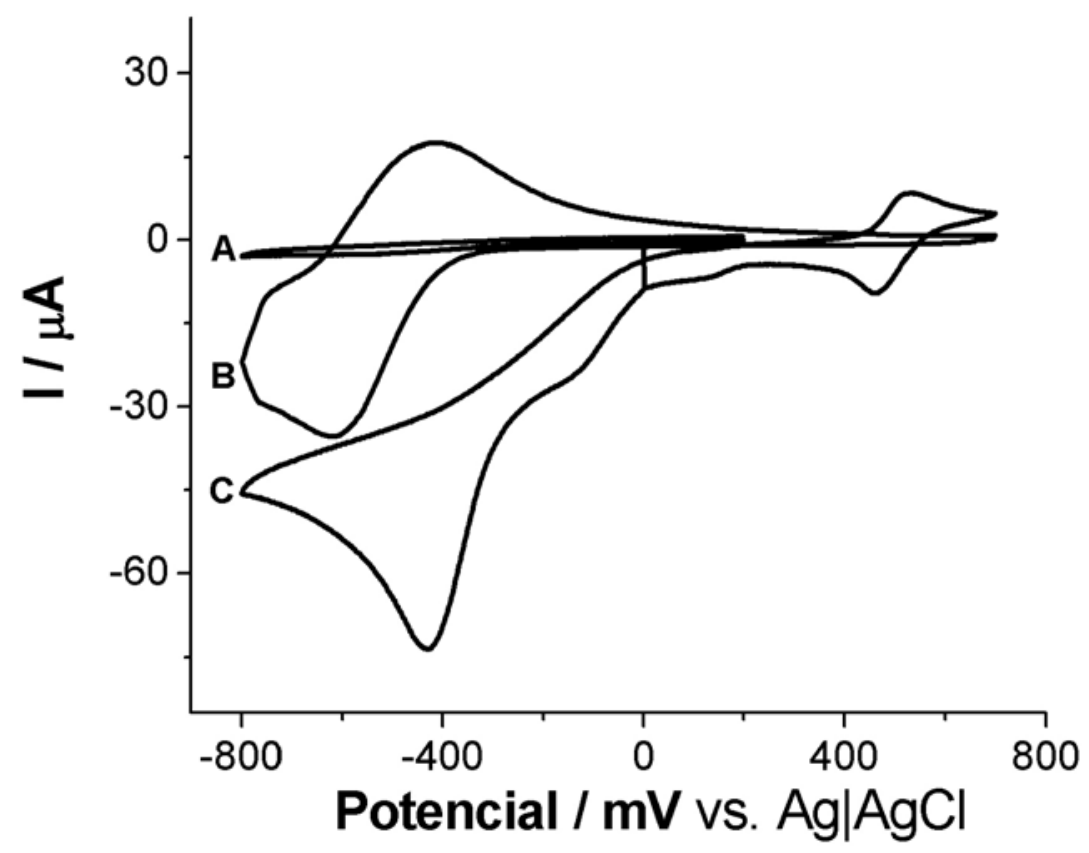

Figura 13 - Voltamogramas cíclicos obtidos variando o potencial de aplicado ao eletrodo de carbono vítreo na faixa de $-800 \mathrm{mV}$ a $700 \mathrm{mV}$ versus eletrodo de $\mathrm{Ag} / \mathrm{AgCl}$ : (A) em solução de sulfato de sódio $50 \mathrm{mmol}^{-1}$ (pH 3) utilizando eletrodo de trabalho polido, (B) em solução de sulfato de sódio $50 \mathrm{mmol}^{-1}(\mathrm{pH} 2,5)$ utilizando eletrodo de trabalho modificado e (C) em solução de sulfato de sódio $50 \mathrm{mmol} \mathrm{L}^{-1} \mathrm{com} 10 \mathrm{mmol} \mathrm{L}^{-1}$ de iodato de sódio $(\mathrm{pH} 2,5)$ utilizando eletrodo de trabalho modificado com óxido de molibdênio. Velocidade de varredura $=50 \mathrm{mV} \mathrm{s}^{-1}$. 


\subsection{Estudos envolvendo a deposição de óxido de tungstênio}

Os estudos envolvendo a eletrodeposição de óxidos de tungstênio em eletrodos de carbono vítreo foram realizados por duas metodologias. A primeira foi utilizando solução coloidal de ácido tungstico [21] a outra utilizando solução de ácido perotungstico [20].

\subsubsection{Eletrodeposicão em Solucão Coloidal de Ácido Tungstico}

Para verificar a deposição de óxidos de tungstênio em eletrodo de carbono vítreo foram realizados ensaios preliminares baseando-se no trabalho de Kulesza e Faulkner [21].

Estes ensaios relatam a possibilidade de deposição eletroquímica de óxidos de tungstênio na superfície de eletrodo de carbono vítreo. O procedimento utilizado consiste em variar o potencial aplicado ao eletrodo de carbono vítreo na faixa de $800 \mathrm{mV}$ a - $300 \mathrm{mV}$ versus eletrodo de $\mathrm{Ag} \mid \mathrm{AgCl}$ - com velocidade de varredura de $50 \mathrm{mV} \mathrm{\textrm {s } ^ { - 1 }}$ - utilizando suspensão coloidal de $\mathrm{Na}_{2} \mathrm{WO}_{4} \cdot 2 \mathrm{H}_{2} \mathrm{O}$ em H $\mathrm{H}_{4} \mathrm{SO}_{4}$.

Para verificar este procedimento de modificação eletroquímica de eletrodos de carbono vítreo com óxidos de tungstênio foram realizados ensaios variando sucessivamente o potencial aplicado ( $n=40$ ciclos) ao eletrodo de trabalho de $800 \mathrm{mV}$ a $-300 \mathrm{mV}$ versus eletrodo de $\mathrm{Ag} / \mathrm{AgCl}$ saturado, com velocidade de $50 \mathrm{mV} \mathrm{s}^{-1}$, perfazendo um tempo total aproximado de 30 minutos. 
Em seguida, este eletrodo modificado é transferido para uma solução de ácido sulfúrico $2 \mathrm{~mol} \mathrm{~L}^{-1}$, para que se verifique a estabilidade do filme de óxido de tungstênio eletrodepositado. Para tanto se realizaram variações sucessivas $(n=40)$ no potencial aplicado ao sistema, de $800 \mathrm{mV}$ a $-300 \mathrm{mV}$ versus eletrodo de $\mathrm{Ag} \mid \mathrm{AgCl}$ saturado.

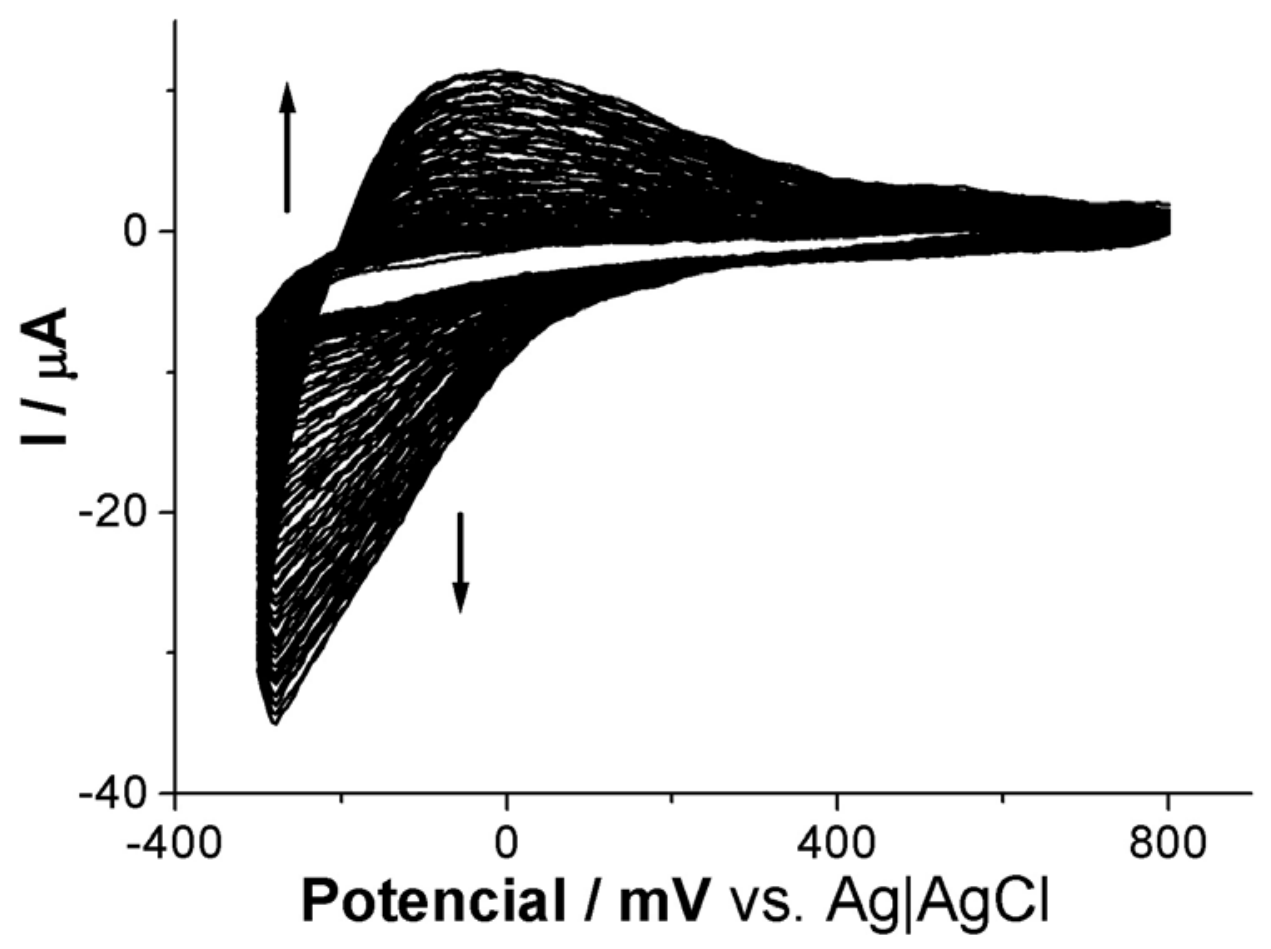

Figura 14 - Voltamogramas cíclicos sucessivos obtidos durante a modificação do eletrodo de carbono vítreo quando se variou o potencial do eletrodo de trabalho de $800 \mathrm{mV} \mathrm{a}-300 \mathrm{mV}$ versus $\mathrm{Ag} / \mathrm{AgCl}$ ( $n=80$ ciclos) com tempo aproximado de 60 minutos. Variação realizada em solução coloidal de tungstato de sódio $0,2 \mathrm{~mol} \mathrm{~L}^{-1}$ e ácido sulfúrico $2 \mathrm{~mol} \mathrm{~L}^{-1} \mathrm{com}$ velocidade de varredura igual a $50 \mathrm{mV} \mathrm{s}^{-1}$.

Posteriormente foram realizados ensaios similares para modificar a superfície do eletrodo de carbono vítreo pela deposição eletroquímica de óxido de tungstênio com 80, 120 e 160 ciclos sucessivos de potencial. Estes processos ocorreram quando se variou o potencial aplicado ao eletrodo de 
trabalho de $800 \mathrm{mV}$ a $-300 \mathrm{mV}$ versus eletrodo de $\mathrm{Ag} \mid \mathrm{AgCl}$ saturado, com velocidade de $50 \mathrm{mV} \mathrm{s}^{-1}$ por um período aproximado de 1 hora, 1 hora e 30 minutos e duas horas. Os voltamogramas cíclicos da modificação do eletrodo com 80 ciclos sucessivos de potencial podem ser observados na Figura 14. Nesta Figura e em todos os tempos de modificação se percebe 0 aumento na intensidade de corrente dos componentes catódicos e anódicos induzindo a se acreditar na eletrodeposição dos eletrodos.

Para verificar a estabilidade dos filmes de óxidos de tungstênio depositado sobre a superfície modificada $(n=80,120$ e 160) se variou o potencial aplicado a célula eletroquímica de $800 \mathrm{mV}$ a $-300 \mathrm{mV}$ versus eletrodo de $\mathrm{Ag} / \mathrm{AgCl}$ saturado em solução de ácido sulfúrico $2 \mathrm{~mol} \mathrm{~L}^{-1} \mathrm{com}$ velocidade de varredura igual a $50 \mathrm{mV} \mathrm{s}^{-1}$. O número de variação sucessiva em cada um dos ensaios foi o mesmo daquele realizado durante o processo de modificação do eletrodo. Os voltamogramas cíclicos obtidos durante 0 processo em que foi verificada a estabilidade do filme de óxido de tungstênio $(n=80)$ pode ser visualizado observando a Figura 15.

Durante este processo percebe-se que os 60 minutos em que se variou o potencial aplicado ao sistema foram insuficientes para a modificação do eletrodo de carbono vítreo. Este fato é percebido pelo resultado de intensidade de corrente observado nesta figura, onde demonstra que o filme não permaneceu sobre a superfície do eletrodo ou que ainda o filme formado é tão fino que a intensidade de corrente observada é equivalente àquela observada quando se registra o voltamograma cíclico utilizando um eletrodo de carbono vítreo polido. 


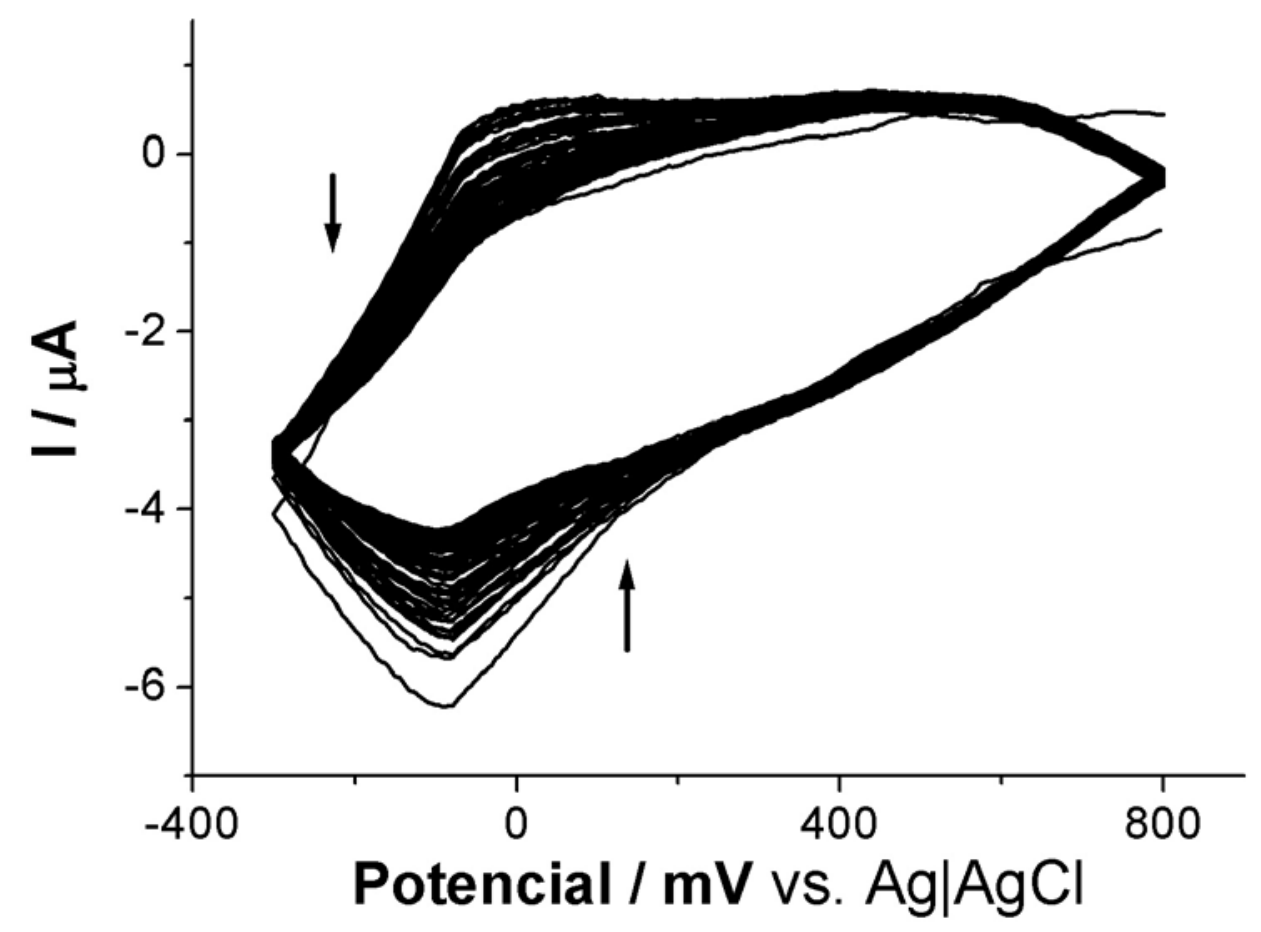

Figura 15 - Voltamogramas cíclicos sucessivos obtidos durante a verificação da estabilidade do filme de óxido de tungstênio ( $n=80$ ciclos) com tempo aproximado de 60 minutos. Variação realizada em solução de ácido sulfúrico $2 \mathrm{~mol} \mathrm{~L}^{-1} \mathrm{com}$ velocidade de varredura igual a $50 \mathrm{mV} \mathrm{s}^{-1}$.

Para períodos de modificação do eletrodo maiores do que 90 minutos, percebe-se que o filme depositado eletroquimicamente é espesso o suficiente pois apresenta valores de intensidade de corrente maiores e por este motivo mais visíveis.

Outro fato importante observado durante este processo de modificação foi que o período de uso desta solução coloidal é muito pequeno, visto que ocorre a formação de um precipitado amarelo de óxido de tungstênio em um período menor do que três horas. Desta forma não é mais possível utilizar esta solução no processo de modificação do eletrodo. 


\subsubsection{Eletrodeposição em Solução de Ácido Perotungstico}

\subsubsection{Modificação da Superfície do Eletrodo}

Neste processo de modificação da superfície do eletrodo de carbono vítreo variou-se o potencial aplicado de $500 \mathrm{mV}$ a $-800 \mathrm{mV}$, por 17 ciclos com velocidade de varredura de $50 \mathrm{mV} \mathrm{s}^{-1}$, em solução $54,4 \mathrm{mmol} \mathrm{L}^{-1}$ de ácido perotungstico $(\mathrm{pH}=1,5)$. $\mathrm{O}$ resultado deste experimento é apresentado na Figura 16, onde se percebe o contínuo aumento da corrente em função do número de ciclos de potencial, com conseqüente aumento na quantidade de material depositado.

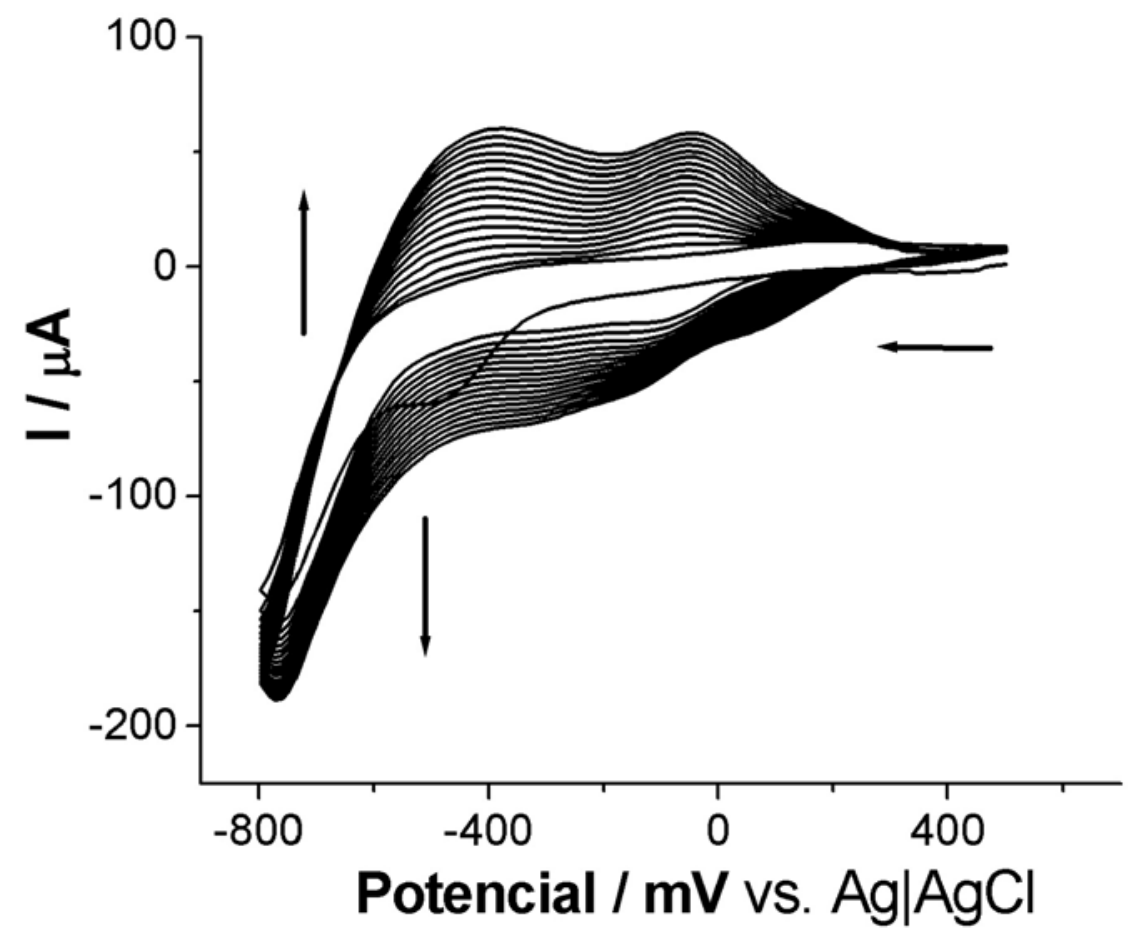

Figura 16 - Voltamogramas cíclicos sucessivos ( $n=17$ ciclos) obtidos durante a modificação do eletrodo de carbono vítreo em solução $54,4 \mathrm{mmol}$ $L^{-1}$ ácido perotungstico $(\mathrm{pH}=1,5)$. Velocidade de varredura $=50 \mathrm{mV} \mathrm{s}^{-1}$. 


\subsubsection{Verificação da Estabilidade do Filme Formado}

Para verificar a estabilidade do filme formado foram realizados ensaios em diferentes soluções $50 \mathrm{mmol} \mathrm{L}^{-1}$ de $\mathrm{SO}_{4}{ }^{2-}$, alterando o valor do $\mathrm{pH}$ das mesmas. No processo para verificar a estabilidade do filme formado sobre a superfície do eletrodo de carbono vítreo variou-se o potencial aplicado de $500 \mathrm{mV}$ a $-800 \mathrm{mV}$, por 10 ciclos com velocidade de varredura de $50 \mathrm{mV} \mathrm{s}^{-1}$, em soluções $50 \mathrm{mmol} \mathrm{L}^{-1}$ de $\mathrm{SO}_{4}{ }^{2-}$ cujos valores de $\mathrm{pH}$ foram 1,$0 ; 2,0 ; 3,0 ; 4,0 ; 5,0 ; 7,0$ e 9,0. Na Figura 17 é possível observar os resultados desses ensaios e verificar que em soluções com $\mathrm{pH}$ superior a 4,0 ocorre permanente dissolução do filme ao longo do experimento voltamétrico, em concordância com relatos da literatura [20].

Os processos referentes às perdas de filme observadas nas curvas $D$, E, F e G podem ser descritos pela Equação 4:

$$
\mathrm{WO}_{3}+2 \mathrm{OH}^{-} \leftrightarrows \mathrm{WO}_{4}{ }^{2-}+\mathrm{H}_{2} \mathrm{O}
$$

(Equação 4)

A diminuição de intensidade de corrente nos resultados observados quando se utilizaram soluções cujos valores de pH foram inferiores a 2,0 devem-se provavelmente a uma reestruturação química do filme e não à perda de material. Tal conclusão é sustentada nos ensaios realizados posteriormente com microbalança eletroquímica de cristal de quartzo, em que se comprovou a estabilidade química do óxido depositado. O resultado destes ensaios está apresentado no item 4.4.5.3. desta tese, em que será discutida a influência do $\mathrm{pH}$ na solubilização de filmes de óxidos de tungstênio. 

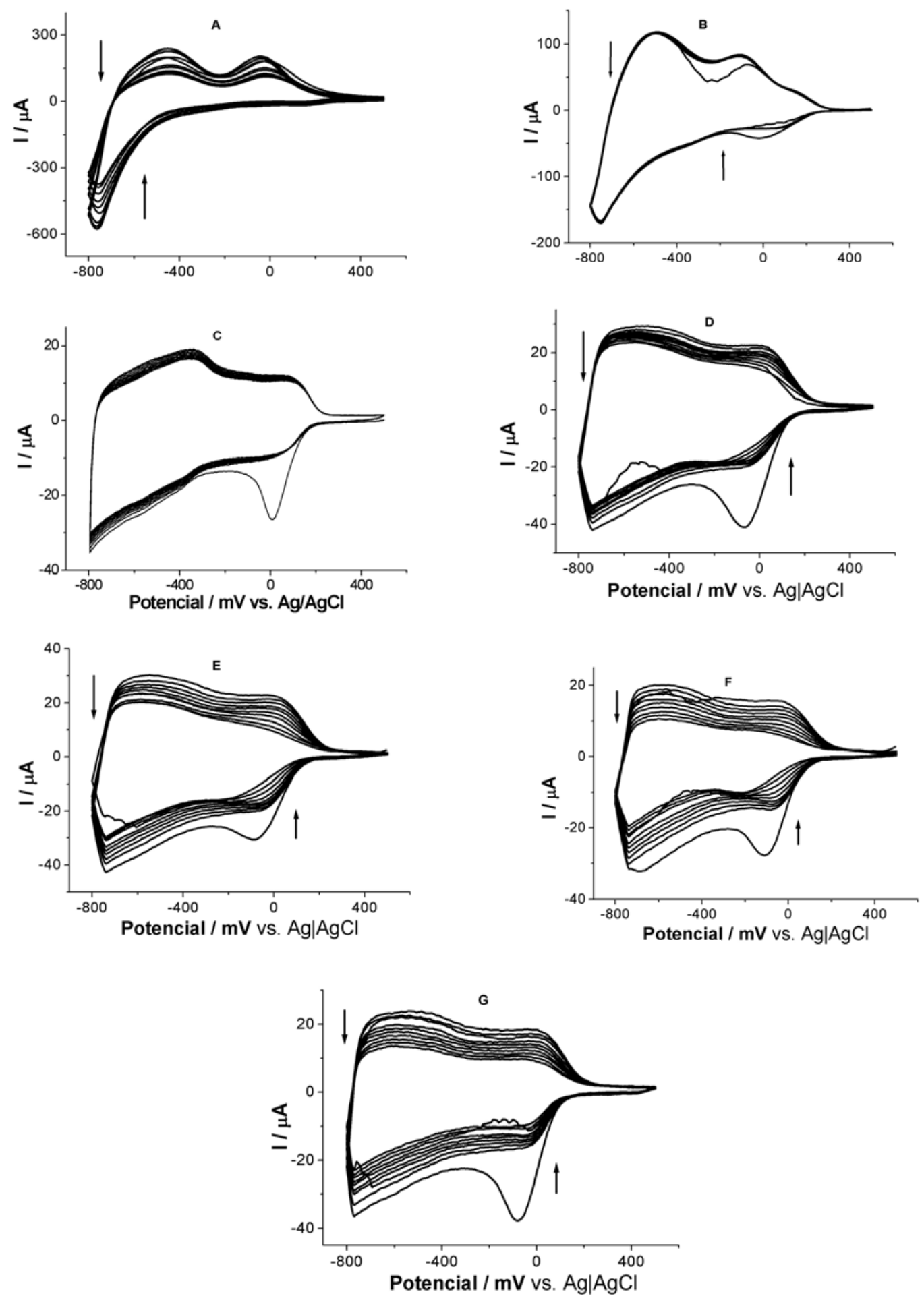

Figura 17 - Voltamogramas cíclicos sucessivos obtidos com eletrodo modificado com filme de óxido de tungstênio em solução de $\mathrm{SO}_{4}{ }^{2-} 50 \mathrm{mmol}$ $L^{-1}$ (A) $p H=1,0$; (B) $p H=2,0$; (C) $p H=3,0$; (D) $p H=4,0$; (E) $p H=5,0$; (F) $p H=7,0$ e $(G) p H=9,0$. Velocidade de varredura $=50 \mathrm{mV} \mathrm{s}^{-1}$. 
Pela análise da Figura 17 observa-se que na faixa de pH entre 2,0 e 3,0 os registros voltamétricos são significativamente constantes, indicando a maior estabilidade dos filmes de óxido de tungstênio nesta região de pH. Experimentos similares foram repetidos em solução $50 \mathrm{mmol} \mathrm{L}^{-1}$ de $\mathrm{SO}_{4}{ }^{2-} \mathrm{em} \mathrm{pH}=2,5$ e os resultados podem ser observados na Figura 18. Como os resultados de verificação da estabilidade do filme foram os melhores nesta condição, todos os ensaios futuros foram realizados em $\mathrm{pH} 2,5$.

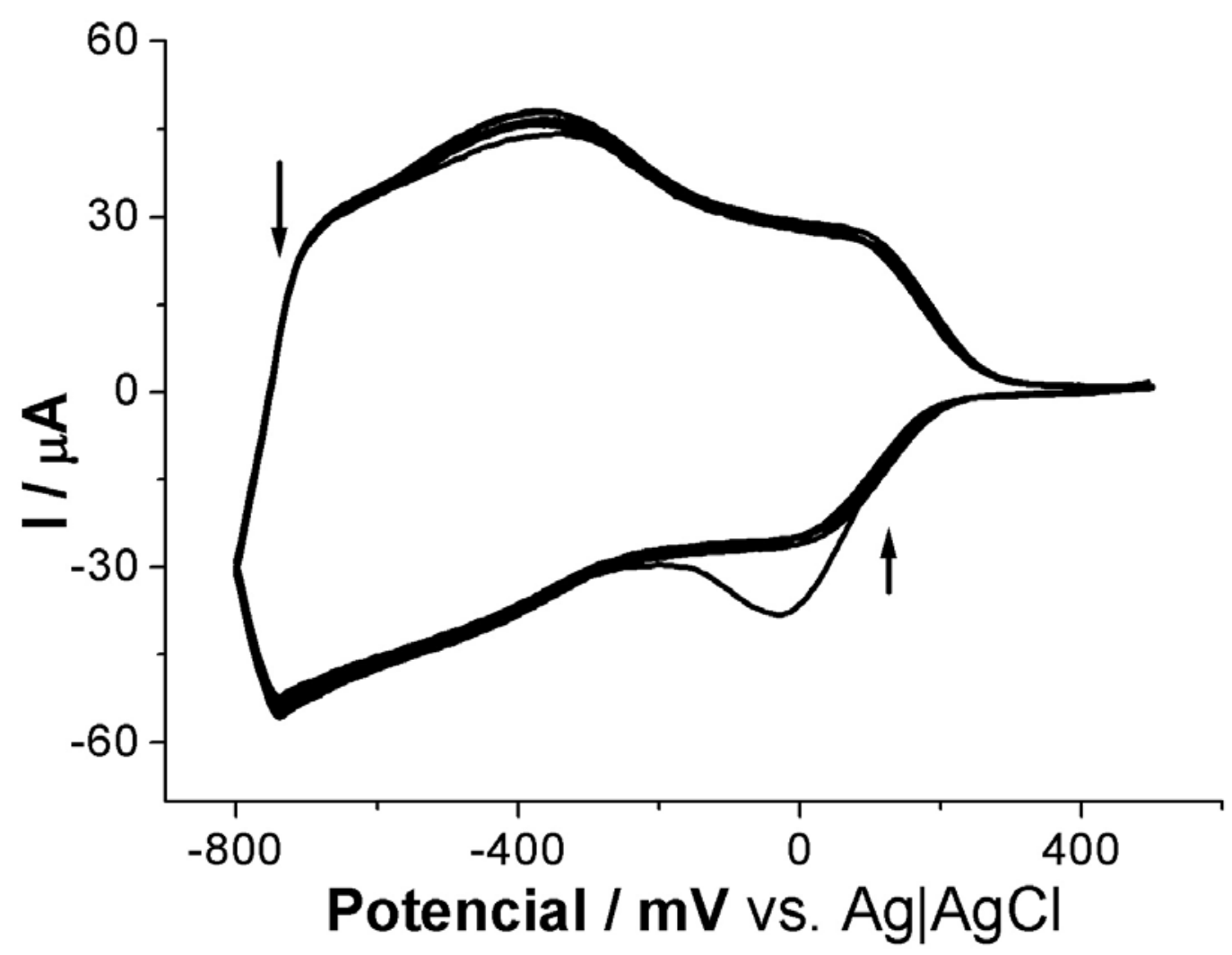

Figura 18 - Voltamogramas cíclicos sucessivos obtidos com eletrodo modificado com filme de óxido de tungstênio em solução de $\mathrm{SO}_{4}^{2-50} \mathrm{mmol}$ $L^{-1}(p H 2,5)$. Velocidade de varredura $=50 \mathrm{mV} \mathrm{s}^{-1}$. 


\subsubsection{Repetibilidade na Modificação de Eletrodos}

Para verificar a repetibilidade na modificação de eletrodos de carbono vítreo se variou o potencial aplicado à célula eletroquímica de $500 \mathrm{~V}$ a -800 $\mathrm{mV}$ (17 ciclos) em solução de ácido perotungstico. Posteriormente verificouse a estabilidade deste filme em $\mathrm{pH}$ 2,5. E finalmente se registrou um voltamograma cíclico na mesma solução em que se verificou a estabilidade do filme. Estes procedimentos foram repetidos mais cinco vezes.

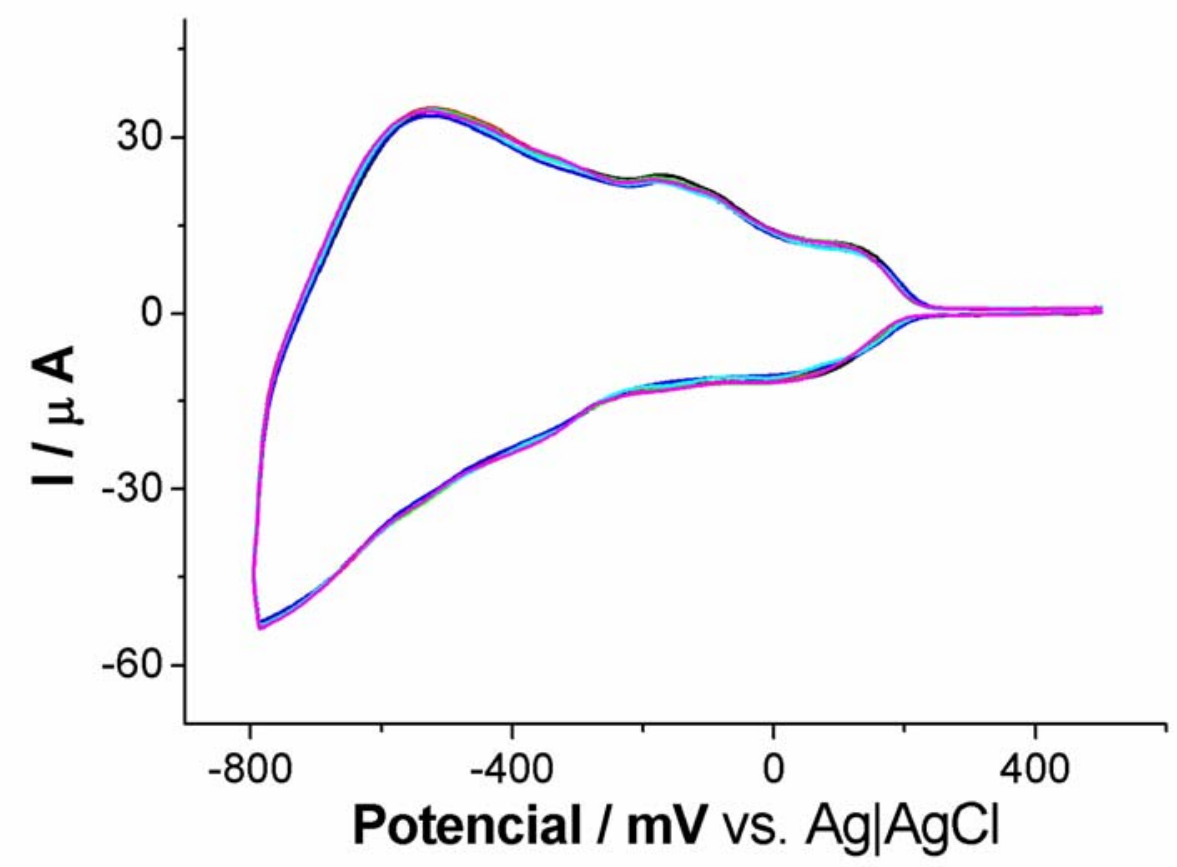

Figura 19 - Voltamogramas cíclicos obtidos com seis diferentes eletrodos modificados com filme de óxido de tungstênio em solução de $\mathrm{SO}_{4}{ }^{2-} 50 \mathrm{mmol}$ $L^{-1}(p H=2,5)$. Velocidade de varredura $=50 \mathrm{mV} \mathrm{s}^{-1}$.

Os voltamogramas cíclicos registrados após a verificação da estabilidade dos mesmos são apresentados na Figura 19. Desta forma é possível indicar que o eletrodo de carbono vítreo modificado com óxido de tungstênio apresenta excelente repetibilidade na sua preparação, pois existe uma sobreposição das curvas apresentadas. 


\subsubsection{Resposta Eletroquímica em função da Quantidade de Material Depositado}

Para verificar a dependência da quantidade de óxido de tungstênio imobilizado na superfície do eletrodo em função do número de ciclos empregados durante o processo de modificação foram realizados ensaios alterando o número de ciclos de potencial de deposição (17, 34, 68 e 136 ciclos). Posteriormente estabilizou-se cada um dos filmes de óxido de tungstênio obtidos em solução $50 \mathrm{mmol} \mathrm{L}^{-1}$ de $\mathrm{SO}_{4}{ }^{2-}(\mathrm{pH} 2,5)$ por 10 ciclos de potencial. Na Figura 20 são apresentados os voltamogramas cíclicos referentes aos eletrodos modificados com 15(B), 30(C), 60(D), 120(E) minutos e o voltamograma cíclico obtido com o eletrodo de carbono vítreo polido (A). Nestes voltamogramas observa-se o aumento nos valores de intensidade de corrente devido ao aumento da quantidade de material depositado na superfície eletródica.

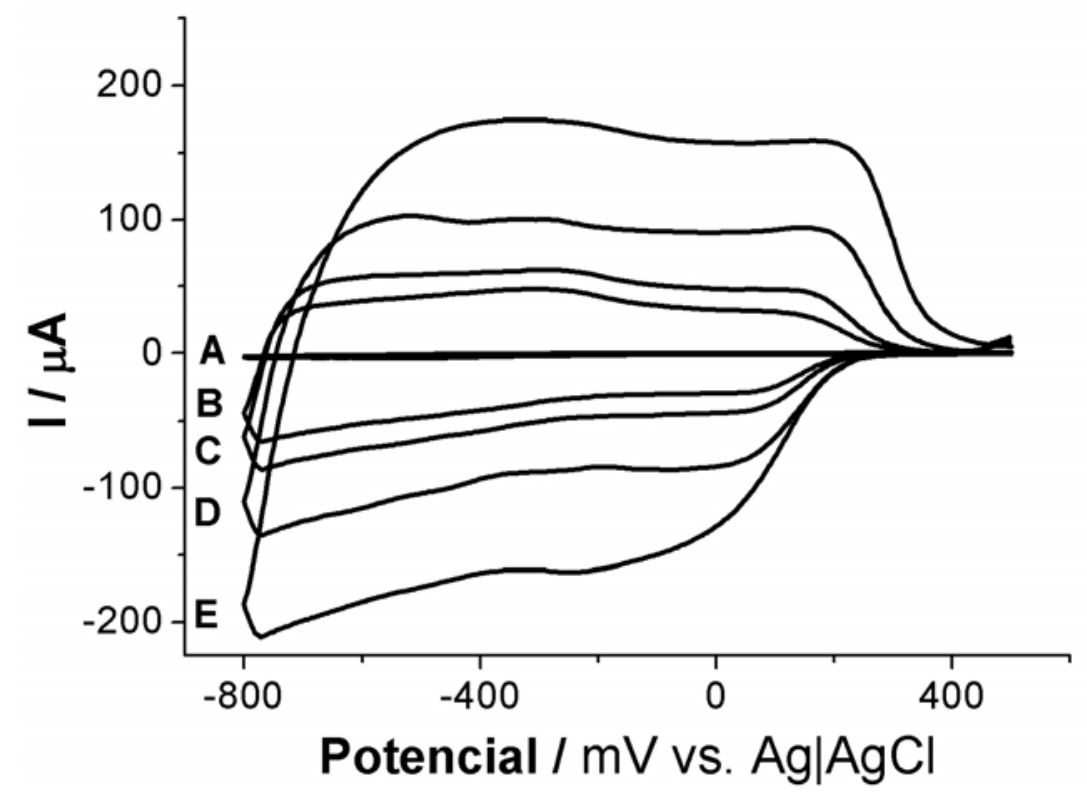

Figura 20 - Voltamogramas cíclicos referentes aos eletrodos modificados com $17(B), 34(C), 68(D), 136$ (E) ciclos de potencial e o voltamograma cíclico obtido com eletrodo de trabalho polido $(A)$ em solução $\mathrm{SO}_{4}{ }^{2-} 50$ $m \mathrm{~mol} \mathrm{~L}^{-1}(\mathrm{pH} 2,5)$. Velocidade de varredura $=50 \mathrm{mV} \mathrm{s}^{-1}$. 


\subsubsection{Estudo da permeabilidade dos filmes de óxidos de tungstênio}

Ensaios com eletrodos rotativos são realizados em investigações sobre o processo de transferência eletrônica no sistema em estudo.

Segundo Levich [81], gráficos lineares de intensidade de corrente $(\Delta \mathrm{I})$ em função da raiz quadrada da velocidade de rotação $\left(\omega^{1 / 2}\right)$ indicam que o processo de transferência é rápido e que a corrente limite é governada por transporte de massa, ou seja todo material que chega a superfície do eletrodo é prontamente consumido. Representações gráficas não lineares indicam a existência de algum componente cinético.

A redução eletroquímica do $\mathrm{Fe}(\mathrm{CN})_{6}^{-3}$ é reversível e governada por transporte de massa como esta descrito na literatura. Foram realizados ensaios para verificar o processo de transferência eletrônica do $\mathrm{Fe}(\mathrm{CN})_{6}^{-3}$ em eletrodo de carbono vítreo modificado com filmes de óxidos de tungstênio. Estes ensaios ocorreram utilizando eletrodo rotativo em diferentes velocidades de rotação (100; 400; 900; 1600; 2500; 3600 e 4900 rpm) e em solução de ferricianeto de potássio em diferentes concentrações $\left(0,1 ; 1\right.$ e $\left.10 \mathrm{mmol} \mathrm{L}^{-1}\right)$.

Nas Figuras 21, 22 e 23 podem ser observados os voltamogramas cíclicos obtidos nestes ensaios. 

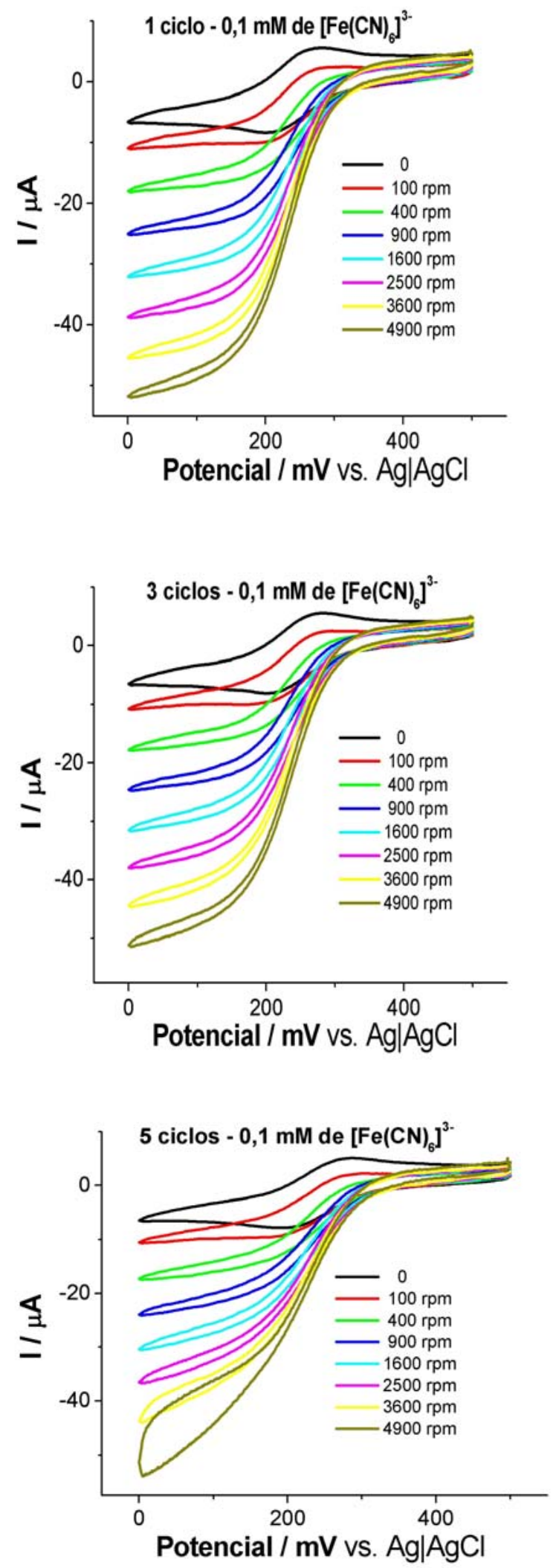
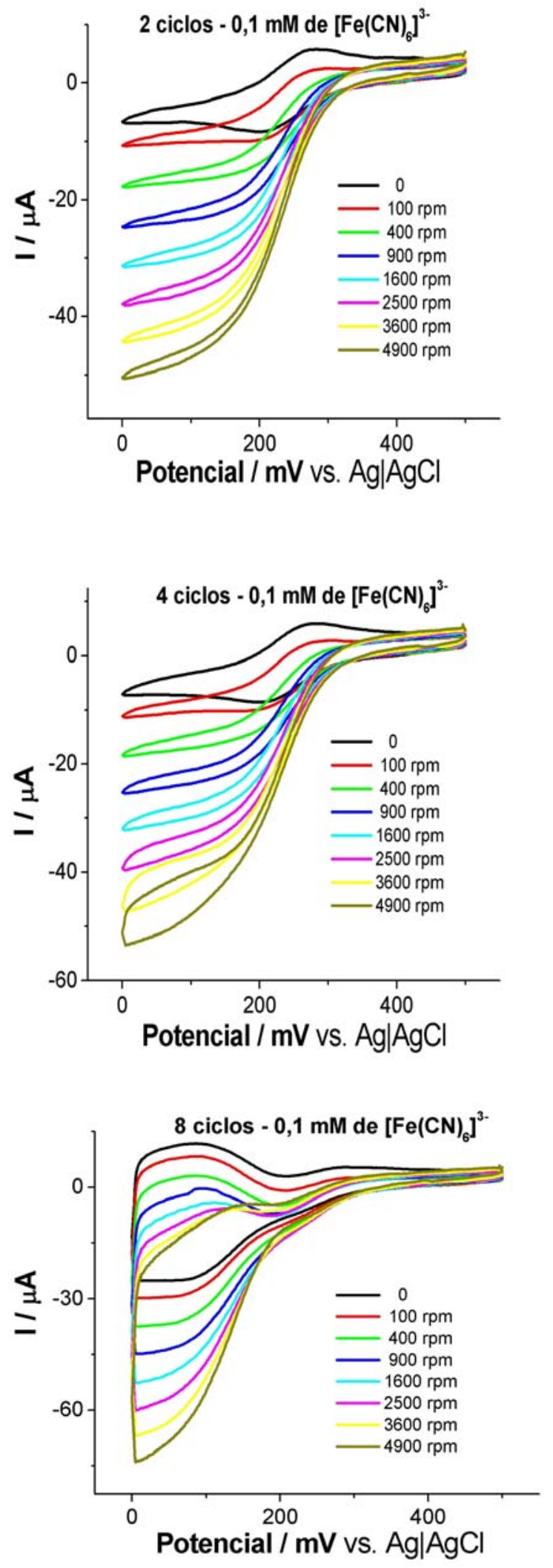

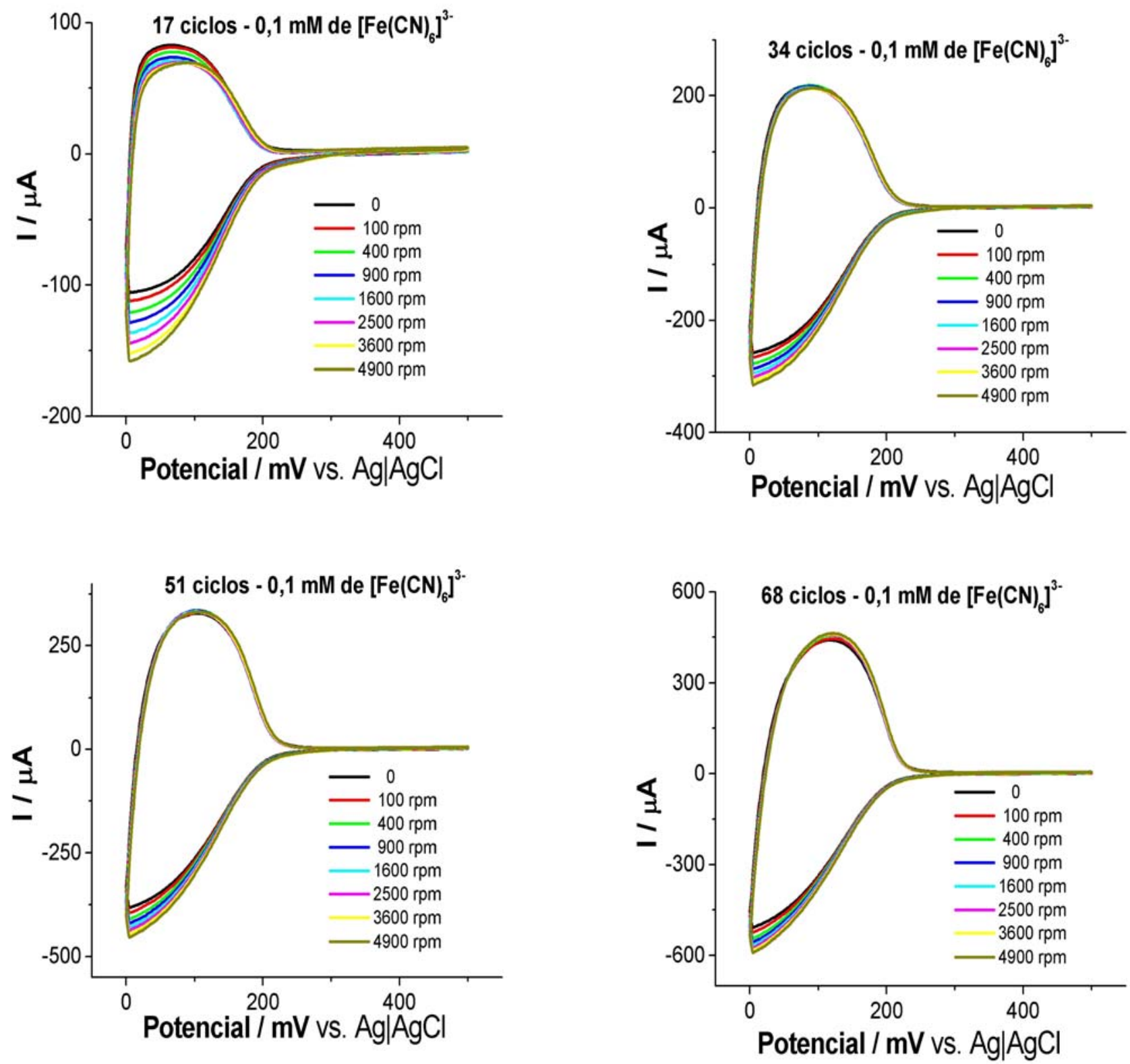

Figura 21 - Voltamogramas cíclicos obtidos em diferentes velocidades de rotação $(100,400,900,1600,2500,3600$ e $4900 \mathrm{rpm})$ em solução $50 \mathrm{mmol}$ $L^{-1}$ de $\mathrm{SO}_{4}{ }^{2-}$ contendo $0,1 \mathrm{mmol} \mathrm{L}^{-1}$ de $K_{3}\left[\mathrm{Fe}(\mathrm{CN})_{6}\right] . V=50 \mathrm{mV} \mathrm{s}^{-1}$. Os voltamogramas foram registrados com eletrodos de carbono vítreo modificados com diferentes quantidades de óxidos de tungstênio $(1,2,3,4$, $5,8,17,34,51$ e 68 ciclos durante a modificação). 

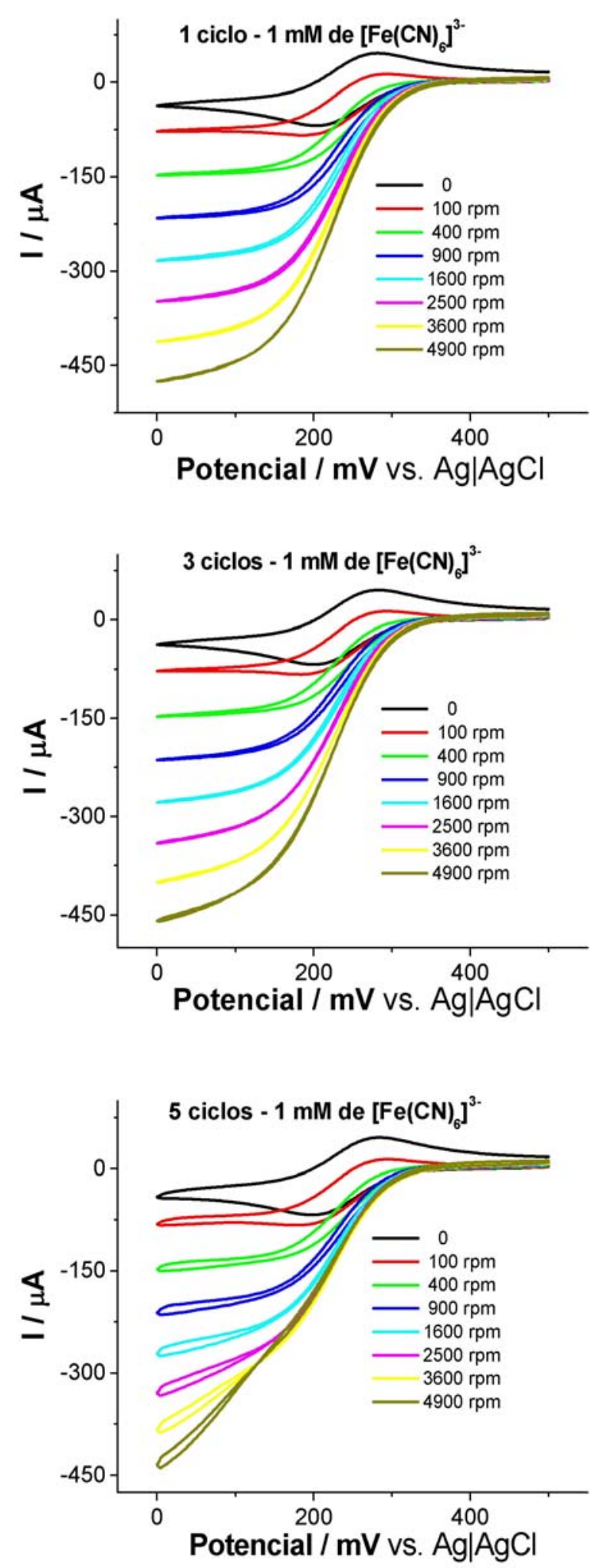
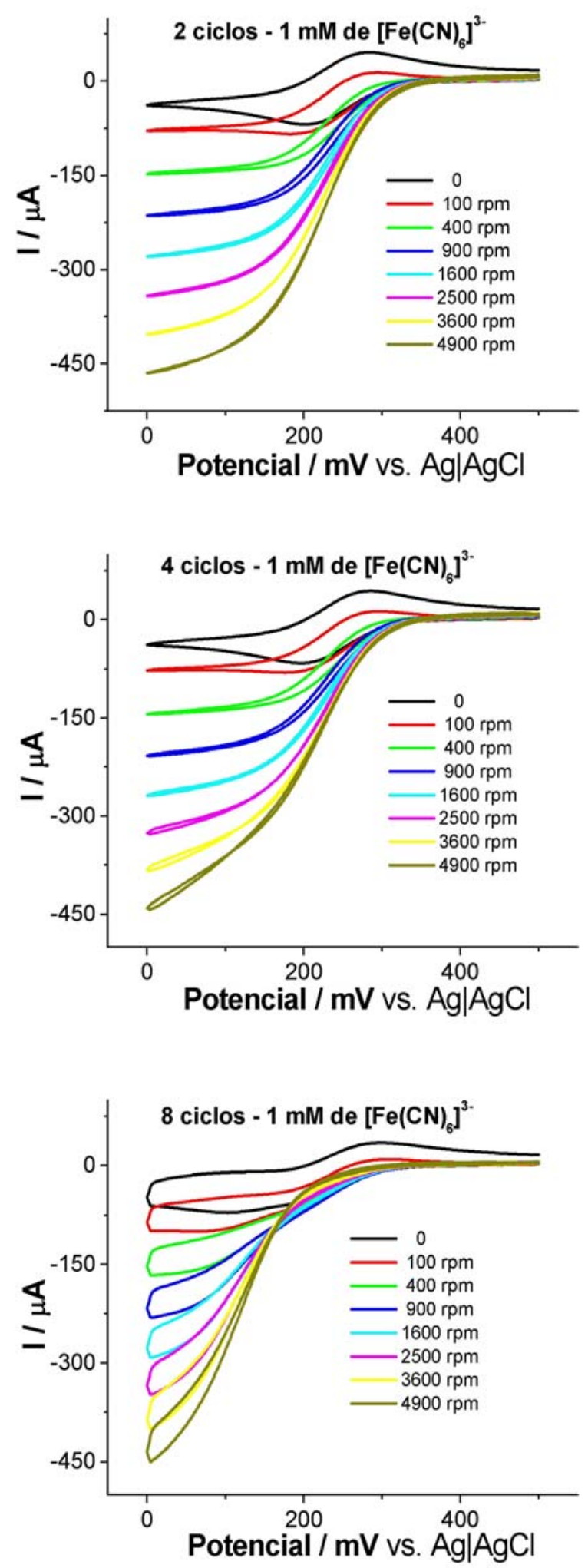

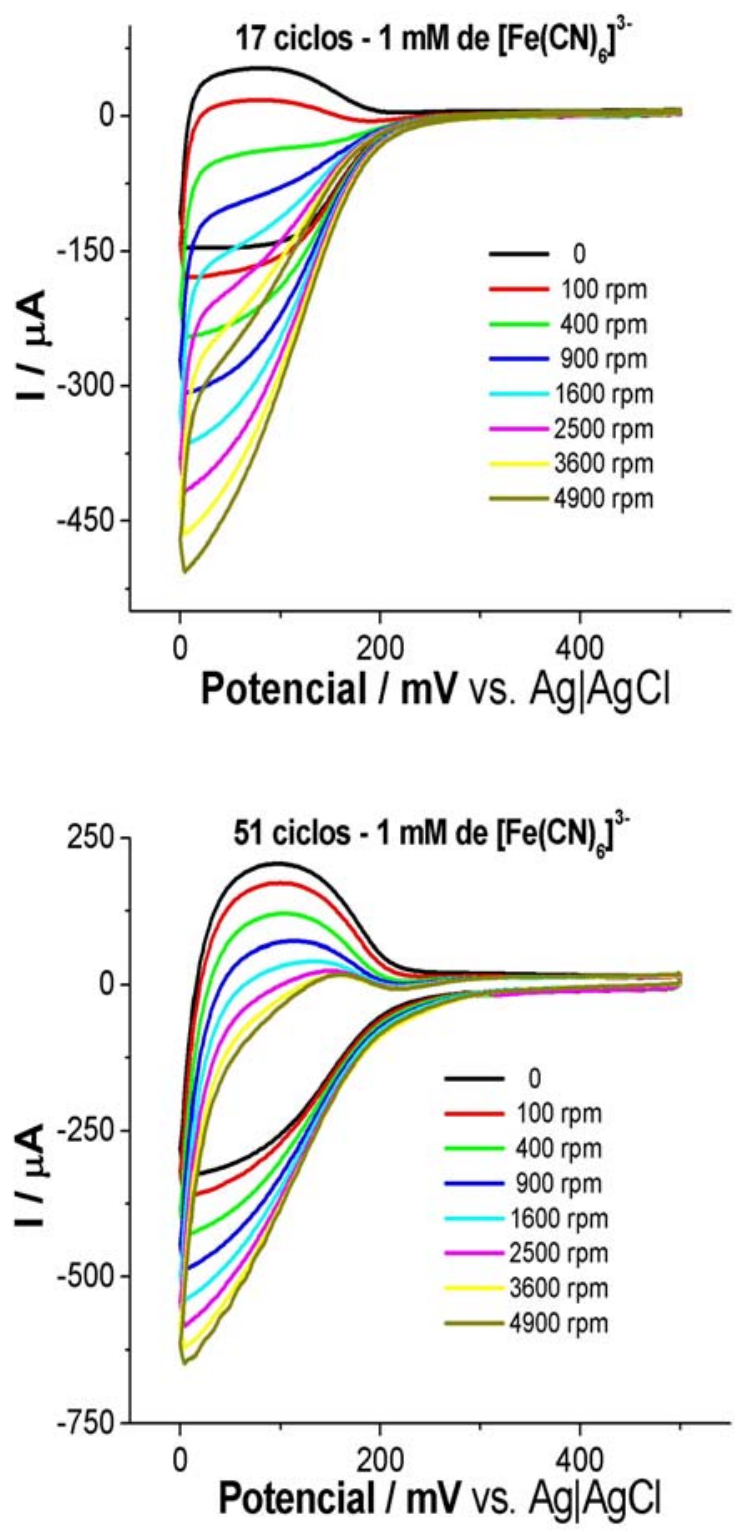
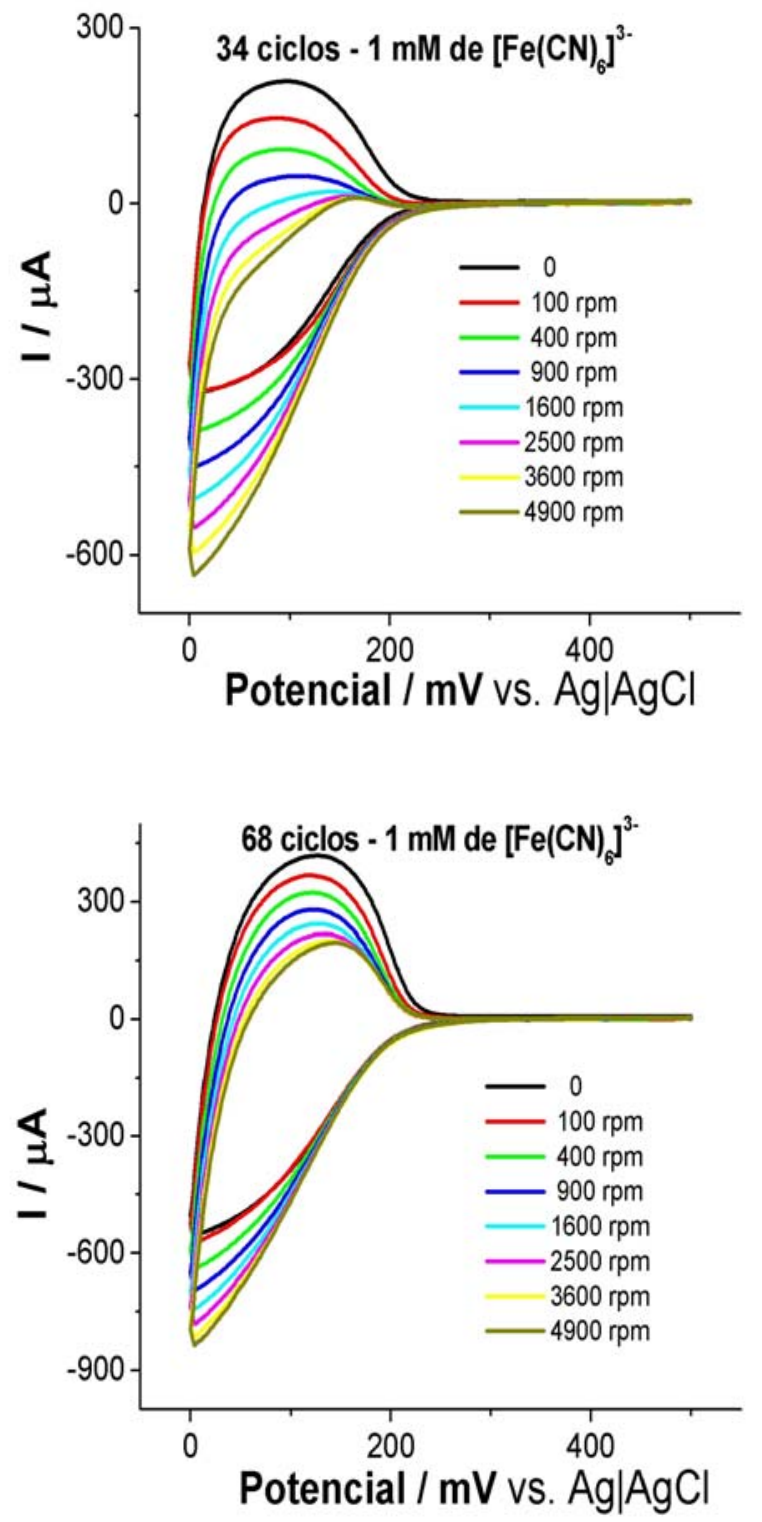

Figura 22 - Voltamogramas cíclicos obtidos em diferentes velocidades de rotação (100, 400, 900, 1600, 2500, 3600 e $4900 \mathrm{rpm})$ em solução $50 \mathrm{mmol}$ $L^{-1}$ de $\mathrm{SO}_{4}{ }^{2-}$ contendo $1 \mathrm{mmol} \mathrm{L}^{-1}$ de $K_{3}\left[\mathrm{Fe}(\mathrm{CN})_{6}\right] . V=50 \mathrm{mV} \mathrm{s}{ }^{-1}$. Os voltamogramas foram registrados com eletrodos de carbono vítreo modificados com diferentes quantidades de óxidos de tungstênio $(1,2,3,4$, $5,8,17,34,51$ e 68 ciclos durante a modificação). 

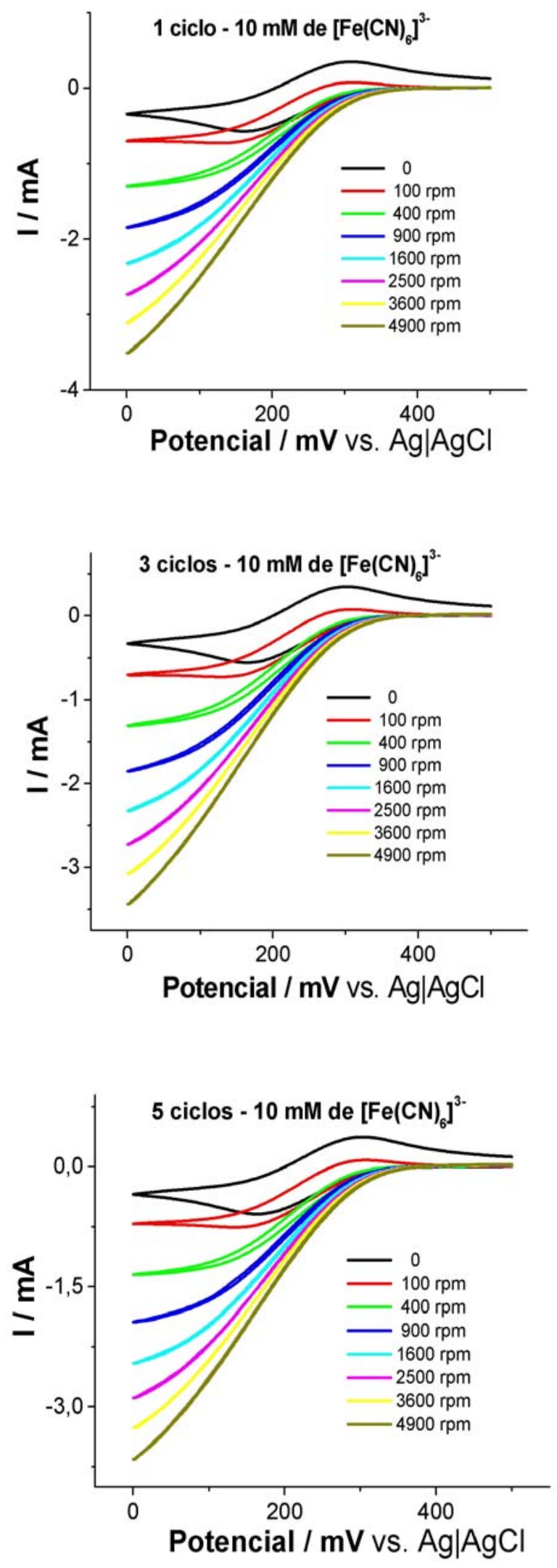
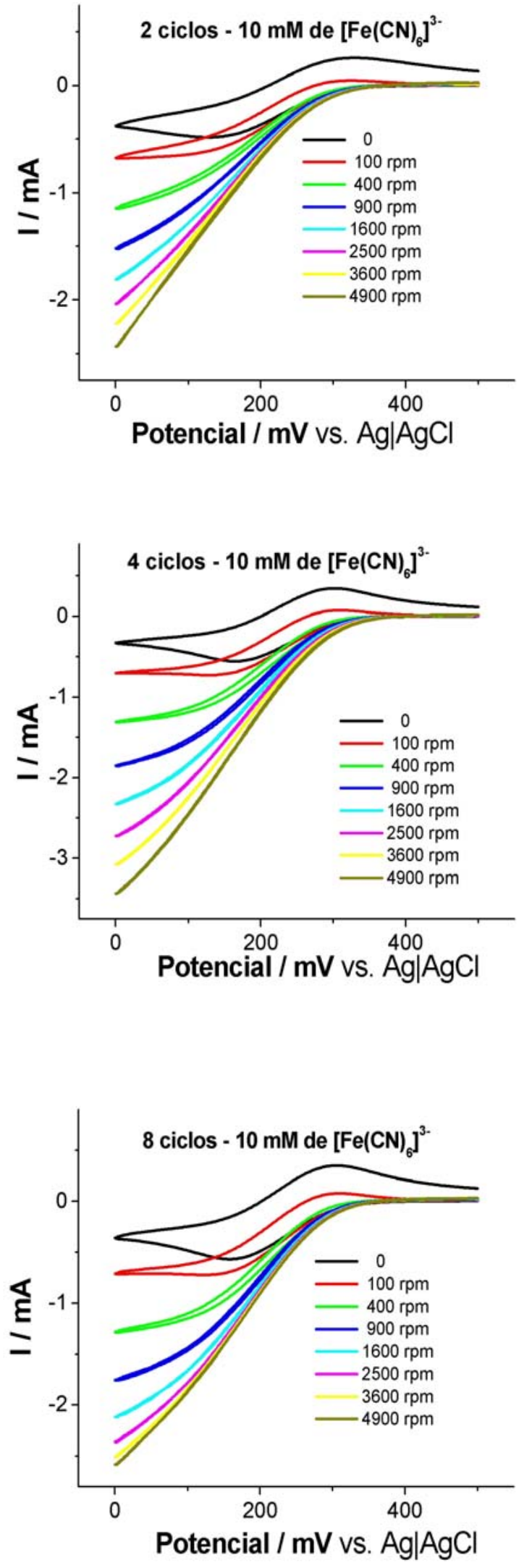

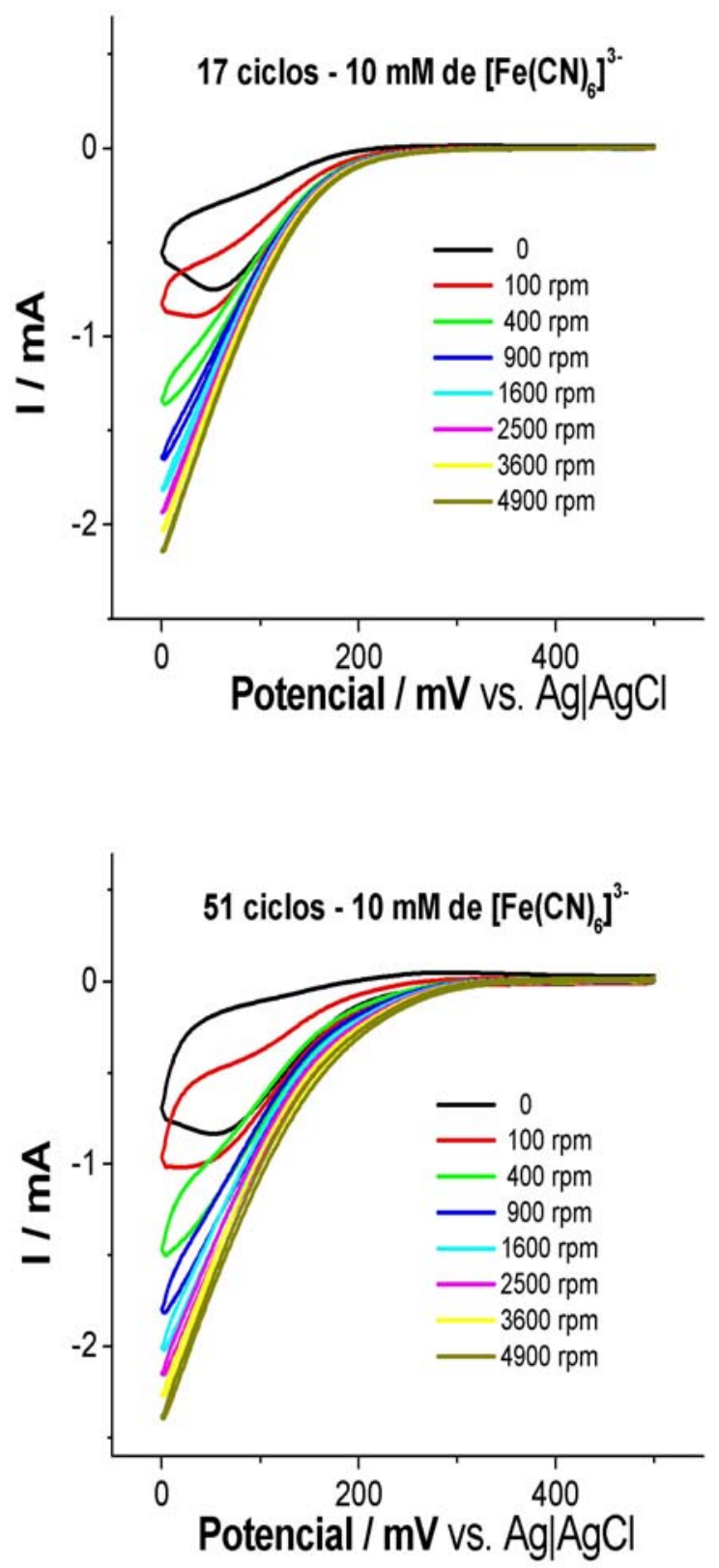
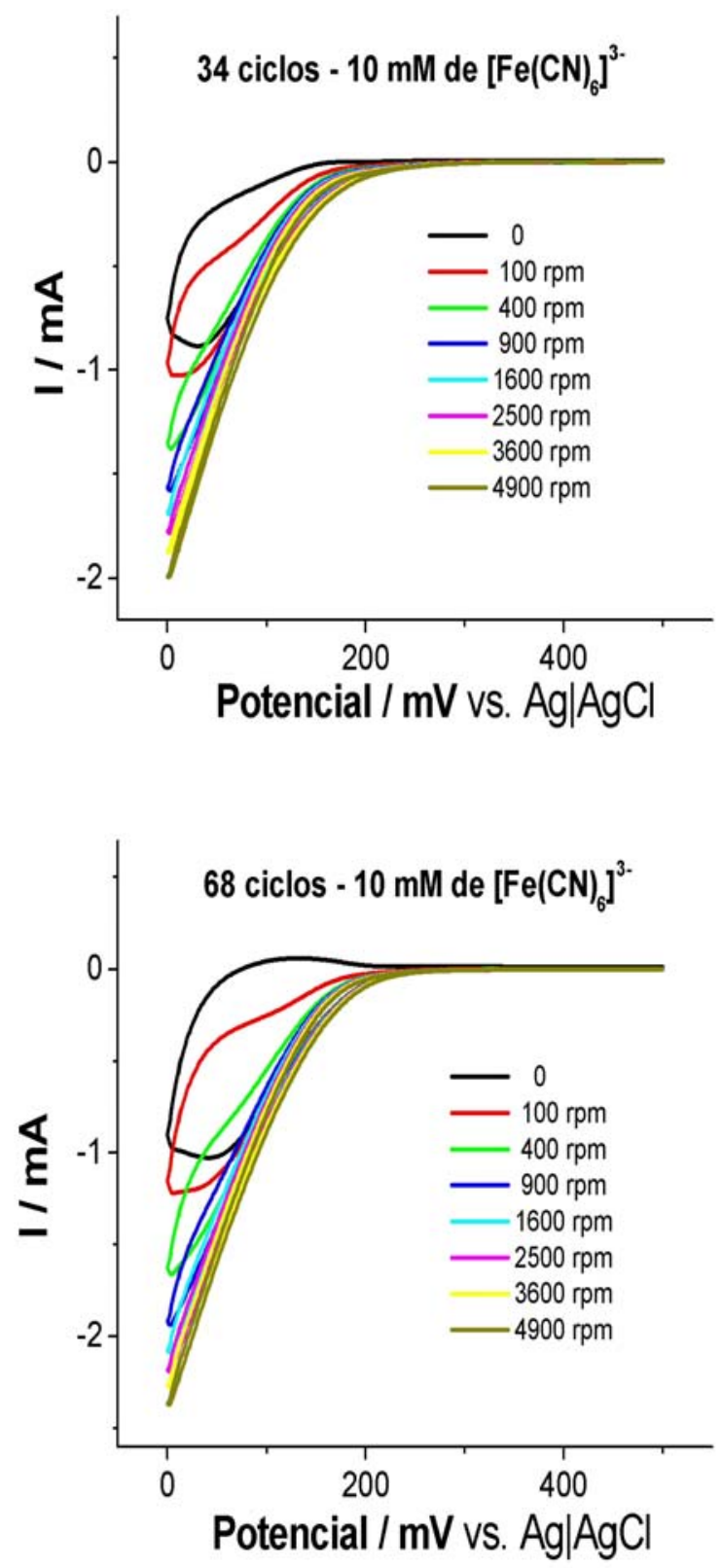

Figura 23 - Voltamogramas cíclicos obtidos com eletrodo de carbono vítreo modificado com óxidos de tungstênio em diferentes velocidades de rotação $(100,400,900,1600,2500,3600$ e $4900 \mathrm{rpm})$ em solução $50 \mathrm{mmol} \mathrm{L}^{-1} \mathrm{de}$ $\mathrm{SO}_{4}{ }^{2-}$ contendo $10 \mathrm{mmol} \mathrm{L}^{-1}$ de $\mathrm{K}_{3}\left[\mathrm{Fe}(\mathrm{CN})_{6}\right]$. $\mathrm{V}=50 \mathrm{mV} \mathrm{\textrm {s } ^ { - 1 }}$. Os voltamogramas foram registrados com eletrodos de carbono vítreo modificados com diferentes quantidades de óxidos de tungstênio $(1,2,3,4$, $5,8,17,34,51$ e 68 ciclos durante a modificação). 
Com os dados obtidos dos voltamogramas cíclicos das Figuras 21, 22 e 23 foram construídos os gráficos de $\Delta \mathrm{I}_{\mathrm{L}}$ versus $\omega^{1 / 2}$ (Figura 24) [81]. Observando estes gráficos é possível perceber que nos experimentos realizados em meio contendo $\mathrm{K}_{3}\left[\mathrm{Fe}(\mathrm{CN})_{6}\right]$ em concentrações mais baixas $\left(0,1\right.$ e $\left.1 \mathrm{mmol} \mathrm{L}^{-1}\right)$ e filmes de óxidos de tungstênio mais finos o processo de transferência eletrônica ainda é governado por transporte de massa, como ocorre em eletrodo polido. Já ao observar os gráficos obtidos com dados de voltamogramas cíclicos realizados em solução de $10 \mathrm{mmol} \mathrm{L}^{-1}$ de $\mathrm{K}_{3}\left[\mathrm{Fe}(\mathrm{CN})_{6}\right]$ e com filmes mais espessos percebe-se que as curvas não são lineares. Isto pode ser explicado pelo fato de que os íons $\left[\mathrm{Fe}(\mathrm{CN})_{6}\right]^{3-}$ são reduzidos na interface eletrodo/filme, ou seja os íons $\left[\mathrm{Fe}(\mathrm{CN})_{6}\right]^{3-}$ devem permear o filme para então serem reduzidos. Portanto é possível indicar que os filmes mais espessos de óxidos de tungstênio são pouco permeáveis.
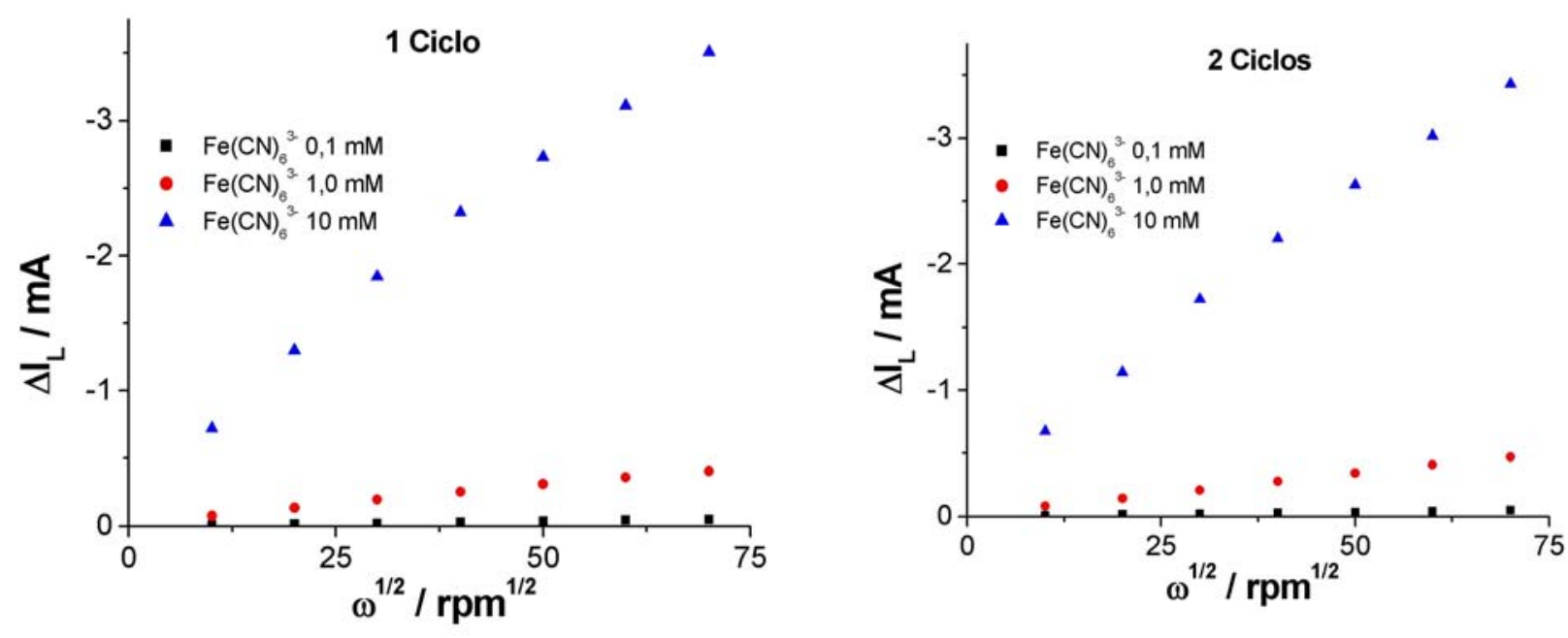

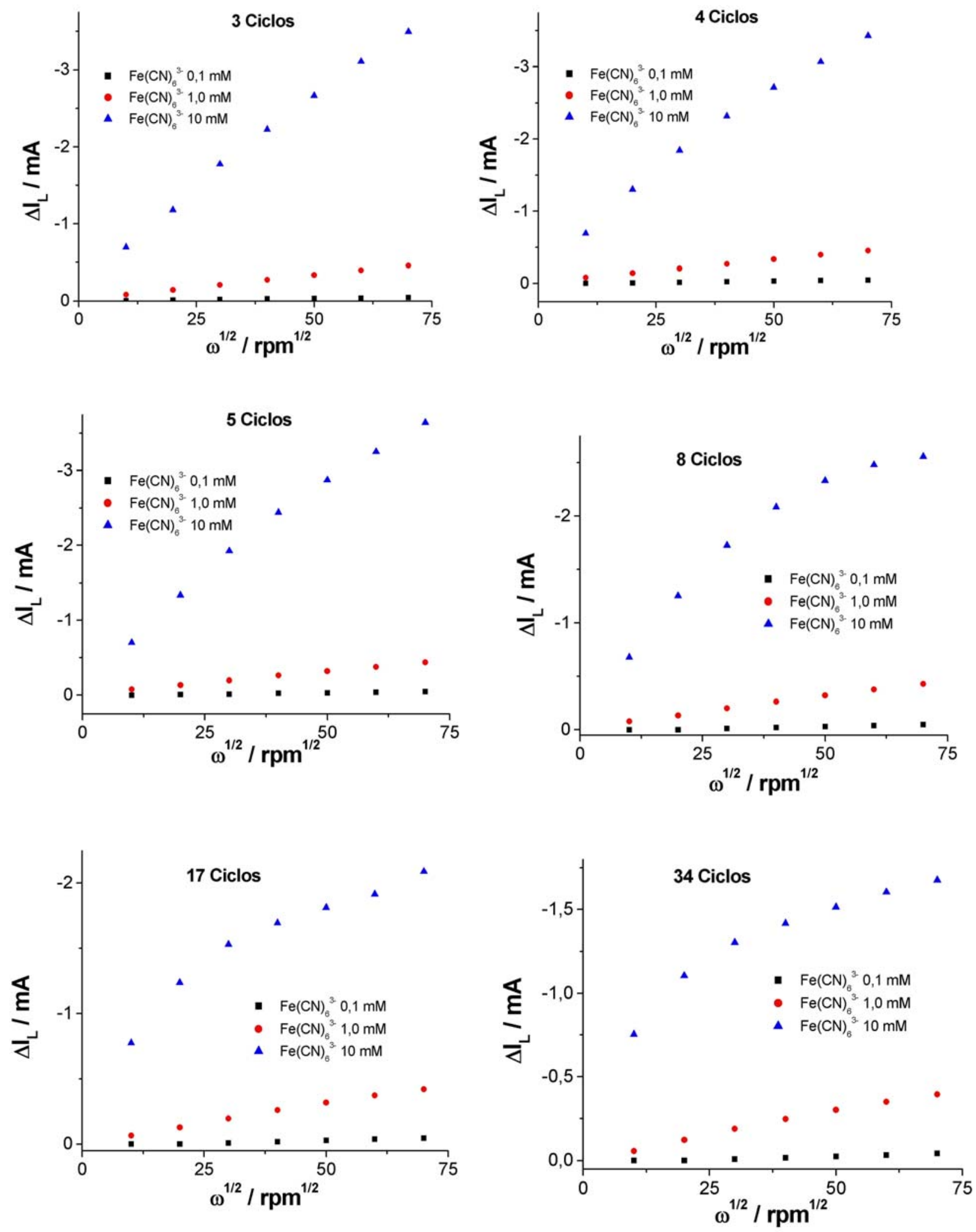

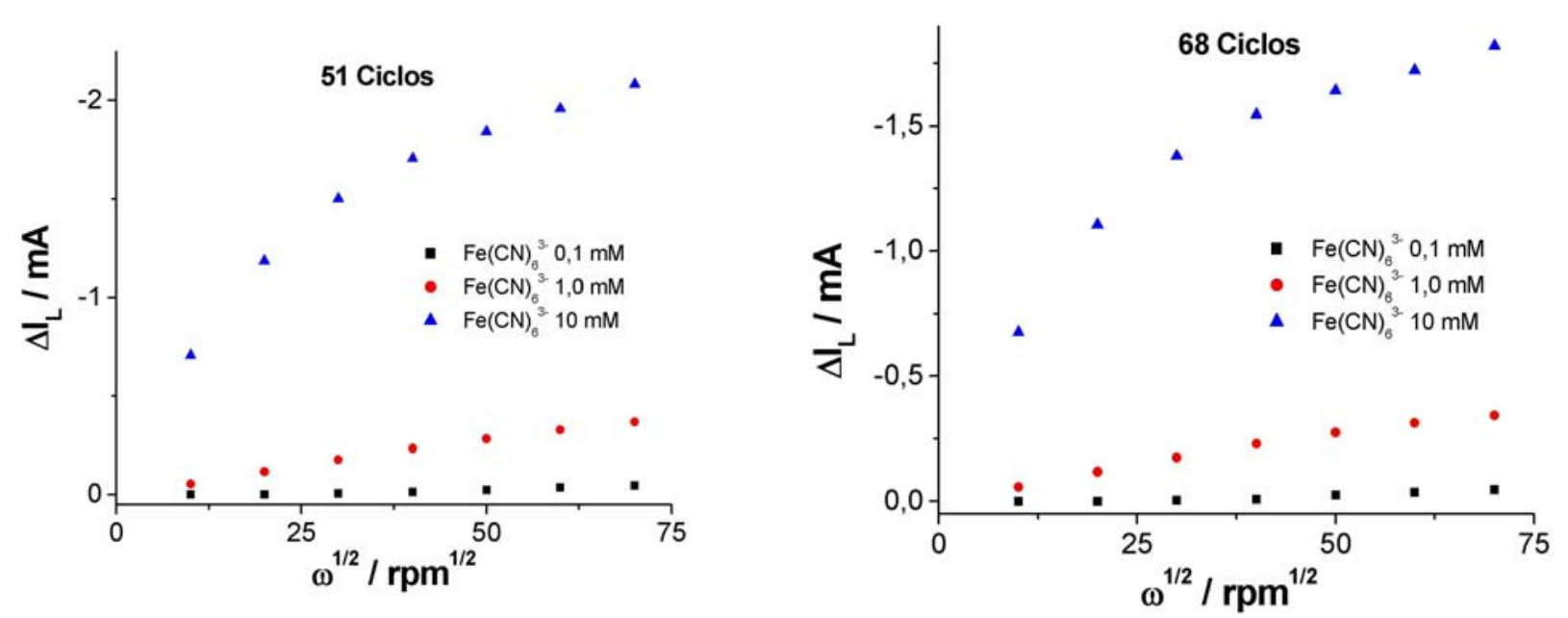

Figura 24 - Gráficos de $\Delta I_{L}$ vs. $\omega^{1 / 2}$ construídos a partir de dados dos voltamogramas cíclicos registrados com eletrodo modificados com óxido de tungstênio (100, 400, 900, 1600, 2500, 3600 e 4900 rpm) em solução de $\mathrm{SO}_{4}^{2-} 50 \mathrm{mmol} \mathrm{L}^{-1}(\mathrm{pH} 2,5)$ contendo respectivamente $(\Delta) 0,1(\bullet) 1,0(\Delta)$ $10,0 \mathrm{mmol} \mathrm{L}^{-1}$ de $\left[\mathrm{Fe}(\mathrm{CN})_{6}\right]^{3-}\left(\mathrm{pH} \mathrm{2,5)}\right.$. Velocidade de varredura $=50 \mathrm{mV} \mathrm{s}^{-1}$. $\Delta L_{L}$ medidos em $0 \mathrm{~V}$.

\subsubsection{Aquisição de Imagem da Superfície do Eletrodo de Carbono}

\section{Vítreo Modificado}

Para observar o filme de óxido de tungstênio depositado sobre a superfície do eletrodo de carbono vítreo foram registradas imagens empregando o microscópio Infinity Photo-Optical Company acoplado a câmera de vídeo colorida CCD-IRIS SONY. Na imagem observada no eletrodo (Figura 25) - quando este foi modificado variando-se o potencial por 30 minutos entre $500 \mathrm{mV}$ a $-800 \mathrm{mV}$ com velocidade de varredura de 50 $\mathrm{mV} \mathrm{s}^{-1}$ - percebem-se fendas provavelmente oriundas do "stress" do filme. Comportamento similar foi relatado na literatura [40] para filmes espessos e secos de óxido de molibdênio. 


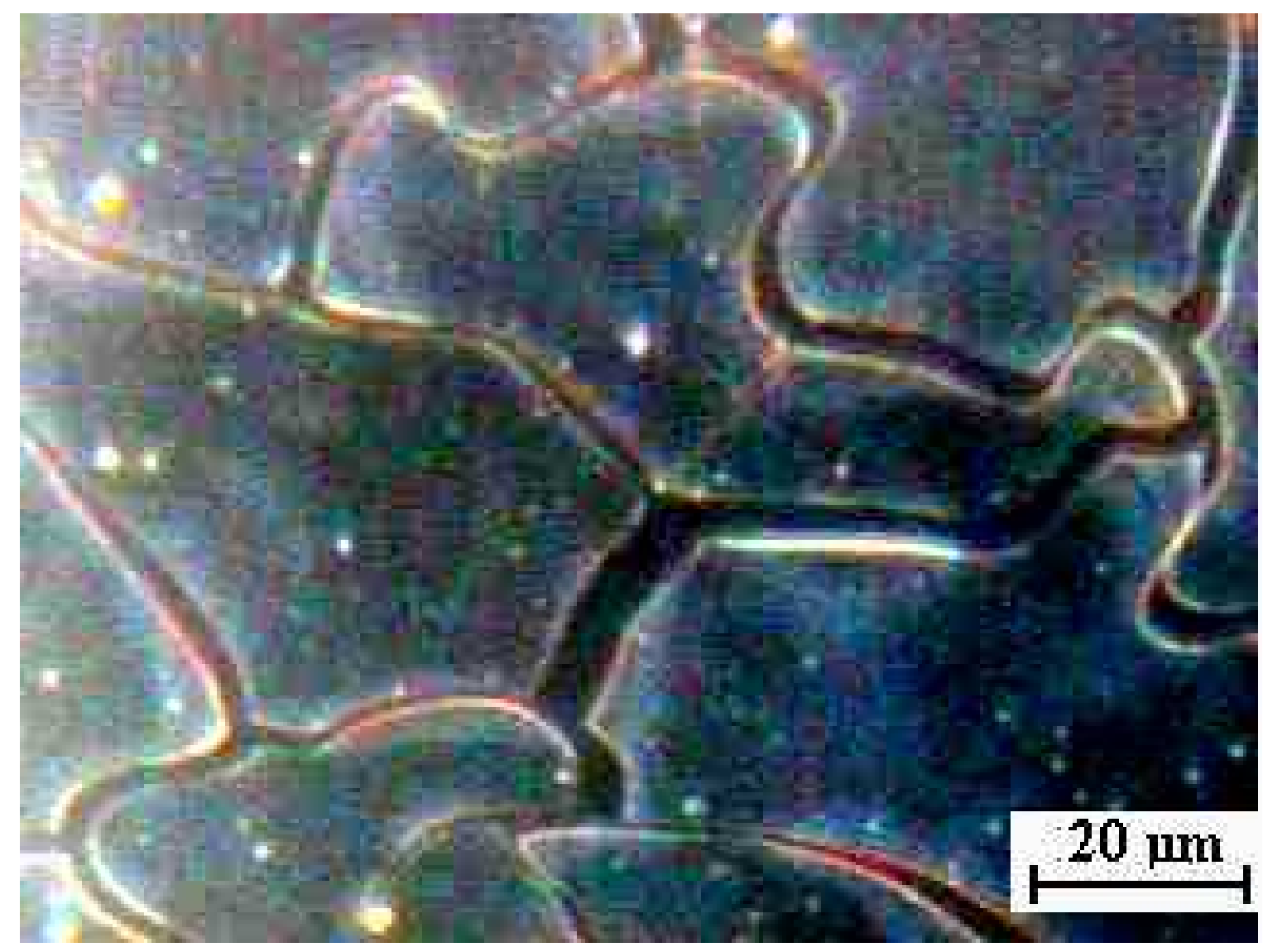

Figura 25 - Imagem da superfície do eletrodo de carbono vítreo modificado com 34 ciclos de potencial em solução de tungstênio (VI) $54,4 \mathrm{mmol} \mathrm{L}^{-1}$ obtida utilizando a câmera de vídeo colorida CCD-IRIS SONY.

Imagens da superfície modificada com óxido de tungstênio também foram obtidas utilizando um microscópio eletrônico de varredura (Figura 26). Estas imagens são similares com aquelas obtidas quando se utilizou o microscópio Infinity Photo-Optical Company (Figura 25). 


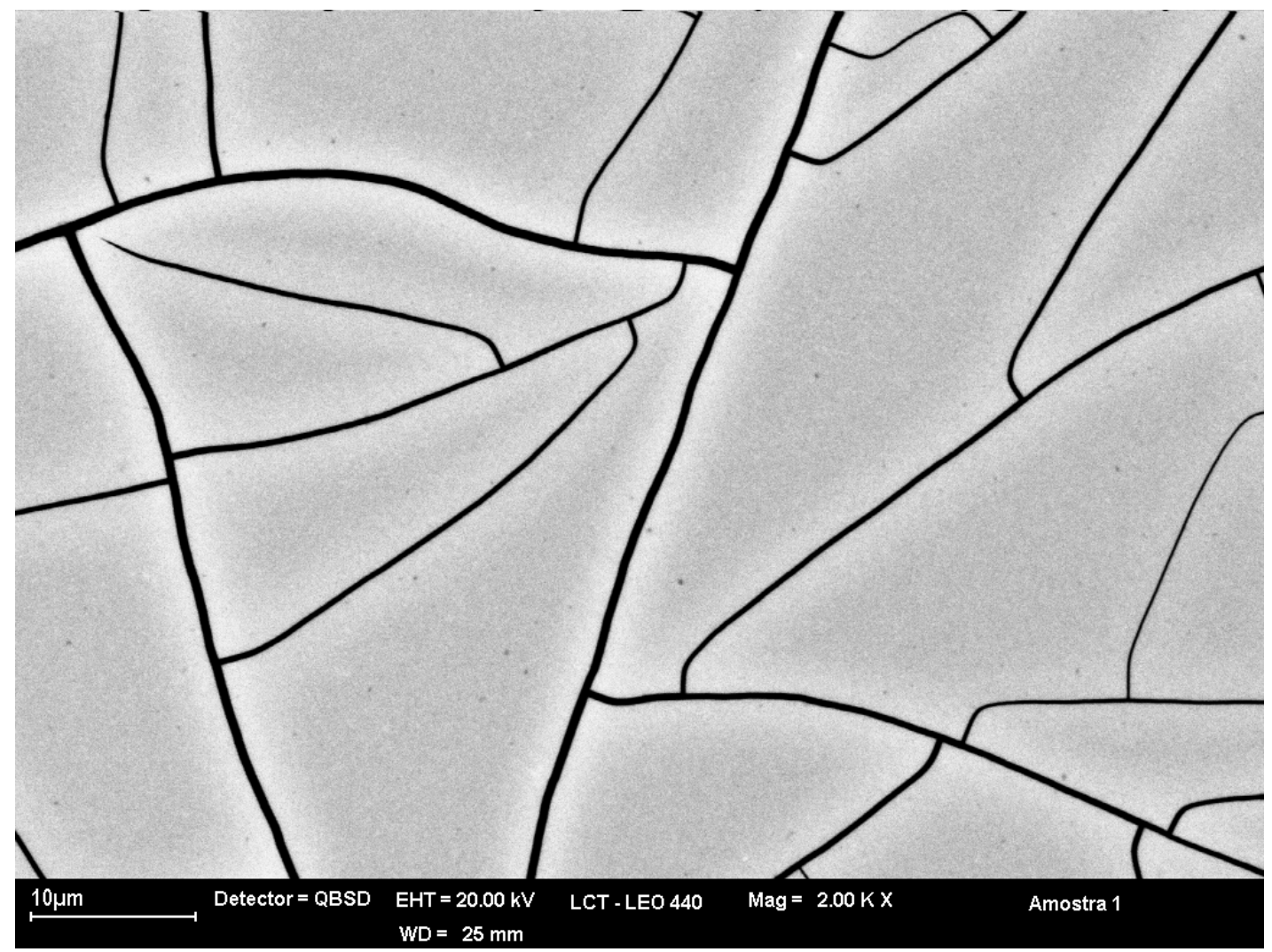

Figura 26 - Imagem da superfície do eletrodo de carbono vítreo modificado com óxido de tungstênio (15 minutos de modificação) utilizando a técnica microscopia eletrônica de varredura.

\subsubsection{Composição da Superfície Modificada}

Para verificar a composição desta superfície modificada foram realizados experimentos por EDS e obteve-se o espectro apresentado na Figura 27. A análise dos dados permitiu a obtenção das porcentagens dos elementos que constituem o filme e os valores estão apresentados na Tabela 1. 
Tabela 1 - Valores obtidos por EDS referente à amostra de óxido de tungstênio depositado em eletrodo de carbono vítreo em porcentagem em massa.

\begin{tabular}{c|c}
\hline Elemento & Massa (\%) \\
\hline $\mathbf{O ~ ( K )}$ & 88,0 \\
\hline $\mathbf{N a}(\mathrm{K})$ & 1,9 \\
\hline $\mathbf{W}(\mathrm{M})$ & 10,1 \\
\hline Total & 100,0 \\
\hline
\end{tabular}

Os dados apresentados na Tabela 1 claramente indicam a existência de oxigênio e tungstênio no filme eletrodepositado. Entretanto, pela análise desses dados obtém-se um estequiometria não compatível com qualquer estrutura conhecida para este tipo de óxido, visto que a relação entre oxigênio e tungstênio é 9:1. Todavia, experimentos posteriores objetivando a confirmação desses resultados não puderam ser realizados.

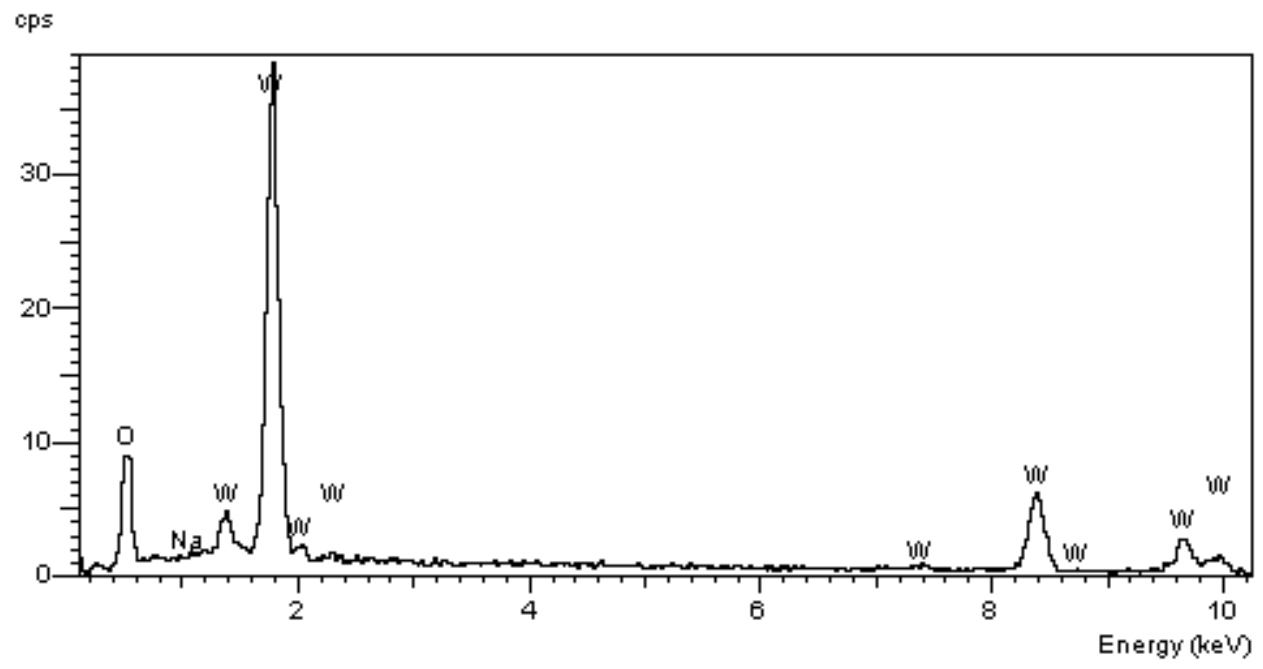

Figura 27 - Espectro de dispersão do eletrodo modificado com óxido de tungstênio. Espectro obtido no Laboratório de Caracterização Tecnológica (LCT) da Escola Politécnica da USP.

Espectros de absorção de raios $X$ foram obtidos no Laboratório Nacional de Luz Síncroton (LNLS) - Campinas - São Paulo - Brasil. O primeiro espetro apresentado na Figura 28 refere-se ao bombardeamento 
de elétrons numa amostra padrão de óxido de tungstênio. Já o segundo espectro foi obtido a partir do bombardeamento de elétrons numa superfície do eletrodo de carbono vítreo modificada com óxido de tungstênio e os resultados não podem ser considerados satisfatórios devido ao ruído e à não estabilização da linha base. Para obter informações satisfatórias tornase necessário o trabalho com filmes aproximadamente 100 vezes mais espessos do que aqueles preparados. Surgiram dúvidas sobre a possibilidade de comparação da composição de filmes com espessuras significativamente diferentes. Como alternativa para o uso de filmes mais espessos existe a possibilidade de mudança no comprimento de onda onde o tungstênio apresenta maior sensibilidade. Até o momento este procedimento não é possível visto que o único laboratório que faz este tipo de análise no país é o LNLS e das linhas de análises que o laboratório possui, nenhuma apresenta o comprimento de onda em que o tungstênio apresenta maior sensibilidade. Portanto no futuro será importante a caracterização deste filme.
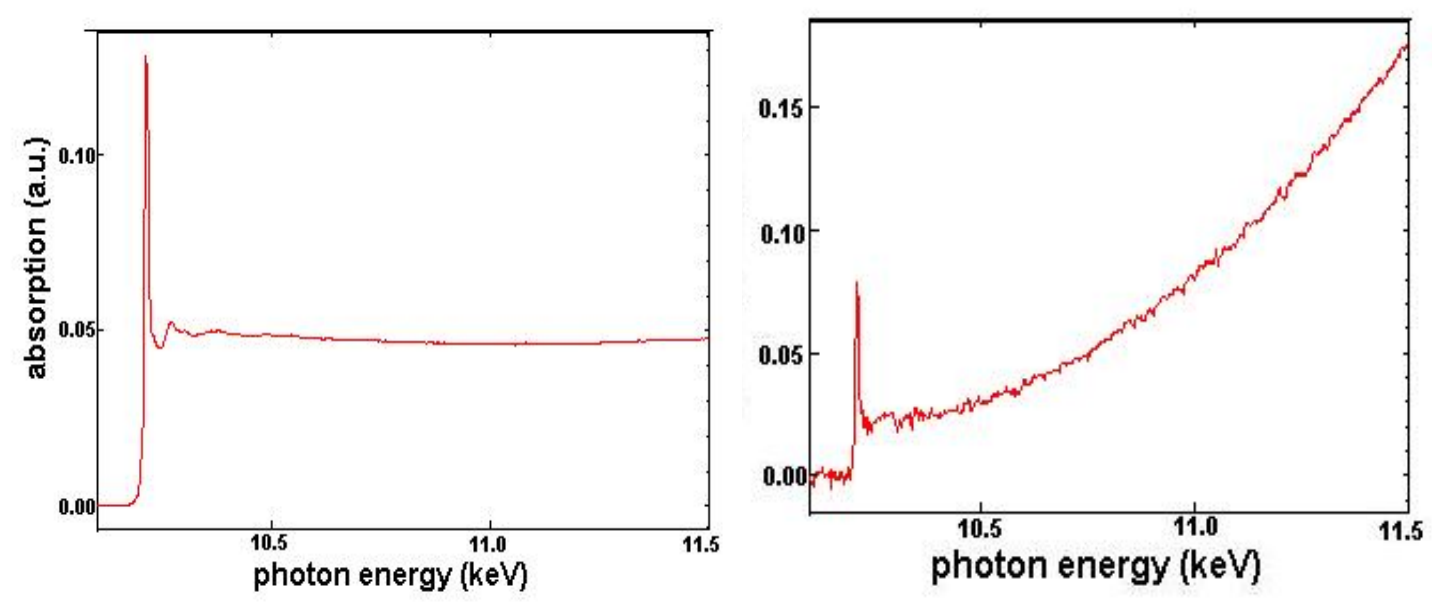

Figura 28 - Espectros de absorção de raios $X$. O primeiro refere-se a um padrão de $\mathrm{WO}_{3}$ e o segundo à superfície modificada com óxido de tungstênio. 


\subsubsection{Eletrocatálise de lodato em Eletrodo Modificado com $\mathrm{WO}_{3}$}

Foram realizados ensaios voltamétricos para verificar se o eletrodo de carbono vítreo modificado com óxido de tungstênio apresentava características eletrocatalíticas como aquelas observadas com íon iodato na superfície modificada com óxidos de molibdênio. Para tanto, após modificar e verificar a estabilidade deste eletrodo realizou-se ensaio voltamétrico com o sistema de três eletrodos imersos em solução $50 \mathrm{mmol} \mathrm{L}^{-1}$ de $\mathrm{SO}_{4}{ }^{2-} \mathrm{e}$ posteriormente na mesma solução contendo $7 \mathrm{mmol} \mathrm{L}^{-1}$ de $\mathrm{IO}_{3}{ }^{-}$. Ensaios iguais foram realizados com o eletrodo de trabalho polido. Os resultados obtidos nestes ensaios podem ser verificados observando a Figura 29.

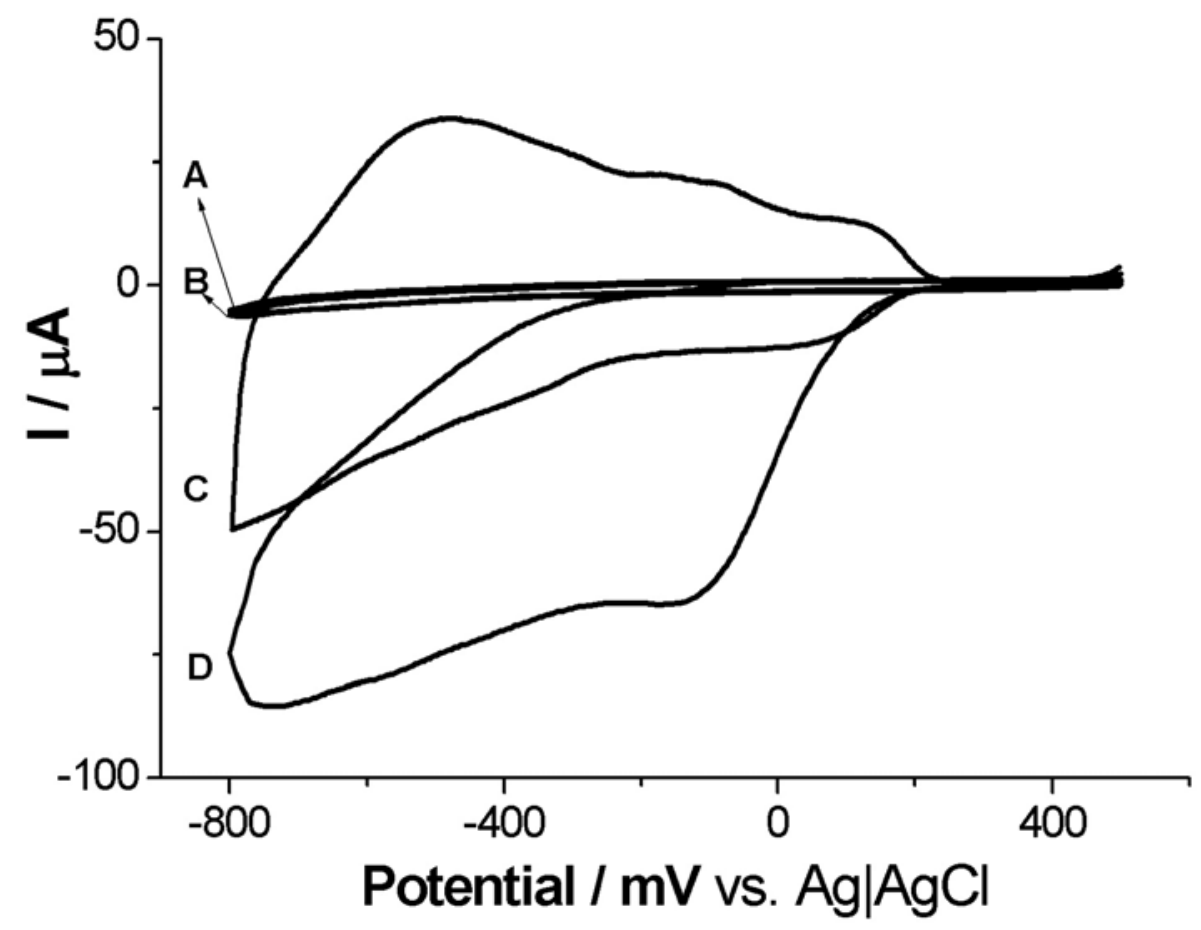

Figura 29 - Voltamogramas cíclicos obtidos utilizando eletrodo de carbono vítreo polido (A) em sol $50 \mathrm{mmol} \mathrm{L}^{-1}$ de $\mathrm{SO}_{4}{ }^{2-}(\mathrm{pH} 2,5)$ e (B) em sol. $50 \mathrm{mmol}$ $L^{-1}$ de $\mathrm{SO}_{4}{ }^{2-}$ contendo $7 \mathrm{mmol}^{-1}$ de $\mathrm{IO}_{3}{ }^{-}(\mathrm{pH} 2,5)$. Os voltamogramas $\mathrm{C}$ e $\mathrm{D}$ foram obtidos utilizando eletrodo de carbono vítreo modificado com óxido de tungstênio (VI,V) em sol. $50 \mathrm{mmol} \mathrm{L}^{-1}$ de $\mathrm{SO}_{4}{ }^{2-}(\mathrm{pH} 2,5)$ e $50 \mathrm{mmol} \mathrm{L^{-1 }}$ de $\mathrm{SO}_{4}^{2-}+7 \mathrm{mmol} \mathrm{L}^{-1} \mathrm{IO}_{3}^{-}(\mathrm{pH} 2,5)$, respectivamente. Velocidade de varredura $=$ $50 \mathrm{mV} \mathrm{s}^{-1}$. 
Analisando estes voltamogramas observa-se que o eletrodo de carbono vítreo modificado com óxido de tungstênio catalisa a redução de $\mathrm{IO}_{3}{ }^{-}$, pois há um grande aumento na intensidade de corrente da onda catódica de iodato no voltamograma cíclico registrado em eletrodo modificado com óxidos de tungstênio (D) em relação ao eletrodo polido (B).

\subsection{Comparação dos Resultados da Eletrocatálise do $\mathrm{IO}_{3}{ }^{-}$ em Eletrodos Modificados com $\mathrm{MoO}_{3}$ ou $\mathrm{WO}_{3}$}

Foram realizados novos ensaios para melhor comparar o processo de redução do iodato em superfície modificada com óxido de tungstênio e em superfície modificada com óxido de molibdênio. Os seus resultados podem ser observados nos voltamogramas cíclicos apresentados na Figura 30, onde (A) foi o voltamograma cíclico obtido com eletrodo de carbono vítreo modificado com óxido de tungstênio e (B) foi o voltamograma cíclico obtido com eletrodo de carbono vítreo modificado com óxido de molibdênio. Em ambos os casos utilizaram-se solução $1 \mathrm{mmol} \mathrm{L}^{-1}$ de iodato $(\mathrm{pH}=2,5)$.

O fato mais importante observado nesta Figura é que na superfície modificada com óxidos de tungstênio o processo catódico se inicia ao redor de $0 \mathrm{~V}$, um potencial muito menos negativo do que aquele observado na eletrocatálise de redução de $1 \mathrm{I}^{-}$em eletrodos modificados com óxido de molibdênio [80]. Com estes resultados pode-se afirmar que o eletrodo modificado com óxido de tungstênio tem potencialidade analítica para iodato em função da menor interferência de espécies eletroativas como o $\mathrm{O}_{2}$. 


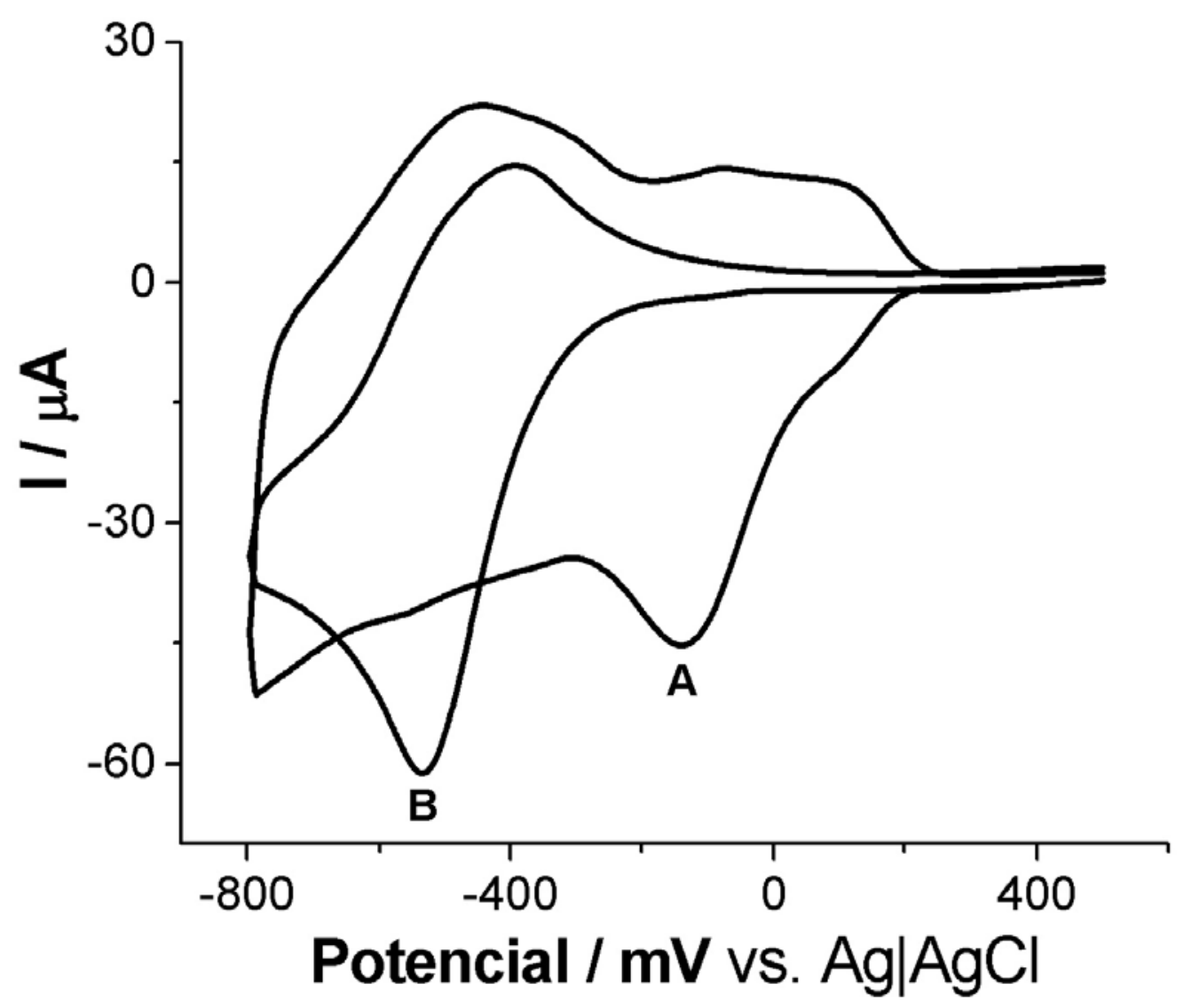

Figura 30 - Voltamogramas cíclicos obtidos utilizando eletrodo de carbono vítreo modificado (A) com óxidos de tungstênio e (B) com óxidos de molibdênio. Os voltamogramas foram obtidos variando o potencial aplicado ao sistema em solução $50 \mathrm{mmol} \mathrm{L}^{-1}$ de $\mathrm{SO}_{4}{ }^{2-}$ contendo $1 \mathrm{mmol} \mathrm{L}^{-1}$ de $1 \mathrm{O}_{3}{ }^{-}$ (pH 2,5). $\mathrm{V}=50 \mathrm{mV} \mathrm{s}^{-1}$.

Para melhor caracterizar as vantagens do eletrodo de carbono vítreo modificado com óxidos de tungstênio se registrou os voltamogramas de iodato subtraindo os voltamogramas que foram registrados em solução 50 $\mathrm{mmol} \mathrm{L}^{-1}$ de $\mathrm{SO}_{4}{ }^{2-}$. Nestes voltamogramas (Figura 31) é possível verificar com maior nitidez que a onda catódica de iodato nos dois eletrodos apresentam valores de intensidade de corrente muito próximos, porém em 
eletrodo modificado com óxidos de tungstênio esta onda catódica aparece em potenciais menos negativo do que com eletrodo de carbono vítreo modificado com óxidos de molibdênio - aproximadamente $400 \mathrm{mV}$ menores - ratificando assim as informações anteriormente assinaladas.

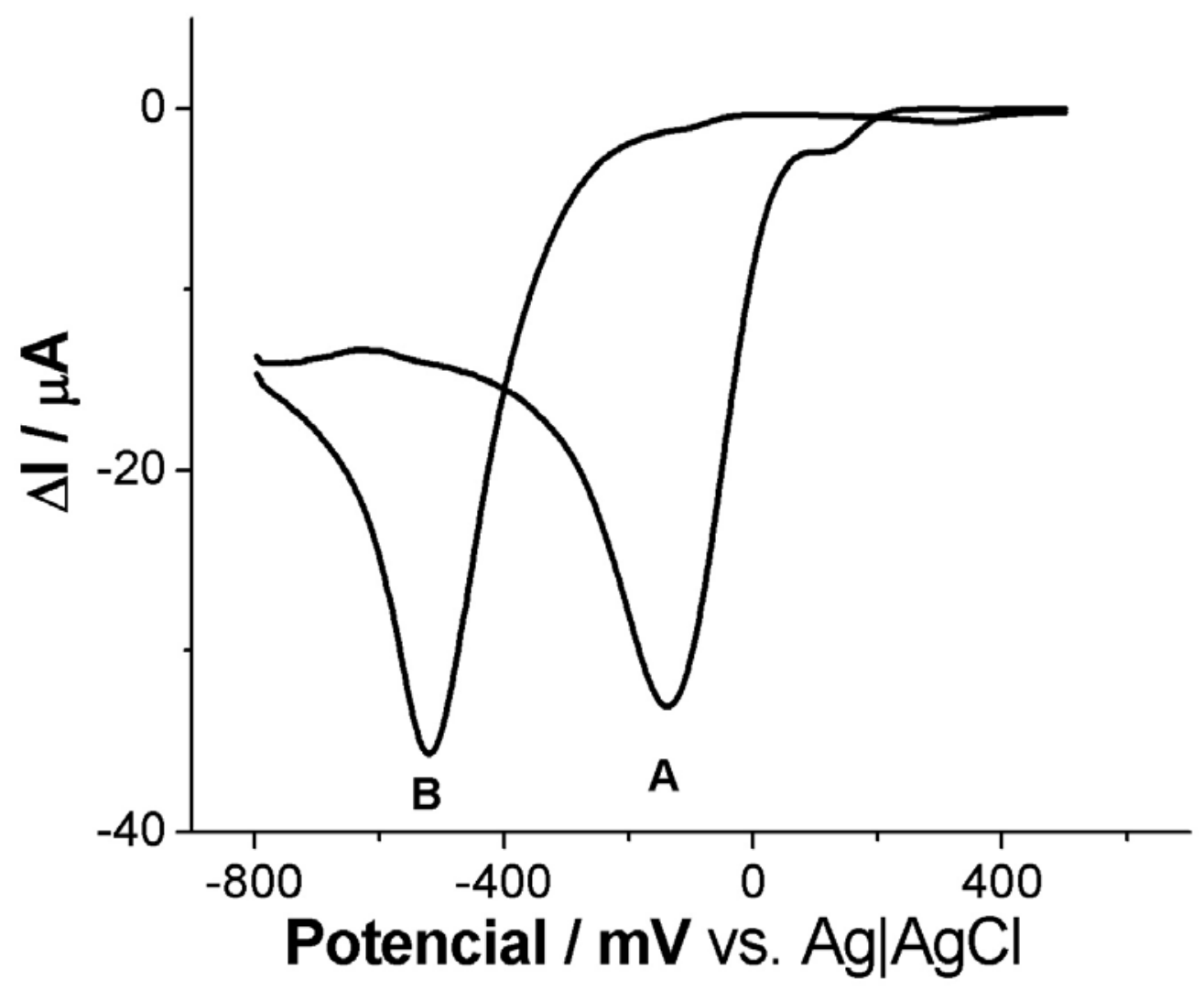

Figura 31 - Voltamogramas obtidos subtraindo os voltamogramas registrados em solução $50 \mathrm{mmol}^{-1}$ de $\mathrm{SO}_{4}{ }^{2-}$ daqueles registrados em solução $50 \mathrm{mmol} \mathrm{L}^{-1}$ de $\mathrm{SO}_{4}^{2-}$ contendo $1 \mathrm{mmol} \mathrm{L}^{-1}$ de $\mathrm{IO}_{3}^{-}(\mathrm{pH} 2,5)$. Em (A) foi utilizado eletrodo de carbono vítreo modificado com óxidos de tungstênio e em (B) eletrodo de carbono vítreo modificado com óxidos de molibdênio. 


\subsection{Estudos de $\mathrm{IO}_{3}{ }^{-}$em Eletrodos Modificados com $\mathrm{WO}_{3}$}

Devido as vantagens observadas na determinação do íon iodato em superfície modificada com óxidos de tungstênio foram realizados estudos sistemáticos para melhor compreender este sistema.

\subsubsection{Resposta Eletroquímica de $\mathrm{IO}_{3}{ }^{-}$em função da Quantidade de Material Depositado}

Para verificar a dependência da resposta eletroquímica de eletrodos modificados com óxidos de tungstênio em função da quantidade de material imobilizado na superfície destes foram realizados ensaios alterando o número de ciclos de varreduras de potencial durante o processo deposição $(1,2,3,4,5,8,17,34$ e 68 ciclos). Após verificar a estabilidade do filme depositado foram realizados ensaios voltamétricos em solução $50 \mathrm{mmol} \mathrm{L}^{-1}$ de $\mathrm{SO}_{4}{ }^{2-}(\mathrm{pH} 2,5)$ na presença e na ausência de substrato $(0,1 ; 0,5 ; 1,5 \mathrm{e}$ $10 \mathrm{mmol} \mathrm{L}^{-1}$ de $\left.\mathrm{IO}_{3}{ }^{-}\right)$. As diferenças de intensidade de corrente $\left(\Delta \mathrm{I}_{\mathrm{L}}\right)$ obtidas foram registradas em função do número de ciclos de potencial e o gráfico resultante é apresentado na Figura 32. Observando esta Figura percebe-se que a resposta de intensidade de corrente em grande parte depende da quantidade de filme depositado. Para filmes de óxido de tungstênio pouco espessos nota-se o aumento nos valores de intensidade de corrente em função do aumento do período de modificação deste eletrodo. Este fato é um indício de que a quantidade de sítios eletroativos destes filmes a princípio é insuficiente para reduzir todo o iodato presente próximo à superfície modificada. Para filmes mais espessos não ocorre aumento nos valores de intensidade de corrente, sugerindo assim que, nestas condições 
experimentais, a concentração de iodato é o fator limitante. Pode-se também constatar que a corrente aumenta à medida que se aumenta a concentração de substrato (iodato) para filmes de mesma espessura. Estas duas análises podem indicar que o efeito de mediação ocorre em regiões vizinhas à interface filme/solução. Além disso, na região catódica onde o iodato é reduzido (Figura 31) a superfície modificada está carregada negativamente - seja em virtude do potencial aplicado ao eletrodo de trabalho, seja em virtude da nuvem eletrônica produzida pelos pares de elétrons livres dos átomos de oxigênio que constitui a estrutura do filme de óxido de tungstênio - dificultando a permeação do iodato pelo filme.

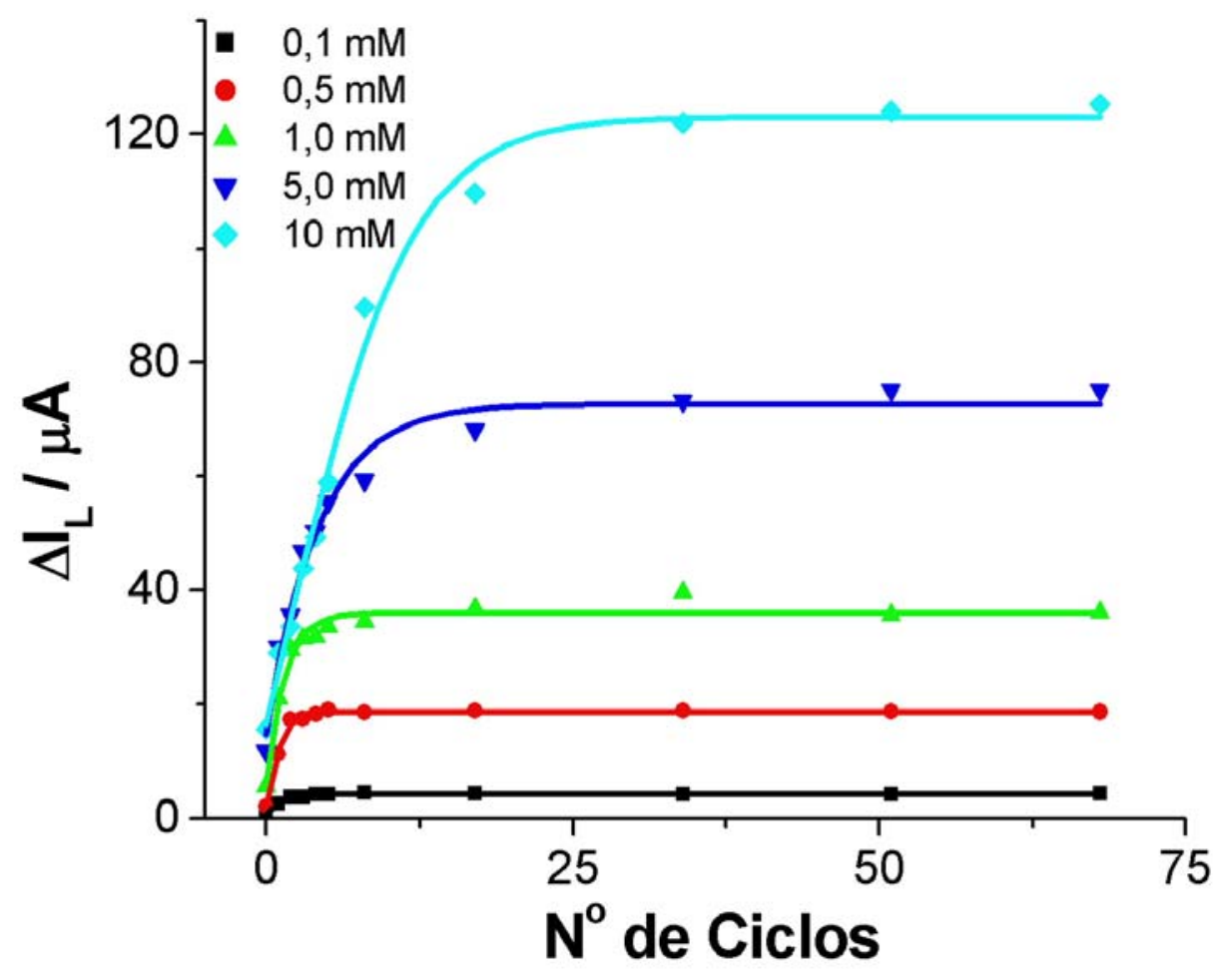

Figura 32 - Dependência de $\Delta l_{L}\left(I_{k}-I_{d}\right)$ em função do número de ciclos utilizados durante o procedimento de deposição do óxido de tungstênio. $I_{k}$ e $I_{d}$ correspondem a valores de intensidade de corrente da onda catódica em presença e ausência de substrato $(0,1 ; 0,5 ; 1 ; 5$ e $\left.10 \mathrm{mmol}^{-1} / \mathrm{O}_{3}^{-}\right) . \mathrm{V}=50 \mathrm{mV} \mathrm{s}^{-1}$. 


\subsubsection{Estudo do processo de transferência de elétrons de $\mathrm{IO}_{3}{ }^{-}$em eletrodo modificado com óxidos de tungstênio}

Foram realizados ensaios para avaliar o processo de transferência de elétrons do íon iodato em eletrodo modificado com óxido de tungstênio.

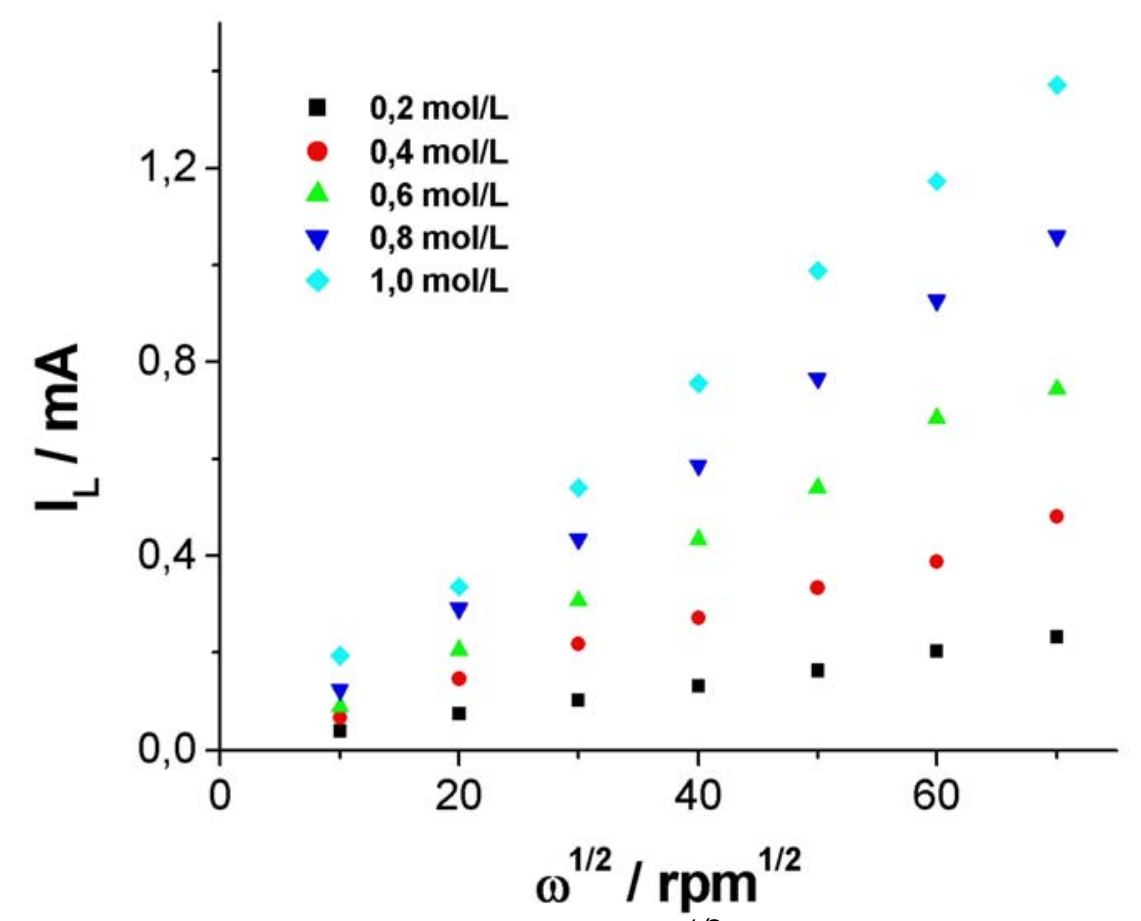

Figura 33 - Gráficos de $\Delta l_{L}$ vs. $\omega^{1 / 2}$ obtidos de voltamogramas cíclicos registrados com eletrodo modificado com óxido de tungstênio (100, $400,900,1600,2500,3600$ e $4900 \mathrm{rpm})$ em solução de $\mathrm{SO}_{4}{ }^{2-} 50$ mmol $L^{-1}(p H 2,5)$ contendo respectivamente $(\square) 0,2(\bullet) 0,4(\Delta) 0,6$ $(\nabla) 0,8$ e $(\diamond) 1,0 \mathrm{mmol}^{-1}$ de $1 \mathrm{O}_{3}^{-}(\mathrm{pH} 2,5)$. Velocidade de varredura $=50 \mathrm{mV} \mathrm{s}^{-1}$. IL medidos em $-800 \mathrm{mV}$.

Nestes ensaios variou-se a velocidade de rotação do eletrodo em $100,400,900,1600,2500,3600$ e 4900 rpm e a concentração das soluções de iodato em 0,$2 ; 0,4 ; 0,6 ; 0,8$ e $1,0 \mathrm{mmol} \mathrm{L}^{-1}$. A espessura do filme depositado foi mantida constante, visto que em todos os ensaios a 
deposição foi realizada variando o potencial aplicado à célula eletroquímica na faixa de $500 \mathrm{mV}$ a $-800 \mathrm{mV}$, por 15 minutos, em solução de tungstênio (VI) $54 \mathrm{mM}$. Os resultados obtidos dos voltamogramas cíclicos foram registrados no gráfico de $\Delta \mathrm{I}_{\mathrm{L}}$ versus $\omega^{1 / 2}$, apresentado na Figura 33. A adequação dos dados experimentais à equação de Levich [82] sugere que o processo de transferência eletrônica é controlado por transporte de massa, ou seja, todo substrato que chega à superfície do eletrodo é prontamente reduzido. Ensaios similares aos descritos na Figura 33 foram realizados e estes envolveram a alteração da espessura do filme.
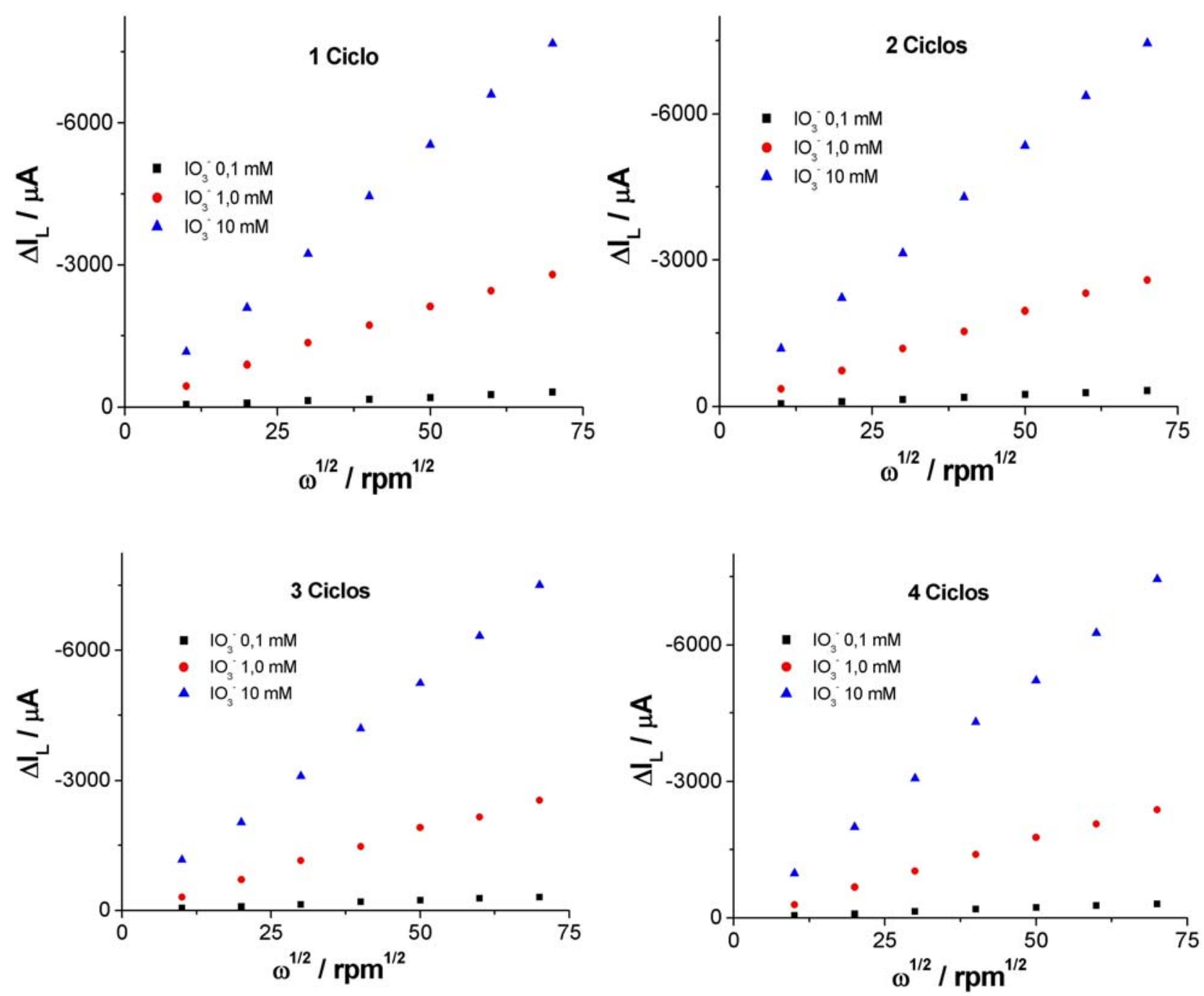

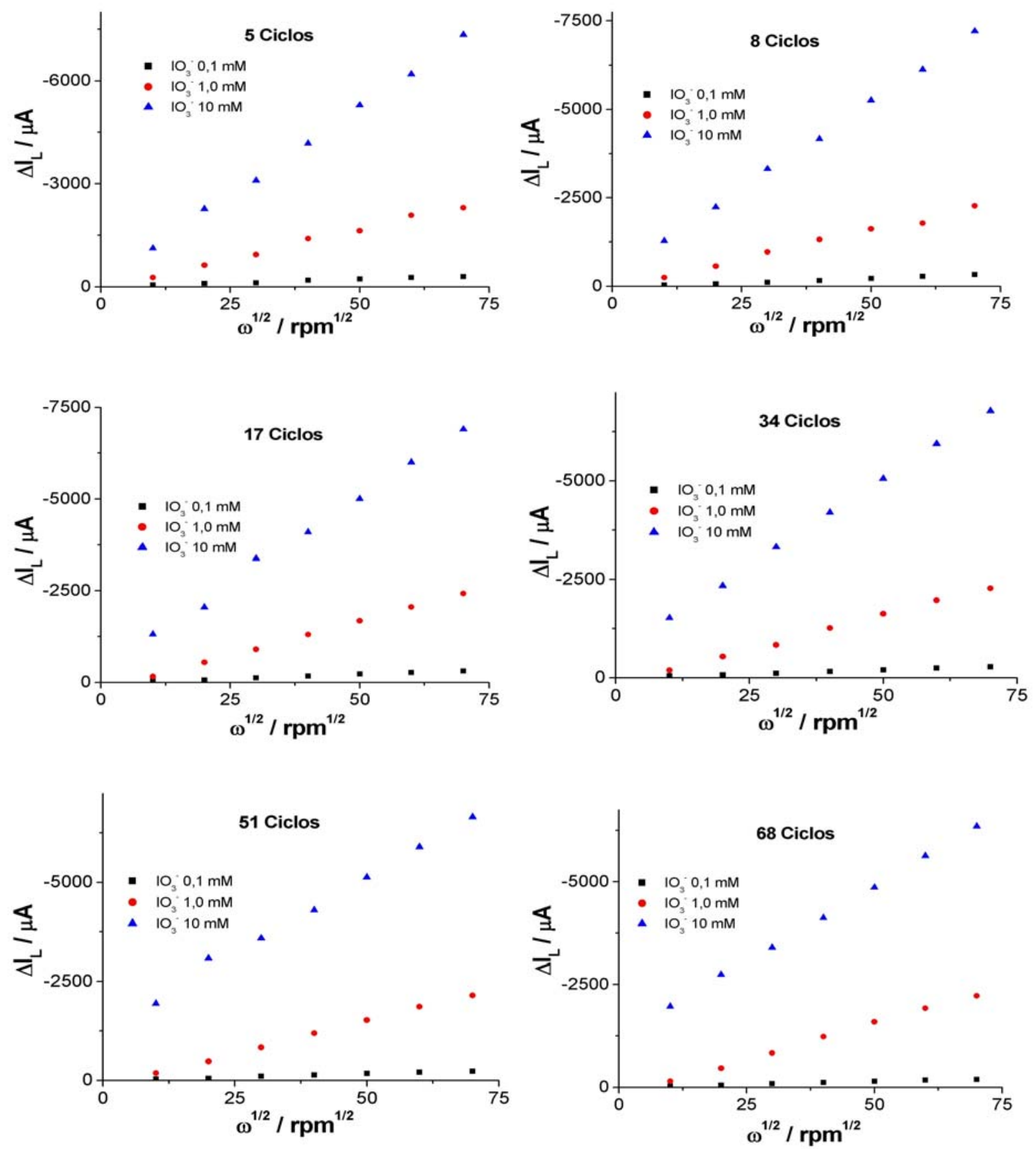

Figura 34 - Gráficos de $\Delta l_{L}$ vs. $\omega^{1 / 2}$ em função da espessura dos filmes de óxido de tungstênio. Dados obtidos de voltamogramas cíclicos registrados em diferentes velocidades de rotação $(100,400,900,1600,2500,3600$ e $4900 \mathrm{rpm})$ em solução de $\mathrm{SO}_{4}{ }^{2-} 50 \mathrm{mmol} \mathrm{L}^{-1}(\mathrm{pH} 2,5)$ contendo (口) 0,1 ( $(0)$ 
1,0 e ( $\triangle$ ) $10,0 \mathrm{mmol}^{-1}$ de $1 \mathrm{O}_{3}^{-}(\mathrm{pH} \mathrm{2,5).} \mathrm{Velocidade} \mathrm{de} \mathrm{varredura}=50 \mathrm{mV}$ $\mathrm{s}^{-1}$. I $I_{\mathrm{L}}$ medidos em $-800 \mathrm{mV}$.

A dependência linear entre $\Delta \mathrm{I}_{\mathrm{L}}$ vs. $\omega^{1 / 2}$ para as várias condições de trabalho demonstra que o processo de transferência eletrônica do íon iodato na superfície modificada com óxidos de tungstênio é governado pelo transporte de massa, especialmente no caso de filmes finos. Aumentandose a espessura do filme depositado conclui-se que as curvas lineares dos gráficos de Levich apresentam coeficiente linear diferente de zero. Este dado indica a presença de algum componente cinético associado ao processo catódico e comentários adicionais serão feitos na próxima seção.

\subsubsection{Estudo da permeabilidade dos filmes de óxidos de tungstênio (Parte II)}

Com os resultados observados nas Figuras 24 e 34 se percebe que 0 filme de óxidos de tungstênio é pouco permeável, como já foi comentado anteriormente.

Os íons $\mathrm{Fe}(\mathrm{CN})_{6}{ }^{3-}$ não sofrem eletrocatálise na superfície modificada e são reduzidos na superfície do eletrodo. Desta forma filmes mais espessos impedem a penetração dos íons, principalmente quando são realizados experimentos em soluções que apresentam concentrações mais elevadas. Esta baixa porosidade dos filmes e dificuldade de penetração do substrato por razões de impedimento elétrico justificam os desvios nos gráficos de Levich.

Já os íons $\mathrm{IO}_{3}{ }^{-}$sofrem eletrocatálise na interfase filme/solução, como foi observado na Figura 32. Portanto, o aumento da espessura do filme facilita a redução do iodato em processo esquematizado na Figura 35. 
Eletrodo

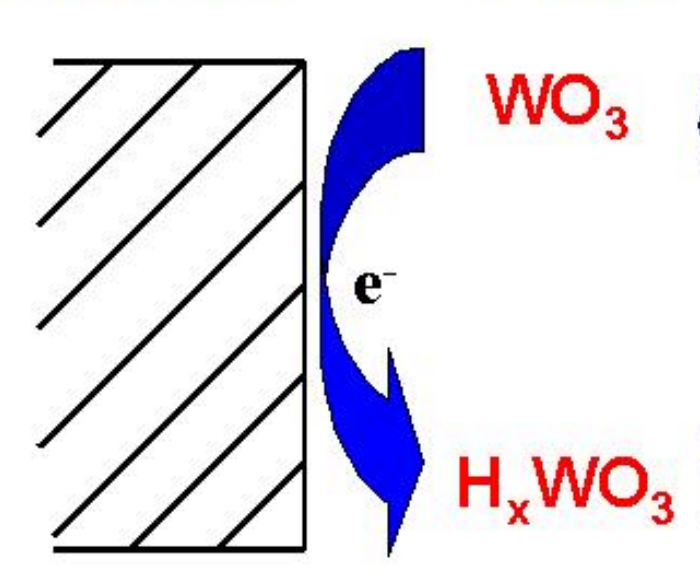

Filme
Solução

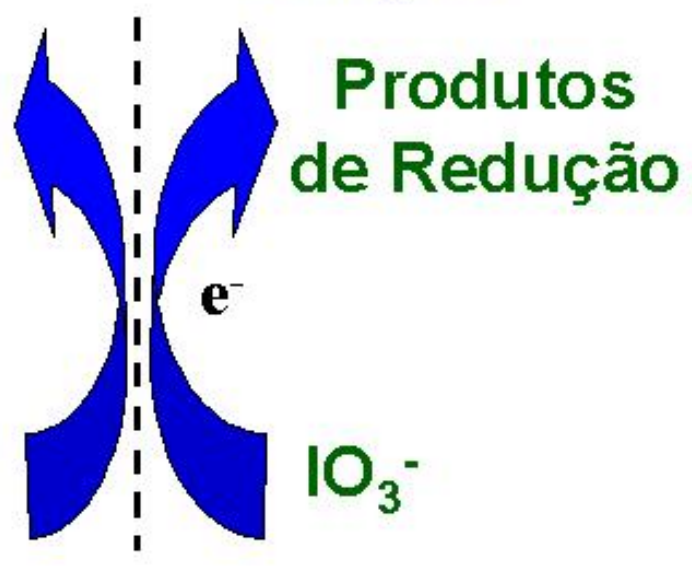

Figura 35 - Esquema do processo eletrocatalítico do iodato na superfície modificada com óxidos de tungstênio.

Os dados de $\Delta \mathrm{I}_{\mathrm{L}}$ da Figura 34 foram também representados em função do número de ciclos de potencial aplicados durante o processo de deposição dos filmes de óxido de tungstênio (Figura 36).

Ao observar os resultados de qualquer uma das concentrações de iodato, na Figura 36, percebe-se que quanto maior a velocidade de rotação do eletrodo de carbono vítreo maior é o valor de intensidade de corrente no processo de redução de iodato. Portanto a concentração do substrato é sempre renovada nas proximidades da superfície modificada, e esta é prontamente consumida [83].

Nos resultados obtidos com a solução $0,1 \mathrm{~mol} \mathrm{~L}^{-1}$ de iodato e observados na Figura 36 percebe-se que para filmes mais espessos ocorre perda nos valores de intensidade de corrente. Este fato pode ser explicado devido aos valores de intensidade dos voltamogramas cíclicos obtidos em solução $50 \mathrm{mmol} \mathrm{L}^{-1}$ de $\mathrm{SO}_{4}{ }^{2-}$ serem muito próximos daqueles obtidos em solução $50 \mathrm{mmol} \mathrm{L}^{-1}$ de $\mathrm{SO}_{4}{ }^{2-}$ contendo $0,1 \mathrm{~mol} \mathrm{~L}^{-1}$ de iodato. Já para solução cuja concentração de iodato $\left(10 \mathrm{mmol} \mathrm{L}^{-1}\right)$ é mais elevada e a 


\section{4 - Resultados e Discussão - 77}

velocidade de rotação do eletrodo é menor os valores de intensidade de corrente aumentam. Nestes casos percebe-se que o processo convectivo não é suficientemente rápido e desta forma a concentração de iodato nas proximidades da superfície modificada não é constante.
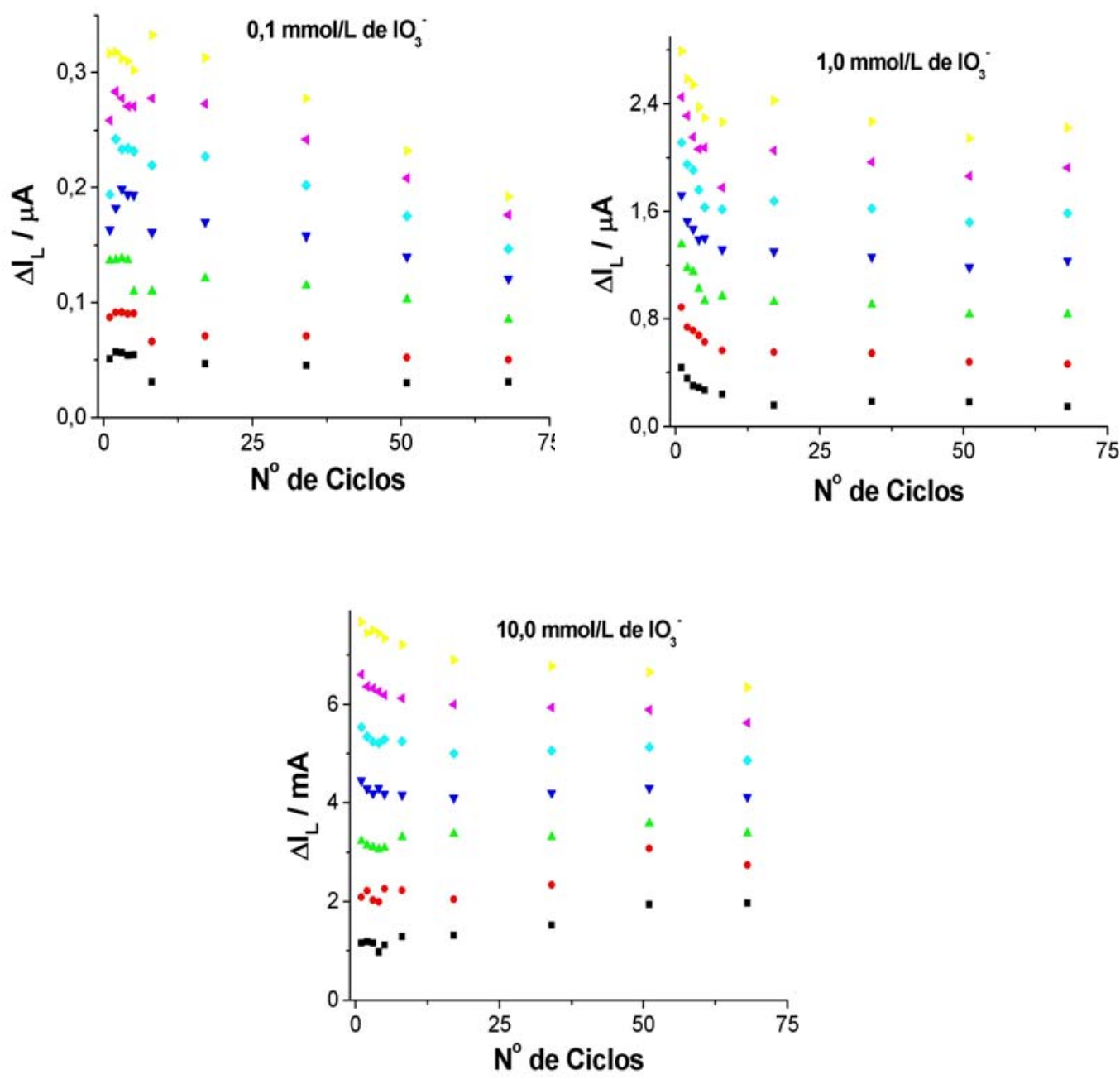

Figura 36 - Gráficos de $\Delta L_{L}$ versus $n^{O}$ de ciclos utilizados durante a modificação do eletrodo de carbono vítreo com óxido de tungstênio (1; 2; 3; 4; 5; 8; 17; 34; 51 e 68 ciclos de potencial). Voltamogramas cíclicos registrados em solução $50 \mathrm{mmol} L^{-1}$ de $\mathrm{SO}_{4}{ }^{2-}(\mathrm{pH} 2,5)$ contendo respectivamente 0,$1 ; 1,0$ e $10 \mathrm{mmol}^{-1}$ de $1 \mathrm{O}_{3}^{-}$. Velocidade de rotação do

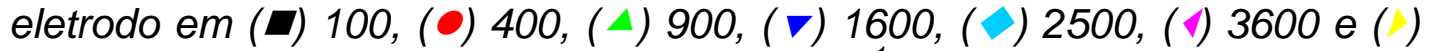
$4900 \mathrm{rpm}$. Velocidade de varredura $=50 \mathrm{mV} \mathrm{s}^{-1} . I_{L}$ medido em $-800 \mathrm{mV}$. 


\subsubsection{Quantificação de $\mathrm{IO}_{3}{ }^{-}$}

O desenvolvimento de método analítico para iodato baseou-se no uso do eletrodo modificado como sensor amperométrico em sistema FIA.

\subsubsection{Parâmetros do Sistema FIA}

Quando se trabalha com um sistema FIA existe a necessidade de otimizar alguns parâmetros tais como vazão da solução carregadora e alça de amostragem. Esta etapa do trabalho é relevante objetivando-se a melhoria dos parâmetros analíticos.

Os resultados dos ensaios realizados para quantificar $\mathrm{IO}_{3}^{-}$foram obtidos utilizando um sistema "wall jet" constituído de uma célula eletroquímica de três eletrodos, conforme esquema apresentado na Figura 10. À solução carregadora — solução $50 \mathrm{mmol} \mathrm{L}^{-1}$ de sulfato $(\mathrm{pH}=2,5)$ foram injetadas cinco alíquotas sucessivas de solução $1 \mathrm{mmol} \mathrm{L}^{-1}$ de iodato $(\mathrm{pH}=2,5)$. Aplicou-se ao eletrodo de trabalho modificado com óxido de tungstênio versus $\mathrm{Ag} \mid \mathrm{AgCl}$ o potencial $-200 \mathrm{mV}$, região onde o iodato é eletroativo na superfície modificada, conforme se observa na Figura 31. Os dados de intensidade de corrente utilizados nos gráficos que estão representados nas Figuras 37 e 38 são médias dos resultados obtidos durante os experimentos para otimização dos parâmetros do sistema FIA.

A Figura 37 mostra o resultado da otimização da vazão da solução carregadora utilizando alça de amostragem de $150 \mu \mathrm{L}$. As vazões da solução carregadora estudadas foram 1,$6 ; 2,0 ; 2,4 ; 3,0$ e $3,5 \mathrm{~mL} \mathrm{~min}^{-1}$. Os valores de intensidade de corrente observados nas vazões mais baixas cresce continuamente e isto se explica pela menor dispersão da amostra quando se aumenta a vazão da solução carregadora. Nas vazões mais altas não ocorrem variações consideráveis nos valores de corrente visto que o processo de eletrodo é controlado por transporte de massa e a corrente não é limitada por transferência eletrônica. Para gerar menor quantidade de 
resíduos definiu-se trabalhar com a vazão da solução carregadora igual a $2,4 \mathrm{~mL} \mathrm{~min}^{-1}$.

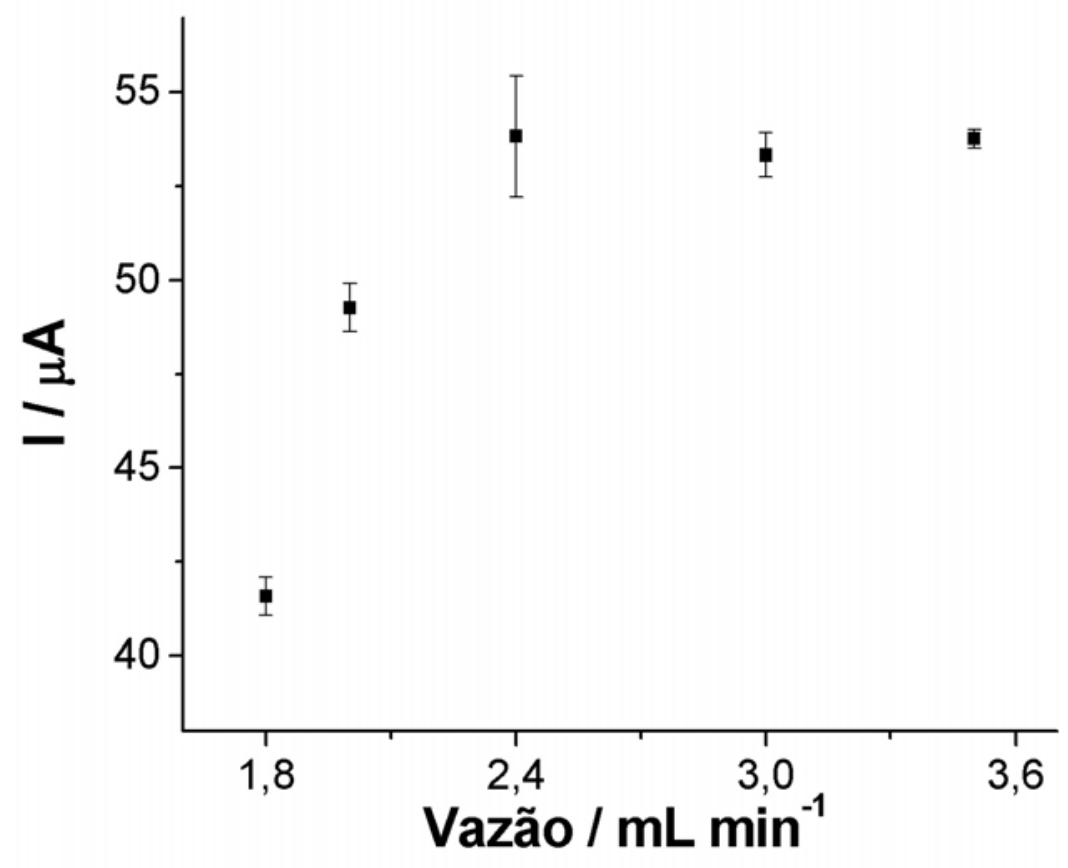

Figura 37 - Influência da vazão da solução carregadora nos sinais de corrente para iodato. Sinais de corrente medidos após injeções de solução $50 \mathrm{mmol} \mathrm{L}^{-1}$ de sulfato contendo $1 \mathrm{mmol} \mathrm{L}^{-1}$ de iodato. $\mathrm{E}=$ $-200 \mathrm{mV}$.

Os volumes de alças de amostragens utilizadas para este estudo foram de 50, 100, 150 e $200 \mu \mathrm{L}$ e os resultados estão representados na Figura 38. Observa-se que o volume de $200 \mu \mathrm{L}$ foi o que conduziu ao maior sinal analítico, entretanto o volume da alça de amostragem escolhida foi de $150 \mu \mathrm{L}$ pois o ganho ao se utilizar à alça de amostragem de maior capacidade foi pouco significativo. 


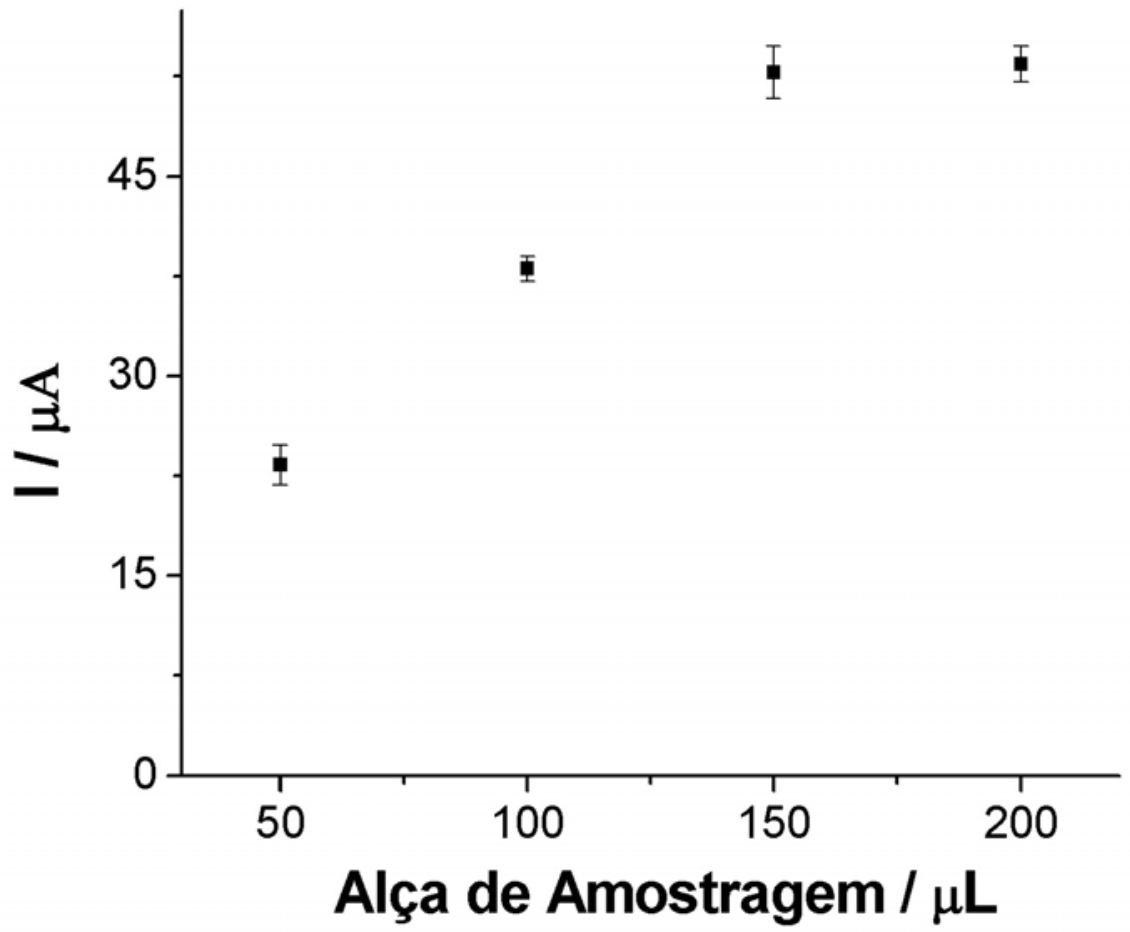

Figura 38 - Influência do volume da alça de amostragem nos sinais de corrente para iodato. Sinais de corrente medidos após injeções de solução $50 \mathrm{mmol} \mathrm{L}^{-1}$ de sulfato contendo $1 \mathrm{mmol}^{-1}$ de iodato. $E=-$ $200 \mathrm{mV}$.

Desta forma os parâmetros adotados para o sistema FIA utilizados no método desenvolvido para a quantificação de iodato foram: vazão da solução carregador de $2,4 \mathrm{~mL} \mathrm{~min}^{-1}$ e alça de amostragem de $150 \mu \mathrm{L}$.

\subsubsection{Resultados Analíticos}

Para a construção de curva analítica foram adicionadas ao sistema FIA alíquotas de $150 \mu \mathrm{L}$ de amostra padrão de iodato, nas concentrações 20; 40; 60; 80 e $100 \mu \mathrm{mol} \mathrm{L}{ }^{-1}$. Como resultado destas injeções foi obtido o fiagrama apresentado na figura 39. 


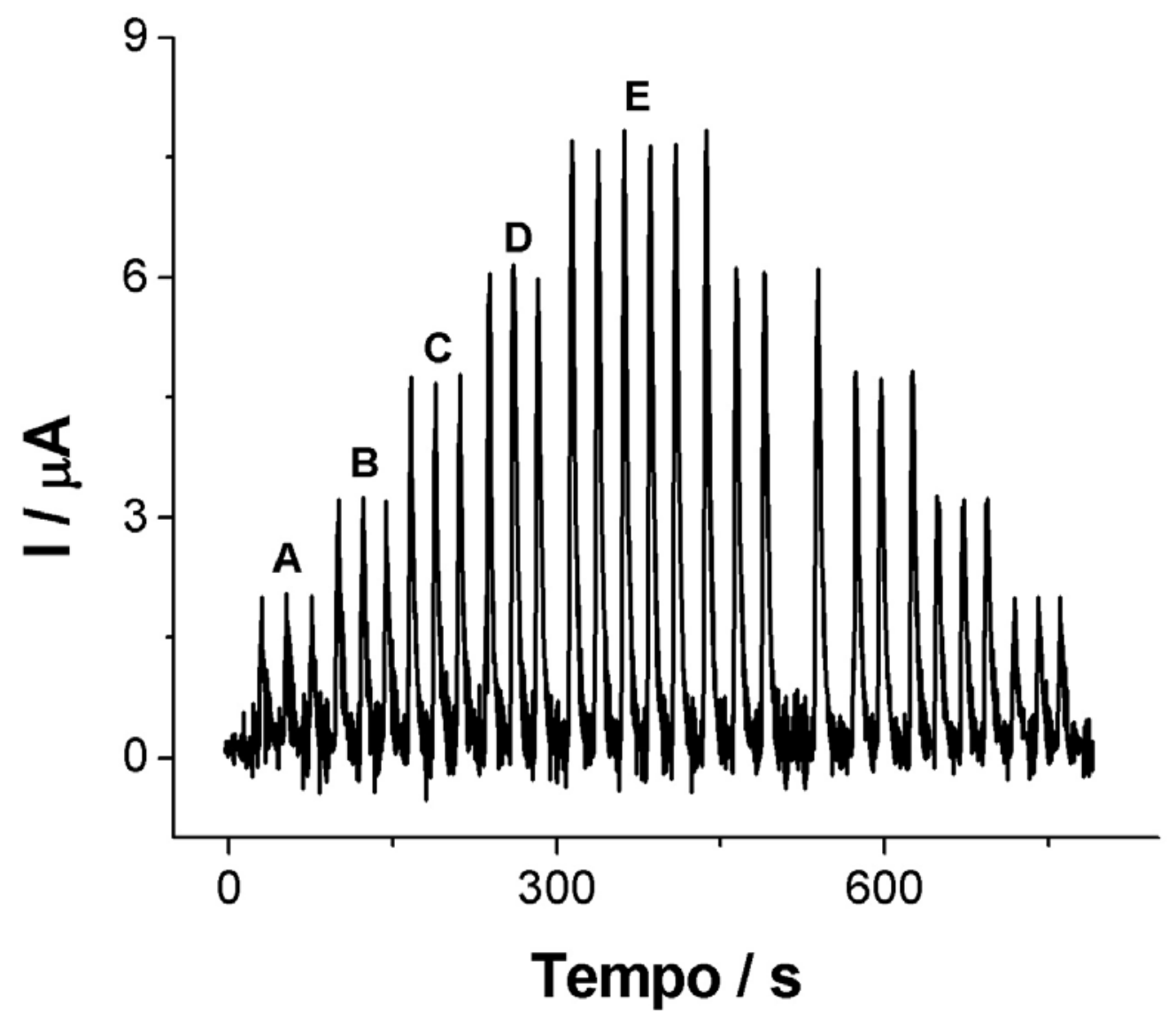

Figura 39 - Resposta amperométrica em fluxo utilizando eletrodo de carbono vítreo modificado com óxido de tungstênio, $E=-200 \mathrm{mV}$ versus $\mathrm{Ag} \mid \mathrm{AgCl}$. Solução carregadora $\mathrm{SO}_{4}{ }^{2-} 50 \mathrm{mmol} / \mathrm{L}(\mathrm{pH} 2,5)$. Vazão da solução carregadora $=2,4 \mathrm{~cm}^{3} \mathrm{~min}^{-1}$. Volume da amostra de $1 \mathrm{O}^{-}=150 \mu \mathrm{L}$. (A) 20, (B) 40, (C) 60, (D) 80 e (E) $100 \mu \mathrm{mol} \mathrm{L}^{-1}$.

Com estes resultados foi possível traçar a curva analítica para iodato nesta faixa de concentração. A Figura 40 apresenta o gráfico obtido, onde também estão inseridos os parâmetros analíticos da equação da reta obtida. 
O limite de detecção foi estimado em $210 \mathrm{nmol} \mathrm{L}^{-1}$ e corresponde a 3 vezes o valor do desvio padrão do branco [84].

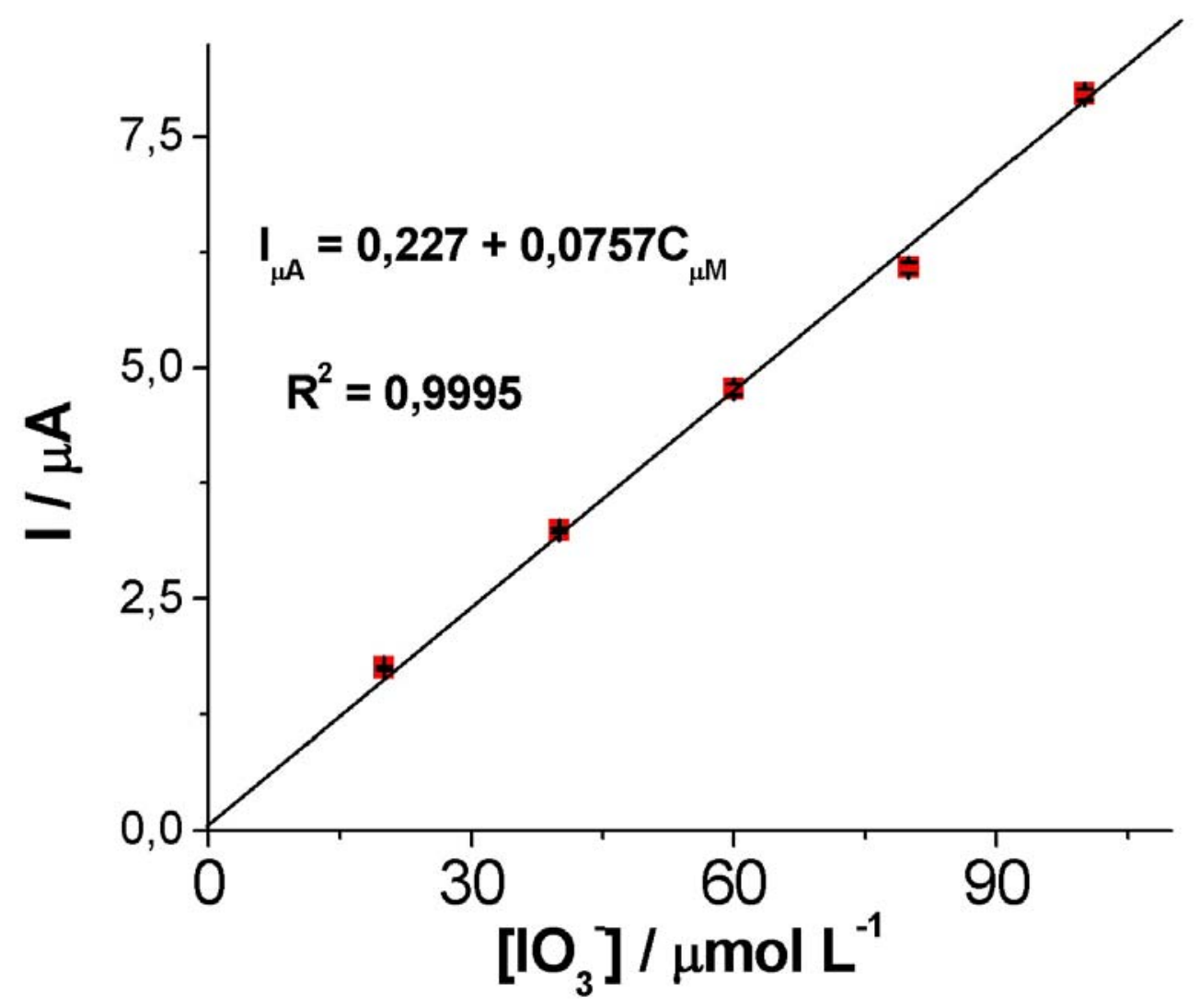

Figura 40 - Curva analítica para iodato obtida com os dados da Figura 39.

Para verificar a repetibilidade do método analítico foram efetuadas 41 injeções de solução $80 \mu \mathrm{mol} \mathrm{L} \mathrm{L}^{-1}$. de iodato, o fiagrama obtido é apresentado na Figura 41. O desvio padrão das determinações foi calculado e a repetibilidade do método foi de $98,3 \%$. 


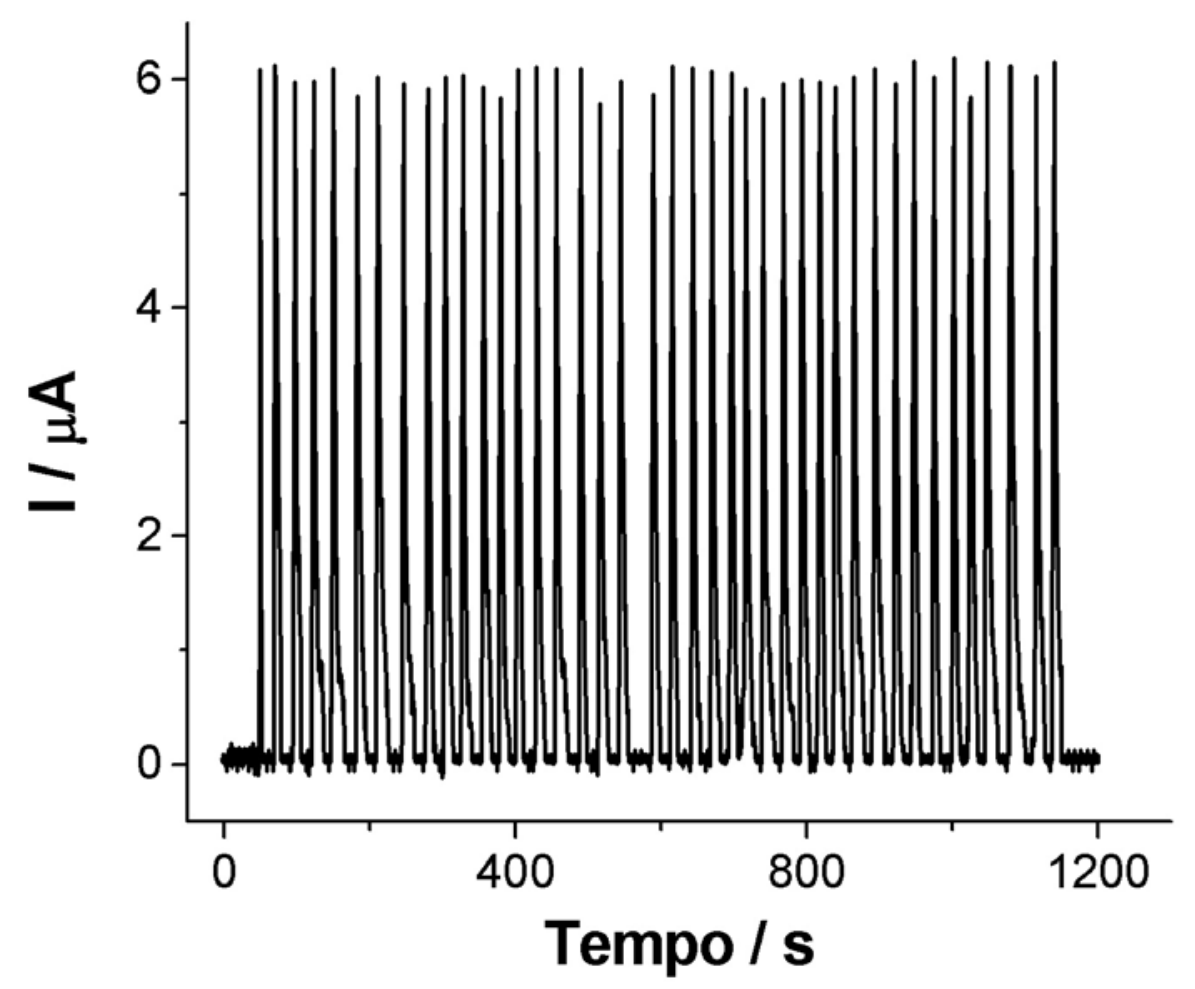

Figura 41 - Fiagrama obtido durante injeções de solução $80 \mu m o l L^{-1}$ de iodato $(150 \mu \mathrm{L})$ à solução carregadora $\mathrm{SO}_{4}{ }^{2-} 50 \mathrm{mmol} \mathrm{L}^{-1}(\mathrm{pH}=$ 2,5). Potencial aplicado: $-0,2 \mathrm{~V}$.

O método desenvolvido foi testado analisando-se o teor de iodato em 4 amostras de sal de cozinha designadas como amostra 1, amostra 2, amostra 3 e amostra 4. Foram injetadas cinco alíquotas de cada uma das amostras à solução carregadora e calculou-se a média dos resultados obtidos. Sabe-se que no sal de cozinha comercializado em todo o território nacional é adicionada, de forma intencional, a quantidade mínima de $40 \mathrm{mg}$ e a máxima de $100 \mathrm{mg}$ de iodato na forma de iodo por quilo de sal para evitar o hipertiroidismo, doença esta causada pela falta de iodo no nosso organismo [57]. 
O fiagrama referente à quantificação de iodato nestas amostras de sal de cozinha é apresentado na Figura 42. O cálculo da concentração de iodato nas amostras de sal foi feito comparando-se com dados da curva analítica.

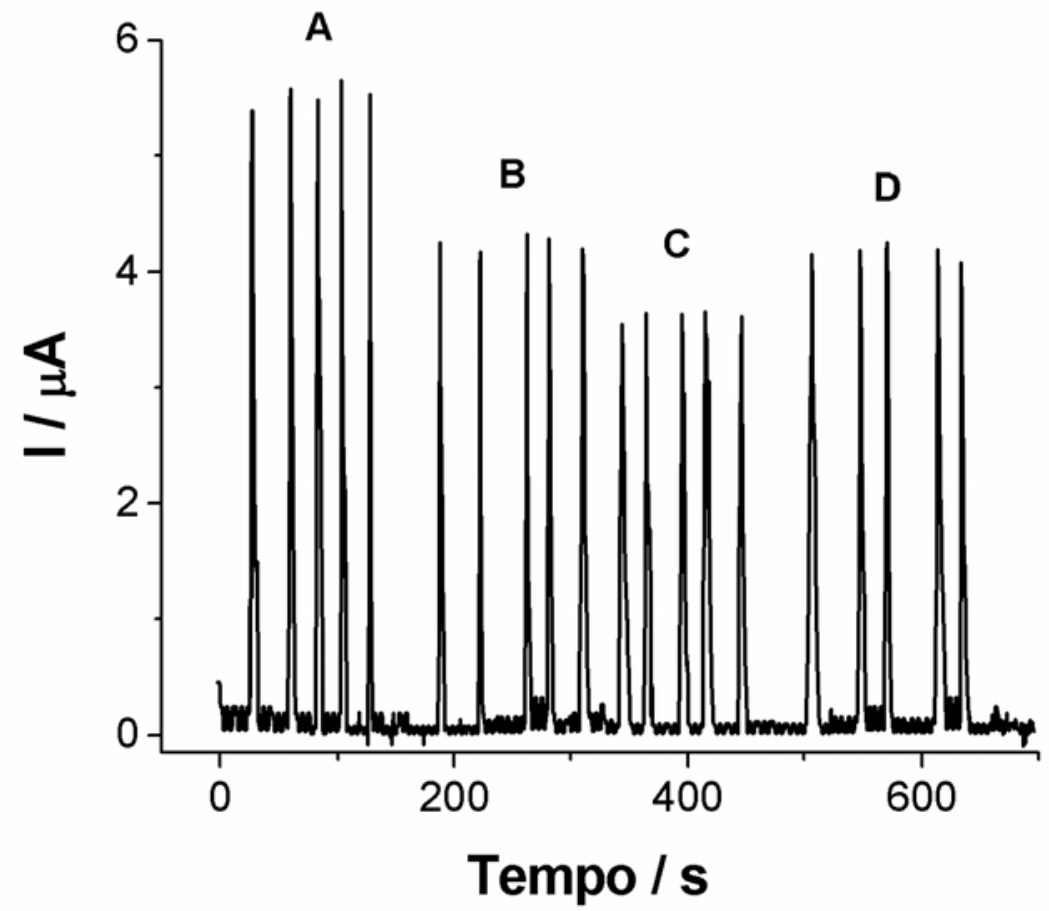

Figura 42 - Fiagrama obtido a partir da injeção de alíquotas de 150 $\mu L$ de amostras de solução de sal de cozinha. $(A)$ refere se à amostra 1, (B) amostra 2, (C) amostra 3 e (D) amostra 4.

Para comparar os resultados obtidos e validar o procedimento amperométrico proposto foi utilizado um método recomendado na literatura (iodométrico). No caso do método iodométrico foram realizados ensaios em triplicadas. Os resultados obtidos pelos dois métodos com os respectivos desvios relativos são apresentados na Tabela 2 e pode-se verificar que os valores obtidos utilizando o método amperométrico proposto são similares àqueles obtidos pelo método oficial. Desta forma é possível indicar que o método proposto é aplicável para a quantificação de iodato em amostras de sal de cozinha. 
Tabela 2 - Valores da concentração de iodato obtidos por meio de ensaios amperométricos e iodométricos em amostras de sal de cozinha.

\begin{tabular}{c|c|c|c}
\hline Amostra & $\begin{array}{c}\text { Iodométrico } \\
\mathbf{m g} / \mathbf{k g}\end{array}$ & $\begin{array}{c}\text { Amperométrico } \\
\mathbf{m g} / \mathbf{k g}\end{array}$ & $\begin{array}{c}\text { Desvio } \\
\%\end{array}$ \\
\hline 1 & $68 \pm 2$ & $70 \pm 1$ & +2 \\
\hline 2 & $54 \pm 2$ & $53 \pm 1$ & -2 \\
\hline 3 & $47 \pm 2$ & $44 \pm 1$ & -6 \\
\hline 4 & $51 \pm 1$ & $52 \pm 1$ & +1 \\
\hline
\end{tabular}

\subsubsection{Ensaios com Microbalança Eletroquímica de Cristal de Quartzo (MECQ)}

Nos estudos eletroquímicos utilizando a MECQ o eletrodo de ouro tinha uma área ativa de $0,31 \mathrm{~cm}^{2}$. Para transformar a variação de freqüência ressonante em variação de massa utilizou-se a Equação de Sauerbrey (Equação 7 ), cuja constante integral de sensibilidade $\left(C_{f}\right)$ foi estimada em $6,7 \times 10^{7} \mathrm{~g} \mathrm{~cm}^{-2} \mathrm{~Hz}$ para um cristal de $6 \mathrm{MHz}$. A calibração da MECQ para obtenção de $\mathrm{C}_{\mathrm{f}}$ foi realizada eletrodepositando-se cobre sobre o eletrodo de ouro usando solução $0,5 \mathrm{~mol} \mathrm{~L}^{-1}$ de sulfato de cobre em meio de ácido sulfúrico $(\mathrm{pH}=1,0)$. Este valor está de acordo com o obtido empregando-se prata como referência (eletrodeposição de prata sobre o eletrodo de ouro a partir de solução $0,5 \mathrm{~mol} \mathrm{~L}^{-1}$ de nitrato de prata em $0,5 \mathrm{~mol} \mathrm{~L}^{-1}$ de ácido nítrico [85]). 


\subsubsection{Modificação da superfície do Eletrodo de Ouro}

No processo de deposição de óxidos de tungstênio na superfície do cristal de quartzo recoberto com ouro variou-se o potencial aplicado de $500 \mathrm{mV}$ a $-800 \mathrm{mV}$, por 15 minutos com velocidade de varredura de $50 \mathrm{mV} \mathrm{s}^{-}$ 1, em solução $54 \mathrm{mmol} \mathrm{L}^{-1}$ de ácido perotungstico $(\mathrm{pH}=1,5)$. O resultado deste experimento é apresentado na Figura 43. Na parte superior (A) estão registrados os voltamogramas cíclicos consecutivos onde se percebe 0 contínuo aumento da corrente em função do número de ciclos de potencial, com conseqüente aumento na quantidade de material depositado. Este fato se torna mais nítido ao se observar a parte inferior da Figura (B) onde se percebe o aumento contínuo da variação de massa depositada sobre a superfície do eletrodo de ouro em função do potencial aplicado ao sistema.

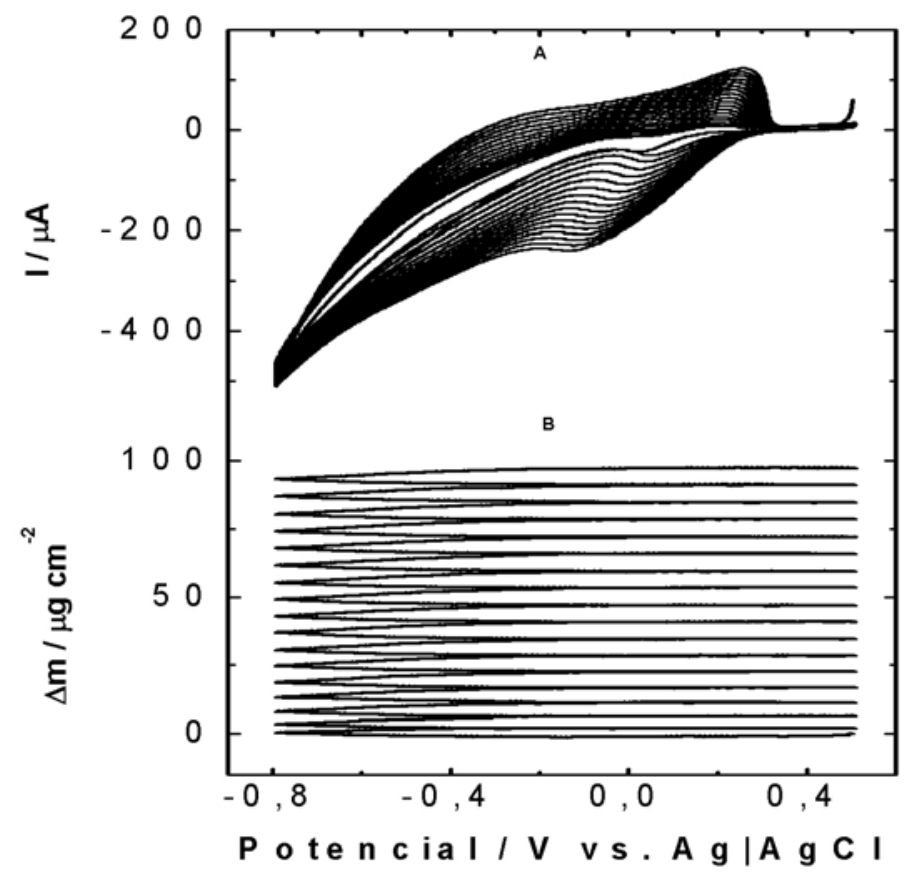

Figura 43 - (A) Voltamogramas cíclicos consecutivos obtidos com eletrodo de ouro $\left(A=0,31 \mathrm{~cm}^{2}\right)$ em solução $54 \mathrm{mmol}^{-1}$ de ácido perotungstico. $V=$ $50 \mathrm{mV} \mathrm{s}^{-1}$. Em (B) observa-se a variação de massa durante o experimento voltamétrico. 


\subsubsection{Determinação da Quantidade de Material Depositado $(I)$ de}

\section{filmes de óxidos de tungstênio}

Uma estimativa da espessura do filme pode ser feita com base na quantidade de material eletrodepositado na superfície do eletrodo. Este valor pode ser obtido utilizando-se a equação 4 :

$$
\Gamma=\mathrm{Q} / \mathrm{nFA}
$$

(Equação 4)

onde: $\mathrm{Q}$ é a carga envolvida no processo eletródico, $\mathrm{n}$ é o número de elétrons envolvido no processo, F é a constante de Faraday e A é a área superficial do eletrodo [86].

A quantidade de agente modificador que recobre a superfície do eletrodo modificado foi avaliada medindo-se a carga referente ao componente catódico em voltamograma registrado em solução $50 \mathrm{mmol} \mathrm{L}^{-1}$ de $\mathrm{SO}_{4}{ }^{2-}(\mathrm{pH}=2,5)$. Considerando o valor médio do número de elétrons envolvidos no processo de redução como $n=0,18$ [37], o resultado estimado para o filme de óxido de tungstênio para o tempo de modificação de 15 minutos foi $\Gamma=2,4 \times 10^{-7} \mathrm{~mol} \mathrm{~cm}^{-2}$ [87].

O valor de $\Gamma$ também foi determinado usando a microbalança eletroquímica de cristal de quartzo (MECQ). A Figura 44 apresenta a variação da freqüência durante o processo de deposição do filme de óxido de tungstênio, podendo-se observar o aumento de massa (diminuição da freqüência) [75]. 


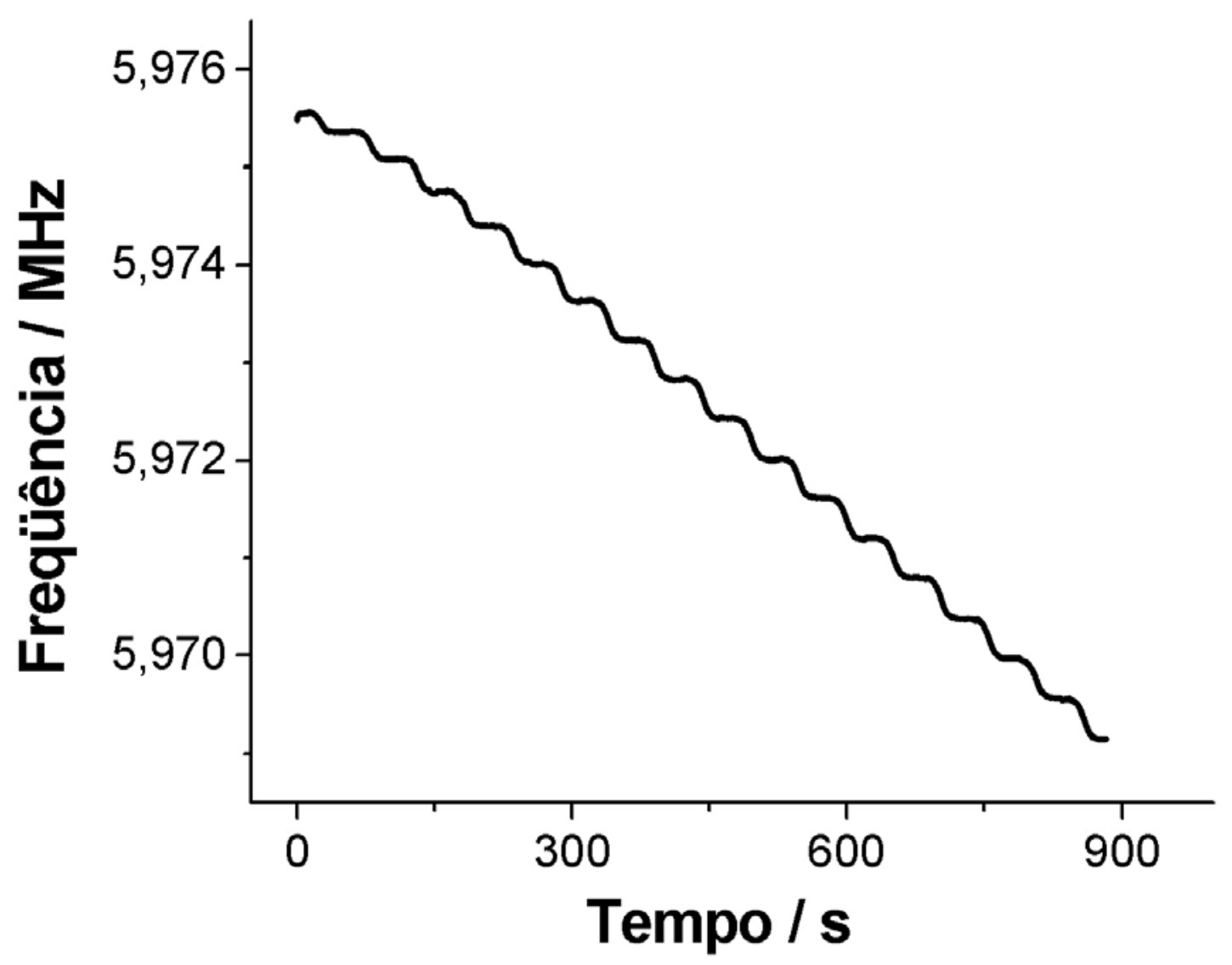

Figura 44 - Variação da freqüência do cristal de quartzo em função do tempo durante o processo de deposição do óxido de tungstênio (polarização do eletrodo entre 0,5 e -0,8 $\vee$ a $v=50 \mathrm{mV} \mathrm{s}^{-1}$ ) em solução 54 $\mathrm{mmol} \mathrm{L}^{-1}$ de ácido perotungstico.

A variação de massa de óxido de tungstênio depositada sobre a superfície do eletrodo de ouro pode ser obtida utilizando-se a equação 7 
[77] e os dados obtidos do gráfico apresentado na Figura 44. A massa de $\mathrm{WO}_{3}$ depositada sobre o eletrodo de ouro, após o tempo de 15 minutos, foi de $97,4 \mu \mathrm{g} \mathrm{cm}^{-2}$. O gráfico da variação de massa depositada em função do número de ciclos de potencial é apresentado na Figura 45, onde se percebe o constante aumento da variação de massa durante o tempo de modificação.

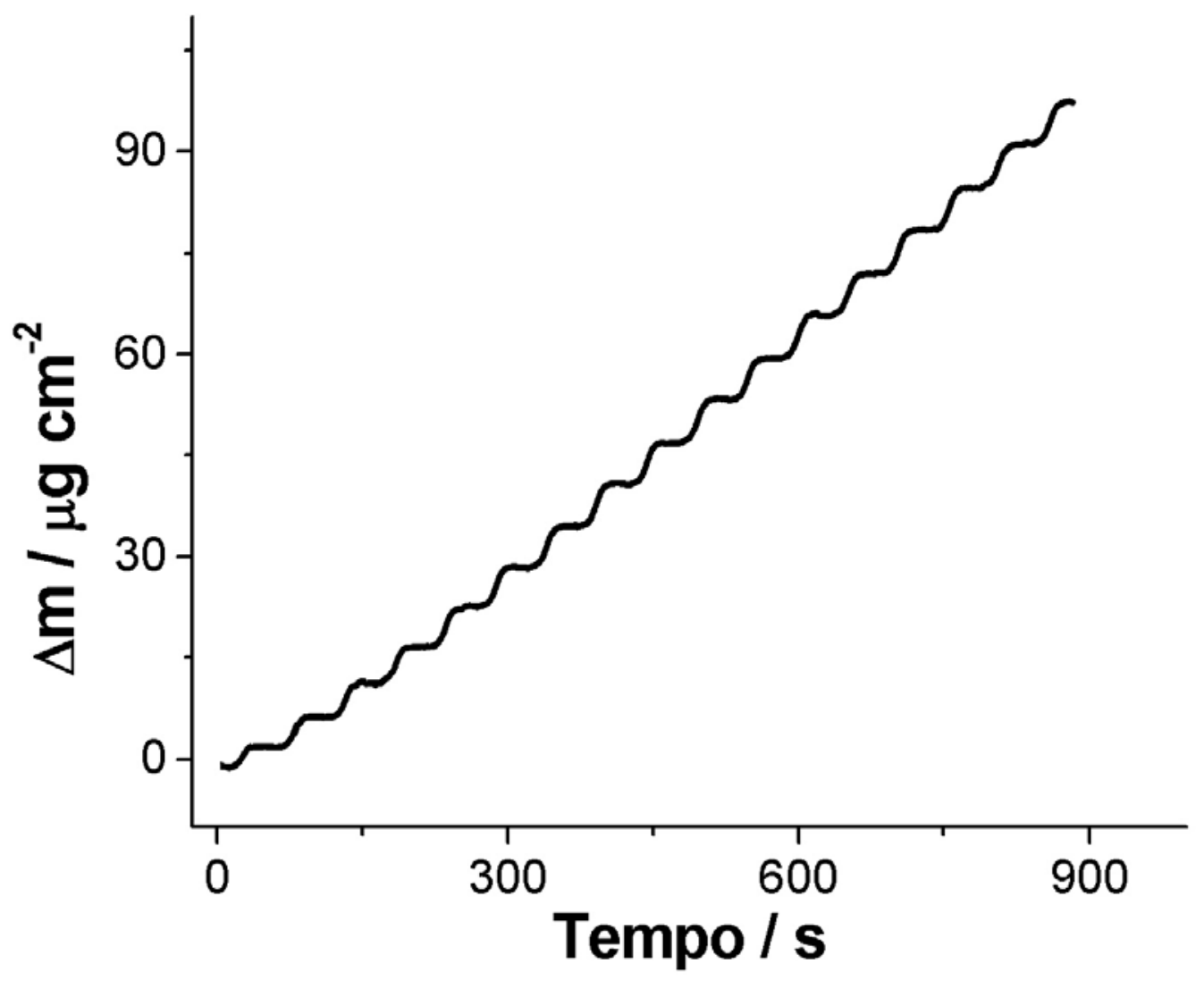

Figura 45 - Variação da massa do cristal de quartzo em função do tempo durante o processo de deposição do óxido de tungstênio (polarização do eletrodo entre 0,5 e $-0,8 \vee$ a $V=50 \mathrm{mV} \mathrm{s}^{-1}$ ) em solução $54 \mathrm{mmol} \mathrm{L^{-1 }}$ de ácido perotungstico. 
Com dados da Figura 45 foi possível estimar que a quantidade de material depositado sobre o eletrodo é $\Gamma=4,2 \times 10^{-7} \mathrm{~mol} \mathrm{~cm}^{-2}$, valor este com a mesma ordem de grandeza do resultado obtido pela integração da corrente num voltamograma obtido com o eletrodo modificado.

\subsubsection{Influência do $\mathrm{pH}$ na solubilização de filmes de óxidos de tungstênio}

Filmes de óxido de tungstênio foram preparados variando-se o potencial (17 ciclos) aplicado à célula eletroquímica entre + 0,5 e -0,8V em solução de $\mathrm{W}(\mathrm{VI})$ $54 \mathrm{mmol} \mathrm{L}^{-1}(\mathrm{pH} 1,5)$. Após a preparação dos filmes, estes foram acondicionados em soluções de $\mathrm{Na}_{2} \mathrm{SO}_{4} 50 \mathrm{mmol} \mathrm{L}^{-1}$ cujos valores de $\mathrm{pH}$ variaram na faixa de 1,5 a 9,0 e durante aproximadamente 10 minutos monitorou-se a variação de massa dos eletrodos.

Observa-se nas curvas A e B da Figura 46 ( $\mathrm{pH}$ 1,5 e 2,5, respectivamente) que não houve variação de massa do eletrodo, demonstrando que nestas condições o filme é quimicamente estável. Entretanto, em pH 4,7 (curva C) verificou-se perda gradativa de massa e consumo total do filme ao término do experimento. Em meio alcalino a dissolução do filme ocorre prontamente, conforme se depreende pela análise da curva $\mathrm{D}(\mathrm{pH}=9,0)$. Os processos referentes às perdas de massa observadas nas curvas $C$ e $D$ podem ser descritos pela Equação 5:

$$
\mathrm{WO}_{3}+2 \mathrm{OH}^{-} \leftrightarrows \mathrm{WO}_{4}{ }^{2-}+\mathrm{H}_{2} \mathrm{O} \quad \text { (Equação 5) }
$$




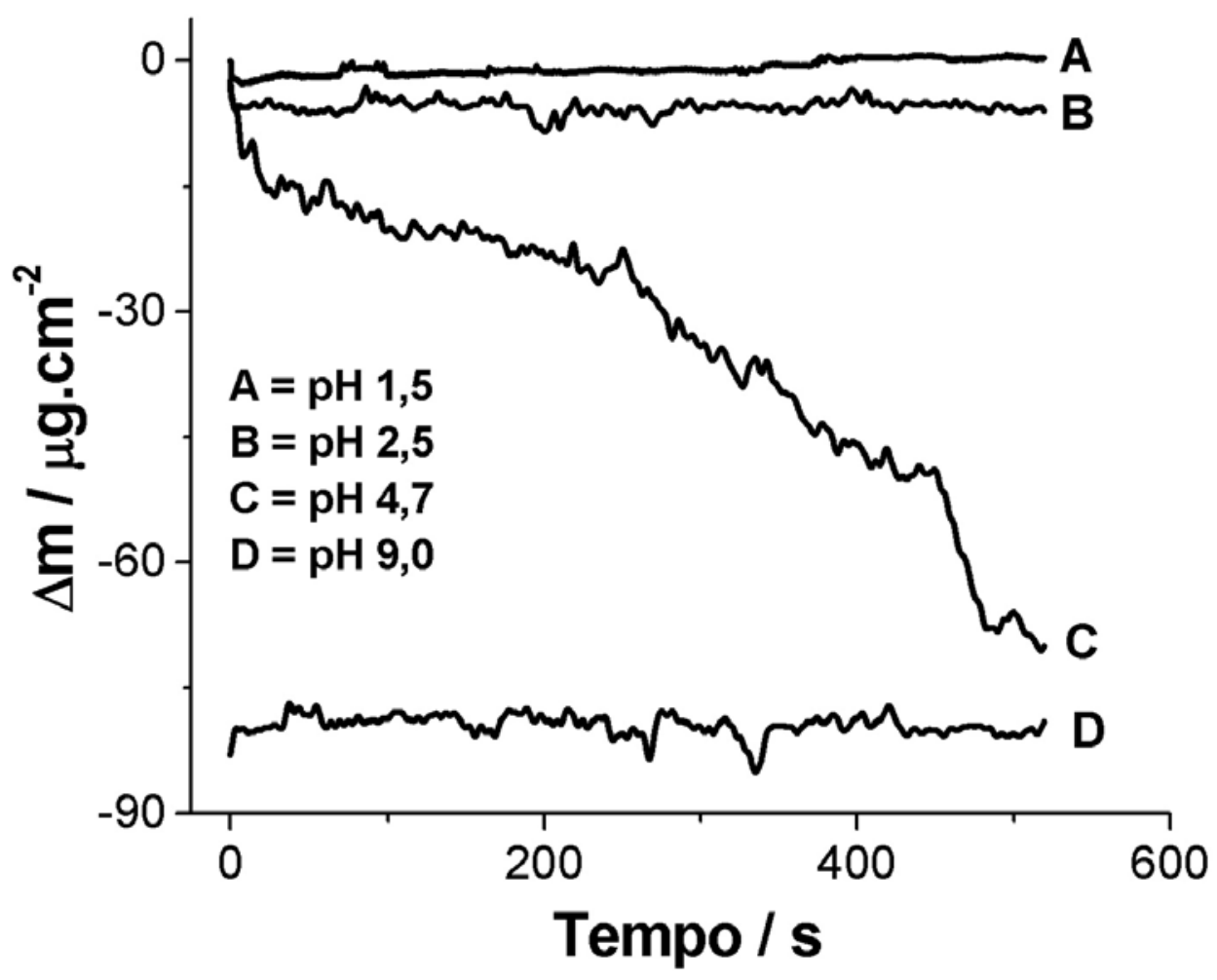

Figura 46 - Variação da massa do eletrodo modificado com filme de $\mathrm{WO}_{3}$ durante a polarização entre 0,5 e $-0,8 \mathrm{~V}, \mathrm{com} v=50 \mathrm{mV} \mathrm{s}^{-1}$ em solução de $\mathrm{Na}_{2} \mathrm{SO}_{4} 50 \mathrm{mmol} L^{-1}$ em diferentes valores de $\mathrm{pH}$.

\subsubsection{Estabilidade dos filmes $\mathrm{WO}_{3}$ em presença de $\mathrm{IO}_{3}=$}

Durante os ensaios realizados com microbalança eletroquímica de cristal de quartzo verificou-se a estabilidade dos filmes de óxidos de tungstênio em diferentes situações. Os resultados de variação de freqüência podem ser observados na Figura 47, onde a representação em preto (- ) se refere ao período em que foi verificada a estabilidade do filme após a modificação do eletrodo em solução $50 \mathrm{mmol}^{-1}$ (10 ciclos), a representação em vermelho (- ) se refere ao período de 5 minutos em que foi aplicado ao eletrodo de trabalho o potencial constante de $-800 \mathrm{mV}$ em 
solução $1 \mathrm{~mol} \mathrm{~L}^{-1}$ de $\mathrm{IO}_{3}^{-}$, a representação em verde $(-)$se refere ao mesmo ensaio realizado no experimento anterior em circuito aberto e a representação em azul (- ) se refere ao ensaio realizado em um ciclo de potencial em solução $1 \mathrm{mmol} \mathrm{L}^{-1}$ de $\mathrm{IO}_{3}^{-}$.

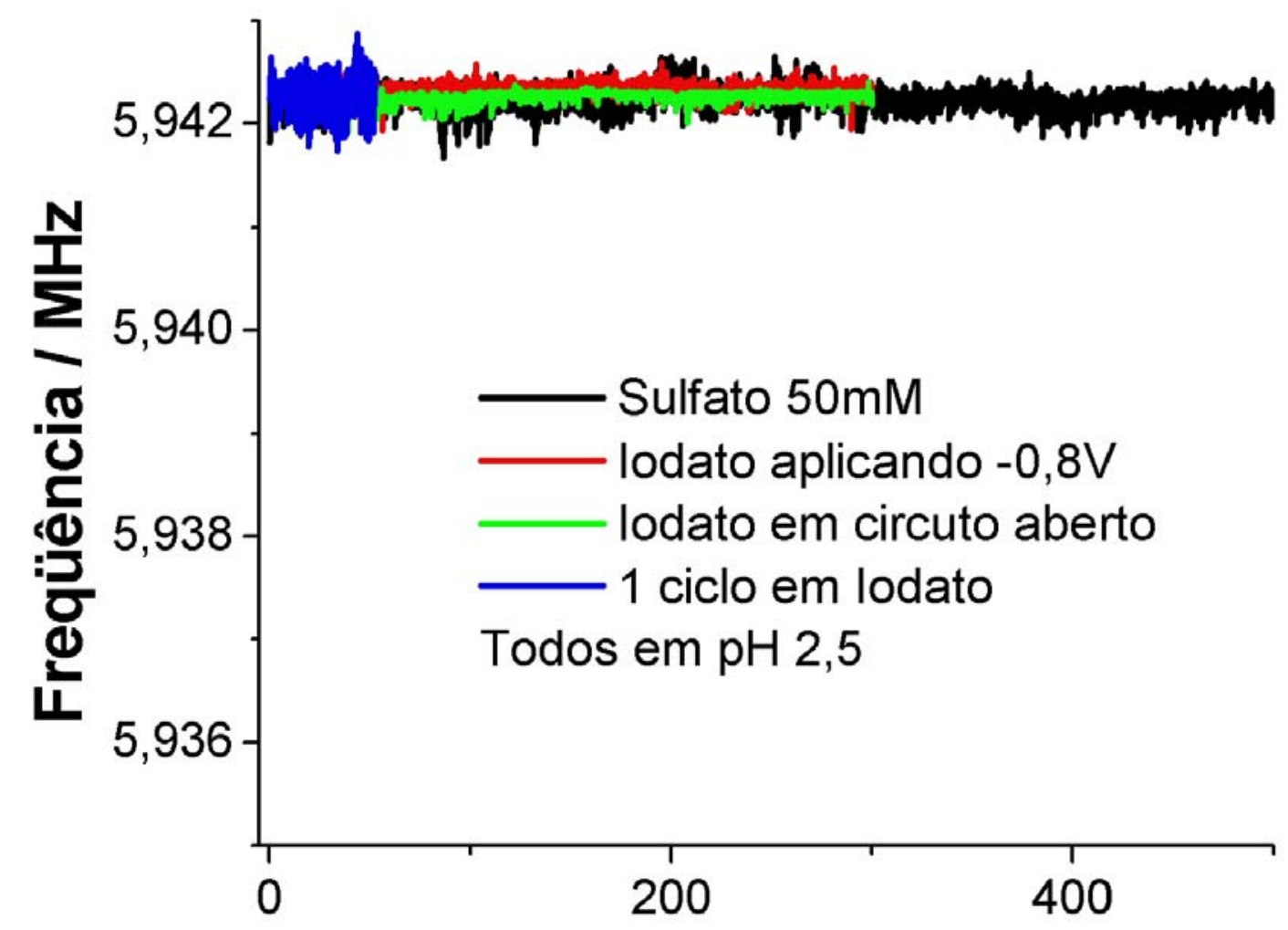

\section{Tempo / s}

Figura 47 - Variação da freqüência do cristal de quartzo em função do tempo durante o período em que foi verificada a estabilidade do filme de óxidos de tungstênio em diferentes situações.

Em todas as situações apresentadas acima observa-se que o filme de óxidos de tungstênio é estável, ou seja permanece sobre a superfície do eletrodo. 


\subsection{Estudos eletroquímicos envolvendo outras espécies químicas}

\subsubsection{Bromato e Clorato}

Os filmes finos de óxidos de molibdênio ou de tungstênio gerados em superfícies eletródicas de carbono vítreo consistem em camadas sobrepostas de um material não condutor. Quando o eletrodo modificado é polarizado em potenciais suficientemente negativos, o filme se torna altamente condutor devido a mudanças estruturais, fazendo com que prótons (ou outros cátions) se incorporem no sólido para efeito de compensação de carga [88]. Devido à alta reatividade do material reduzido pela hidrogenação ou por processos de transferência de átomos de oxigênio, o eletrodo modificado apresenta propriedade eletrocatalítica perante a redução de substratos oxigenados [88].

Neste sentido, foram realizados estudos para verificar possíveis interferentes na identificação quantitativa de iodato. Em função do reconhecido poder oxidante, considerou-se necessário avaliar o comportamento eletroquímico do clorato e do bromato em superfícies eletródicas modificadas com óxidos de tungstênio e óxidos de molibdênio.

\subsubsection{Redução Catódica de $\mathrm{IO}_{3}^{-}, \mathrm{BrO}_{3}^{-}$e $\mathrm{ClO}_{3}^{-}$em Eletrodos} Modificados com $\mathrm{WO}_{3}$ e com Eletrodos Modificados com $\mathrm{MoO}_{3}$.

A Figura 48 mostra os voltamogramas cíclicos obtidos com eletrodo de carbono vítreo modificado com óxido de tungstênio em soluções contendo diferentes oxiânions. Percebe-se por esta figura que na presença de iodato ocorre um aumento no sinal de corrente na região de $\mathrm{OV}$ em função de processo eletrocatalítico envolvendo espécies reduzidas de óxidos de tungstênio e os diferentes substratos. Na presença de bromato 
este efeito é menos pronunciado que no caso do iodato, e praticamente não existe em soluções contendo clorato.

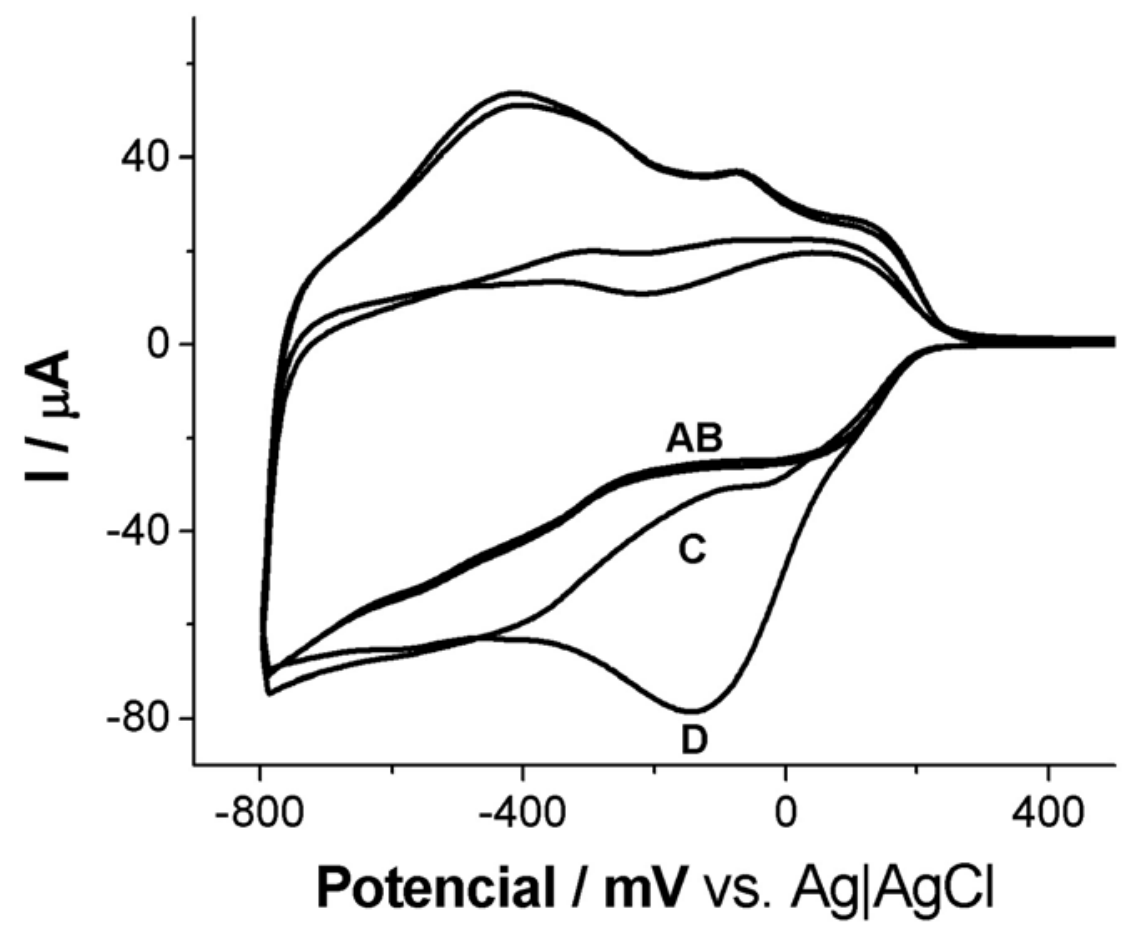

Figura 48 - Voltamogramas cíclicos obtidos com eletrodo de carbono vítreo modificado com óxidos de tungstênio $(\boldsymbol{A})$ em solução $50 \mathrm{mmol}^{-1}$ de $\mathrm{SO}_{4}{ }^{2-}$, (B) em solução $50 \mathrm{mmol} / \mathrm{L}$ de $\mathrm{SO}_{4}{ }^{2-}$ contendo $2 \mathrm{mmol} \mathrm{L}^{-1}$ de $\mathrm{ClO}_{3}{ }^{-}$, (C) em solução $50 \mathrm{mmol} \mathrm{L} L^{-1}$ de $\mathrm{SO}_{4}{ }^{2-}$ contendo $2 \mathrm{mmol} \mathrm{L}^{-1}$ de $\mathrm{BrO}_{3}{ }^{-}$e (D) em solução $50 \mathrm{mmol} \mathrm{L}^{-1}$ de $\mathrm{SO}_{4}{ }^{2-}$ contendo $2 \mathrm{mmol} \mathrm{L}^{-1}$ de $1 \mathrm{O}_{3}{ }^{-}$. Soluções com $\mathrm{pH}=2,5$. Velocidade de varredura $=50 \mathrm{mV} \mathrm{s}^{-1}$.

Os voltamogramas cíclicos que são apresentados na Figura 49 foram obtidos com eletrodo de carbono vítreo modificado com óxidos de molibdênio em soluções $50 \mathrm{mmol} \mathrm{L}^{-1}$ de sulfato de sódio na ausência e na presença de iodato, bromato ou clorato. Percebe-se que os resultados desta figura são similares aos obtidos com eletrodo modificado com óxidos de tungstênio, ou seja, quanto menor o tamanho do átomo central dos 
oxianions estudados, menor será o valor de intensidade de corrente. Isto se deve ao fato de que a transferência de átomos de oxigênio é facilitada no caso do iodato em função da maior polarizabilidade deste íon em relação aos outros dois, visto que em geral, quanto maior o átomo central e quanto mais elétrons ele possuir na camada de valência, tanto maior é o efeito de polarização [89-90].

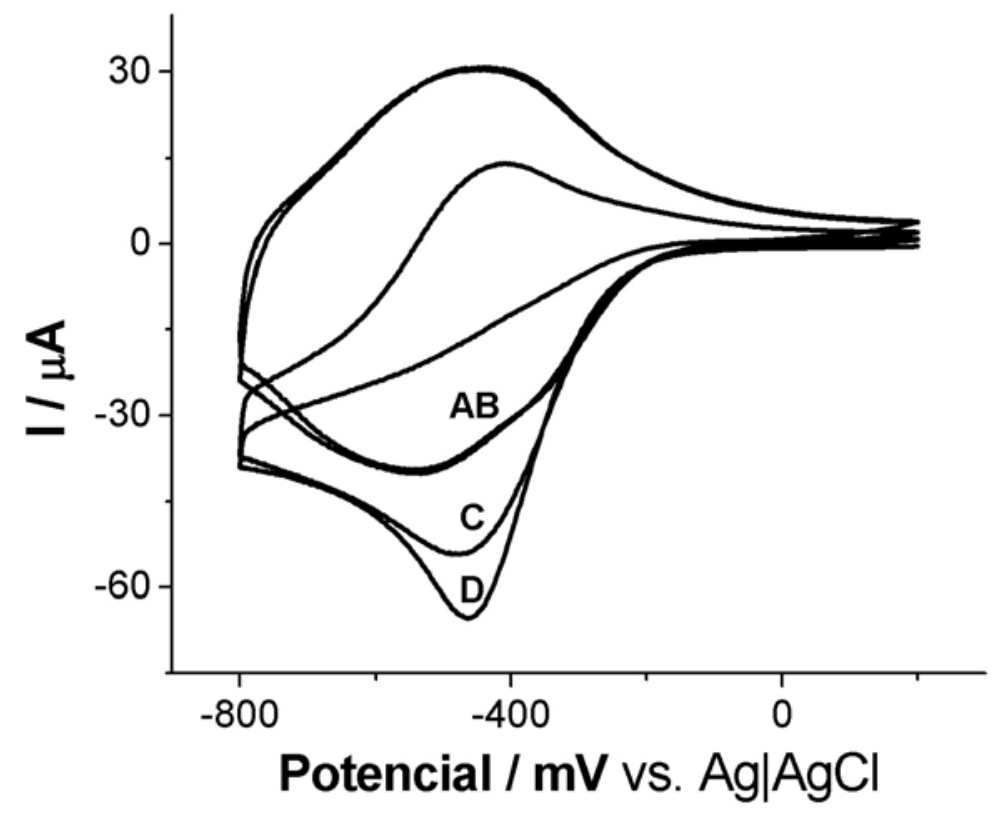

Figura 49 - Voltamogramas cíclicos obtidos com eletrodo de carbono vítreo modificado com óxidos de molibdênio (A) em solução $50 \mathrm{mmol} \mathrm{L}^{-1}$ de $\mathrm{SO}_{4}{ }^{2-}$, (B) em solução $50 \mathrm{mmol} \mathrm{L}^{-1}$ de $\mathrm{SO}_{4}{ }^{2-}$ contendo $2 \mathrm{mmol} \mathrm{L}^{-1}$ de $\mathrm{ClO}_{3}^{-}$, (C) em solução $50 \mathrm{mmol} \mathrm{L}{ }^{-1}$ de $\mathrm{SO}_{4}{ }^{2-}$ contendo $2 \mathrm{mmol} \mathrm{L}^{-1}$ de $\mathrm{BrO}_{3}{ }^{-}$e (D) em solução $50 \mathrm{mmol} \mathrm{L}^{-1}$ de $\mathrm{SO}_{4}{ }^{2-}$ contendo $2 \mathrm{mmol} \mathrm{L}^{-1}$ de $1 \mathrm{O}_{3}{ }^{-}$. Todas as soluções com $\mathrm{pH}=2,5$. Velocidade de varredura $=50 \mathrm{mV} \mathrm{s}^{-1}$.

Com as informações extraídas dos voltamogramas cíclicos das Figuras 48 e 49 foi possível montar a Tabela 3, onde estão apresentados os valores de corrente catódica referente ao processo de redução dos diversos ânions. 
Tabela 3 - Comparação dos valores de $\Delta l_{p c}$ (diferença entre o valor de corrente catódica na presença e na ausência do oxiânion) obtidos com eletrodo de carbono vítreo modificado com $\mathrm{WO}_{3}$ ou $\mathrm{MoO}_{3}$. Os valores de corrente foram medidos em -139 $\mathrm{mV}\left(\mathrm{WO}_{3}\right)$ e - $463 \mathrm{mV}\left(\mathrm{MoO}_{3}\right)$.

\begin{tabular}{c|c|c}
\hline Ânion & $\mathbf{W O}_{3}$ & $\mathbf{M o O}_{3}$ \\
\hline & $\Delta \mathbf{l}_{\mathrm{pc}}(\mu \mathrm{A})$ & $\Delta \mathrm{I}_{\mathrm{pc}}(\mu \mathrm{A})$ \\
\hline lodato & 53,0 & 29,3 \\
\hline Bromato & 7,2 & 18,0 \\
\hline Clorato & 1,1 & 0,8 \\
\hline
\end{tabular}

A análise da Tabela 3 indica que os sinais de corrente para bromato em eletrodos modificados com óxido de tungstênio representam 13,6\% do valor obtido ao se trabalhar com iodato e apenas $2,1 \%$ no caso de clorato. Como amostras de sal de cozinha não possuem em sua composição bromato e clorato não houve preocupação com possíveis interferências destas espécies químicas.

Uma outra informação relevante extraída após análise dos dados apresentados na Tabela 3 refere-se ao fato de que o $\Delta \mathrm{I}_{\mathrm{pc}}$ para iodato apresenta valor muito maior em eletrodo de carbono vítreo modificado com óxido de tungstênio, indicando que para este oxianion a transferência de átomos de oxigênio é mais efetiva em comparação com filmes de óxido de molibdênio, visto que os valores de intensidade de corrente são mais altos. Cabe ressaltar adicionalmente que o fato de os sinais de corrente serem medidos em potenciais menos negativos ao se trabalhar com filmes de óxido de tungstênio constitui-se em vantagem analítica bastante importante no desenvolvimento de metodologias analíticas.

$\mathrm{Na}$ Figura 50 são mostrados voltamogramas cíclicos obtidos com eletrodo de carbono vítreo modificado com óxido de tungstênio em soluções contendo iodato em duas concentrações diferentes. Ao observar o 
voltamograma obtido utilizando solução $7 \mathrm{mmol} \mathrm{L}^{-1}$ de iodato, nota-se que existem dois processos eletrocatalíticos envolvendo a redução do substrato, diferentemente do que ocorre em solução de iodato menos concentrada (curva B). Neste caso, o consumo de iodato no primeiro processo de redução é suficientemente efetivo para que não haja material disponível para a reação eletrocatalítica no potencial mais negativo. Isto é observado no caso do bromato (curva $C$ da Figura 48) e para concentrações mais elevadas de iodato (curva $\mathrm{C}$ da Figura 50).

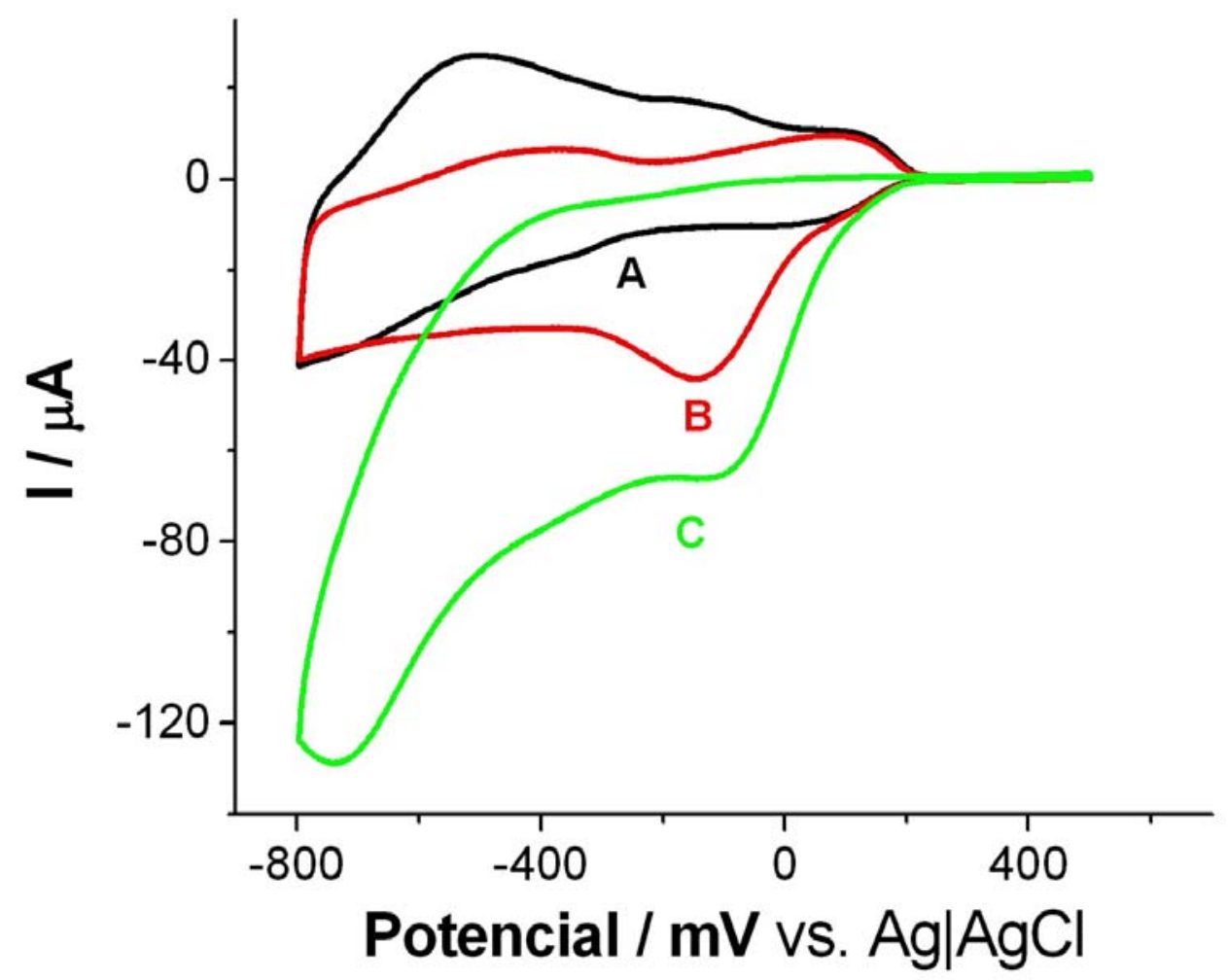

Figura 50 - Voltamogramas cíclicos obtidos com eletrodo de carbono vítreo modificado com óxidos de tungstênio: (A) solução $50 \mathrm{mmol}^{-1}$ de $\mathrm{SO}_{4}{ }^{2-}$; (B) solução $50 \mathrm{mmol} \mathrm{L}^{-1}$ de $\mathrm{SO}_{4}{ }^{2-}$ contendo $1 \mathrm{mmol} \mathrm{L}^{-1}$ de $1 \mathrm{O}_{3}^{-}$e (C) solução 50 mmol $L^{-1}$ contendo $7 \mathrm{mmol} \mathrm{L}^{-1}$ de $1 \mathrm{O}_{3}^{-}$. Todas as soluções com $\mathrm{pH}=2,5$. Velocidade de varredura $=50 \mathrm{mV} \mathrm{s}^{-1}$. 


\subsubsection{Nitrito e Óxido Nítrico}

A idéia inicial do projeto deste doutoramento consistia em investigar o comportamento eletroquímico do óxido nítrico em eletrodo modificado com óxido de tungstênio, tendo em vista resultados promissores obtidos no trabalho de Kosminsky et al. realizado com eletrodos modificados com óxidos de molibdênio [91].

Devido às dificuldades experimentais associadas ao trabalho com soluções de óxido nítrico, decidiu-se realizar testes preliminares usando nitrito visto que os perfis das curvas voltamétricas de ambas as espécies ( $\mathrm{NO}$ e $\mathrm{NO}_{2}{ }^{-}$) são muito similares, conforme mostra a Figura 51. Nesta Figura percebe-se que o potencial de pico anódico medido nos voltamogramas situa-se em torno de $+900 \mathrm{mV}$.
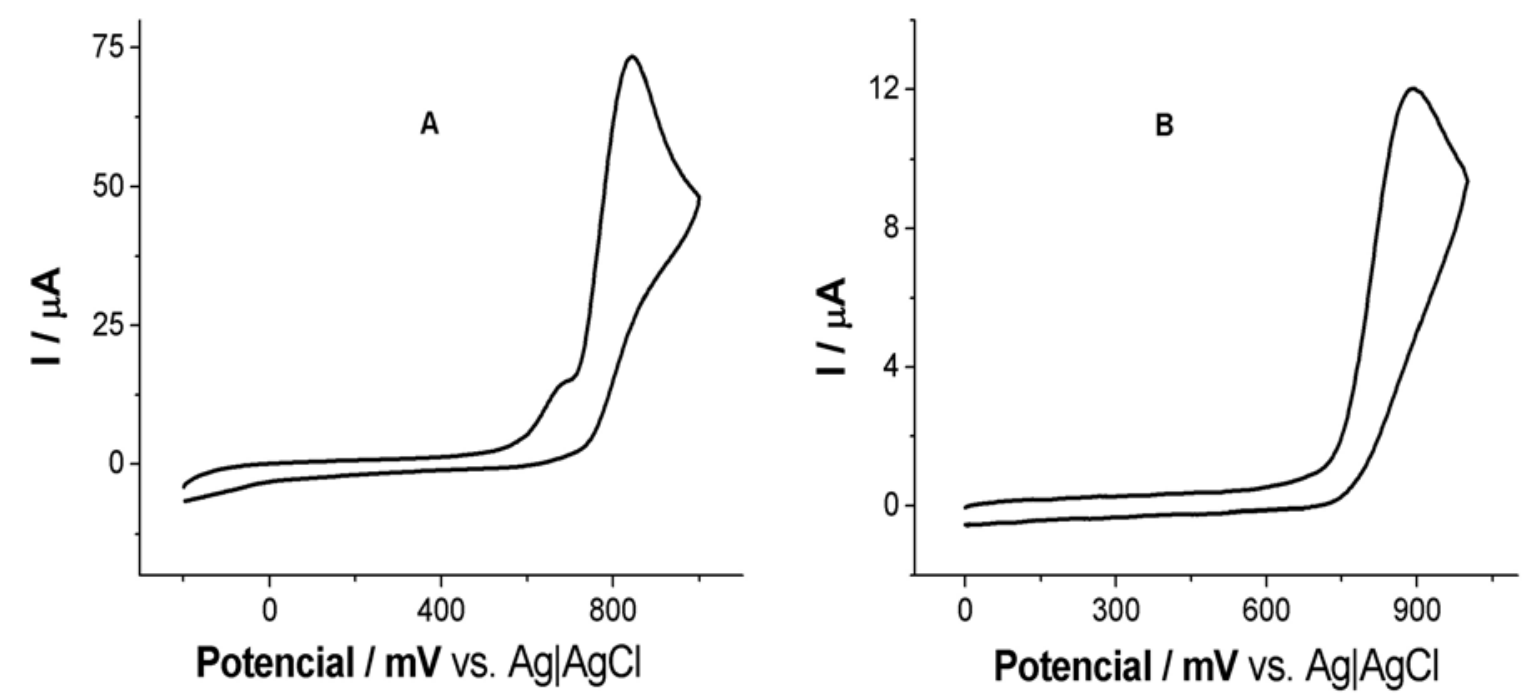

Figura 51 - Voltamogramas cíclicos obtidos em solução $2 \mathrm{mmol} \mathrm{L}^{-1}$ de $(A)$ óxido nítrico (Velocidade de varredura $=100 \mathrm{mV} \mathrm{s}^{-1}$ ) e $1 \mathrm{mmol} \mathrm{L}^{-1}$ de $(B)$ nitrito (Velocidade de varredura $=50 \mathrm{mV} \mathrm{s}^{-1}$ ). Eletrodo de trabalho carbono vítreo polido $(d=3 \mathrm{~mm})$. 
Para estudar o comportamento eletroquímico do $\mathrm{NO}_{2}^{-}$em eletrodo de carbono vítreo modificado com óxido de tungstênio, trabalhou-se com solução $50 \mathrm{mmol} \mathrm{L}^{-1}$ de $\mathrm{SO}_{4}{ }^{2-}(\mathrm{pH}=2,5)$ contendo ou não $1 \mathrm{mmol} \mathrm{L}^{-1} \mathrm{de}$ $\mathrm{NO}_{2}{ }^{-}$. Na figura 52 pode se observar que em eletrodo de carbono vítreo polido a intensidade do sinal de corrente anódica para nitrito é maior do que aquela observada em eletrodo de carbono vítreo modificado com óxido de tungstênio. Percebe-se, portanto, que a presença do filme não exerce influência positiva no que tange ao aumento de sensibilidade ou deslocamento de potencial do processo anódico.

O comportamento eletroquímico do NO em eletrodo de carbono vítreo modificado com óxido de tungstênio foi também investigado. Para tanto, utilizou-se uma célula de acrílico hermeticamente fechada onde se borbulhou argônio por 15 minutos para eliminar todo oxigênio dissolvido na solução $50 \mathrm{mmol} \mathrm{L}^{-1}$ de sulfato. Este procedimento é importante para minimizar a oxidação do NO adicionado ao eletrólito suporte, em processo explicado pelas equações 6, 7 e 8 [92].

$$
\begin{array}{llll}
\mathrm{NO}+1 / 2 \mathrm{O}_{2} & \leftrightarrows & \mathrm{NO}_{2} & \text { (Equação 6) } \\
\mathrm{NO}_{2}+\mathrm{NO} & \leftrightarrows & \mathrm{N}_{2} \mathrm{O}_{3} & \text { (Equação 7) } \\
\mathrm{N}_{2} \mathrm{O}_{3}+\mathrm{H}_{2} \mathrm{O} \leftrightarrows 2 \mathrm{HNO}_{2} \leftrightarrows 2 \mathrm{H}^{+}+2 \mathrm{NO}_{2}^{-} \text {(Equação 8) }
\end{array}
$$




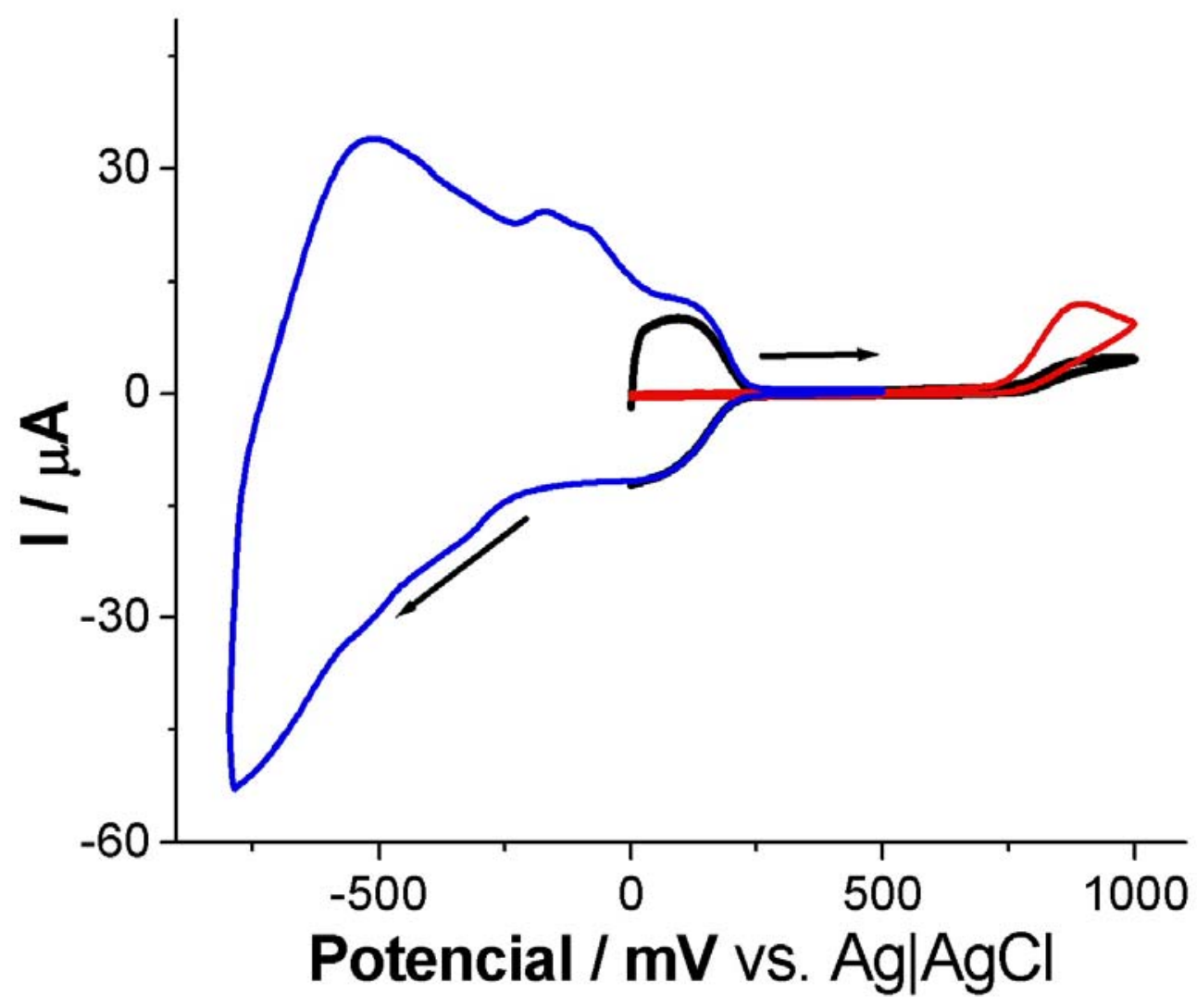

Figura 52 - Voltamogramas cíclicos obtidos em solução $50 \mathrm{mmol} \mathrm{L}^{-1}$ de sulfato contendo $1 \mathrm{mmol} \mathrm{L^{-1 }}$ de nitrito $(\mathrm{pH}=2,5)$ com eletrodo de carbono vítreo polido $(\rightarrow)$ e eletrodo de carbono vítreo modificado com óxido de tungstênio (-). Voltamograma cíclico obtido com eletrodo de carbono vítreo modificado $\Leftrightarrow$ imerso em solução $50 \mathrm{mmol} \mathrm{L}^{-1}$ de sulfato $(\mathrm{pH}=2,5)$. Velocidade de varredura $50 \mathrm{mV} \mathrm{s}^{-1}$.

Após 30 minutos de borbulhamento de NO na célula eletroquímica, obtêm-se soluções saturadas com a espécie e de concentração ao redor de $2 \mathrm{mmol} \mathrm{L}^{-1}[91,93]$. Na figura 53 é possível observar os voltamogramas cíclicos obtidos utilizando eletrodo de carbono vítreo polido e utilizando eletrodo de carbono vítreo modificado com óxido de tungstênio. Assim como 
ocorreu no caso do nitrito, observou-se menor sinal anódico com eletrodo de carbono vítreo modificado com óxido de tungstênio em relação ao sinal obtido com o eletrodo de carbono vítreo polido.

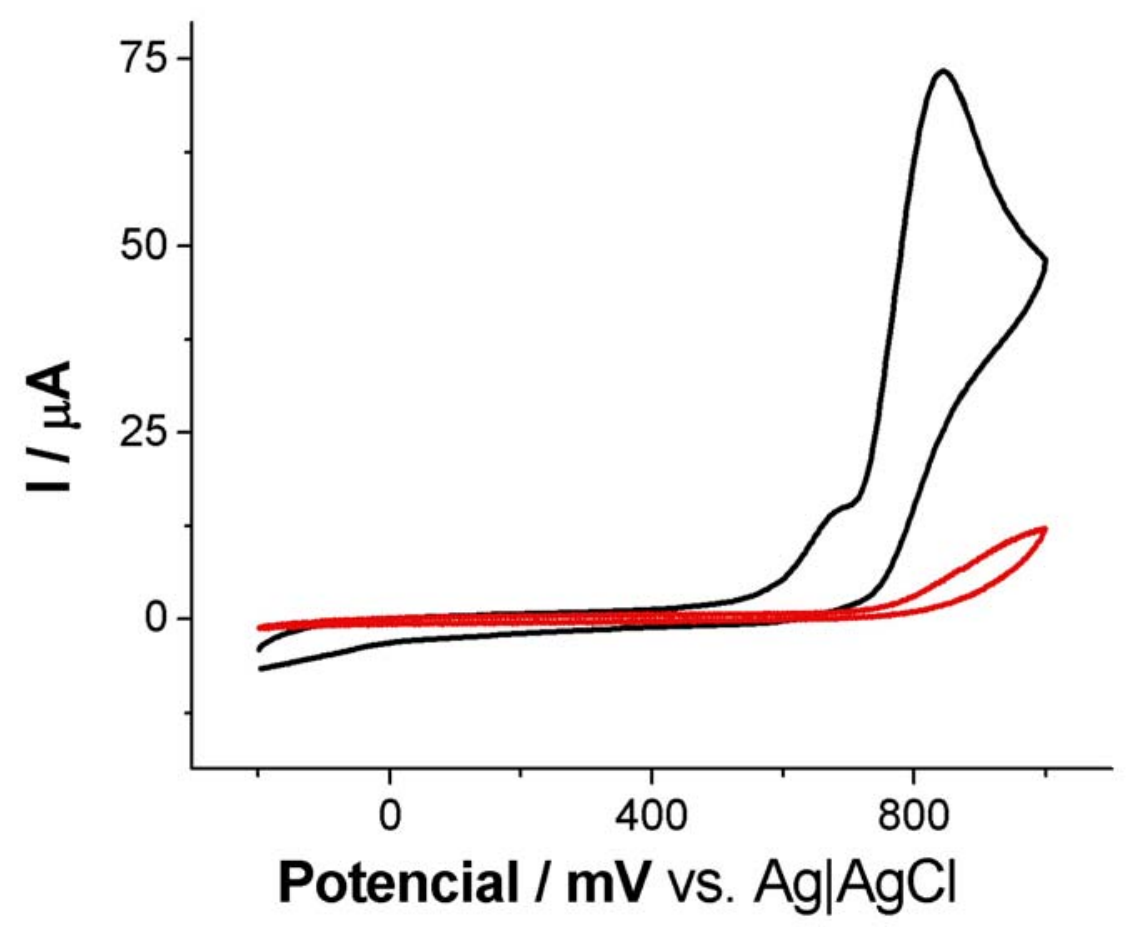

Figura 53 - Voltamogramas cíclicos referentes ao sinal anódico de NO obtidos em solução $50 \mathrm{mmol} \mathrm{L}^{-1}$ de sulfato contendo $2 \mathrm{mmol} \mathrm{L}^{-1}$ de $\mathrm{NO}(\mathrm{pH}=2,5)$ com eletrodo de carbono vítreo polido $(\rightarrow)$ e eletrodo de carbono vítreo modificado com óxido de tungstênio $(-)$. Velocidade de varredura $=50 \mathrm{mV} \mathrm{s}^{-1}$.

Pretende-se retomar estas investigações com o intuito de elucidar o papel exercido pelo filme na restrição do processo de transferência eletrônica e, neste caso, um parâmetro importante a ser analisado diz respeito à espessura do filme eletrodepositado. 


\section{Capítulo V}

Conclusões 


\section{5 - CONCLUSÕES}

Neste trabalho foram apresentados resultados referentes à modificação de eletrodos com $W_{x}$ utilizando dois métodos de eletrodeposição, o primeiro proposto por Kulesza e Faulkner [20,37] e o segundo proposto por Guelfi e Dao [40]. Comparando os resultados obtidos, percebe-se que no segundo procedimento o tempo de modificação é muito menor. Outro fator preponderante é o tempo de vida das soluções modificadoras utilizadas; enquanto a estabilidade da solução utilizada no primeiro método é de poucas horas, a solução utilizada no segundo método pode ser empregada pelo menos por dois meses e meio. Outro fato importante a ser destacado é sobre a repetibilidade do procedimento de preparação de filmes de $W_{\mathrm{x}}$ sobre a superfície de eletrodos, que é excepcionalmente boa.

Quanto às imagens obtidas por microscopia eletrônica de varredura ou utilizando o microscópio Infinity Photo-Optical Company, percebe-se que os filmes formados sobre os eletrodos modificados com $\mathrm{WO}_{\mathrm{x}}$ apresentaram sulcos provocados pela quebra do filme. Estes fatos estão de acordo com os observados por Guerfi e Dao [40] em eletrodos modificados por $\mathrm{MoO}_{\mathrm{x}}$, em que os mesmos indicam que este evento ocorre quando filmes finos de óxidos de metais de transição estão secos [44].

Há fortes indícios de que processo cinético de redução catódica de $\mathrm{IO}_{3}{ }^{-}$em filmes de $\mathrm{WO}_{\mathrm{x}}$ é governado por transporte de massa. Parâmetros experimentais como o pH e a espessura do filme são importantes em considerações sobre este processo eletródico.

Os resultados obtidos usando a microbalança eletroquímica de cristal de quartzo confirmam a dissolução de filmes de $W O_{x}$ em soluções de $\mathrm{Na}_{2} \mathrm{SO}_{4}$ fracamente ácidas ou alcalinas e a boa estabilidade química em meios relativamente ácidos. Esta verificação é relevante do ponto de vista 
da fabricação de sensores eletroquímicos de longa duração, tendo em vista que os processos eletrocatalíticos envolvendo a redução de íons oxigenados como iodato, clorato e bromato são favorecidos em meio ácido.

Com os dados obtidos pode-se concluir que 0 processo eletrocatalítico de redução do iodato ocorre em potencias menos negativos do que o observado com filmes de $\mathrm{MoO}_{\mathrm{x}}$ [80], minimizando assim eventuais interferências do oxigênio dissolvido nas soluções empregadas no sistema FIA. Os resultados referentes à determinação amperométrica de iodato em amostras de sal de cozinha foram considerados bons. Esta conclusão baseia-se na observação dos resultados apresentados na Tabela 2, bem como na confiabilidade no método proposto, quando se observa o valor do desvio médio obtido entre os métodos iodométrico e o amperométrico.

A metodologia proposta e os resultados obtidos aproximam-se muito daqueles apresentados por Kosminsky e Bertotti [80]. No caso anterior os autores modificaram o eletrodo de carbono vítreo com $\mathrm{MoO}_{\mathrm{x}}$ e quantificaram iodato em amostras de sal de cozinha. Esta nova metodologia não amplia o limite de detecção de forma significativa, visto que no método proposto por Kosminsky e Bertotti [80] o limite de detecção é $6 \mu \mathrm{mol} \mathrm{L^{-1 }}$ e no método proposto este limite é de $210 \mathrm{nmol} \mathrm{L^{-1 }}$. A faixa linear observada por Kosminsky e Bertotti é de $10 \mu \mathrm{mol} \mathrm{L}^{-1}$ a $10 \mathrm{mmol} \mathrm{L}^{-1}$, já no método proposto é de $5 \mu \mathrm{mol} / \mathrm{L}$ a $5 \mathrm{mmol} / \mathrm{L}$. A principal vantagem desta nova metodologia é a possibilidade de se trabalhar em potenciais menos negativos $(-0,2 \mathrm{~V})$ do que no caso de eletrodos modificados com $\mathrm{MoO}_{\mathrm{x}}(-0,6 \mathrm{~V})$ e assim não há necessidade de eliminar o oxigênio, conforme já ressaltado.

A repetibilidade do método para 41 injeções de solução $80 \mu \mathrm{mol} / \mathrm{L}$ de $\mathrm{IO}_{3}{ }^{-}$foi de $98,3 \%$. Também foram realizados ensaios para determinar o analito em amostras de sal de cozinha e os dados obtidos foram concordantes com os resultados oriundos do uso de método oficial. 


\section{Capítulo VI}

\section{Perspectivas}

Futuras 


\section{6 - PERSPECTIVAS FUTURAS}

$\leftrightarrow$ Caracterizar a superfície do eletrodo modificado com óxido de tungstênio. Os ensaios serão realizados no LNLS utilizando a técnica espectroscopia de absorção de raios $X$.

$\stackrel{\leftrightarrow}{\rightarrow}$ Verificar a possibilidade de caracterizar a composição do filme pela técnica RBS.

$\Leftrightarrow$ Ampliar investigações sobre o papel do filme de óxidos de tungstênio e de óxidos de molibdênio em processos eletrocatalíticos de redução de herbicidas.

$\Leftrightarrow$ Verificar as potencialidades eletrocatalíticas de óxidos de tungstênio dopado com metais de transição, tais como rutênio e cobalto.

$\stackrel{\leftrightarrow}{*}$ Iniciar investigações sobre a possível eletrocatálise de filmes de óxido de vanádio e possíveis aplicações analíticas.

$\stackrel{\leftrightarrow}{*}$ Estudar outras formas de modificações de eletrodos e suas possíveis aplicações analíticas, tais como porfirinas. 


\section{Capítulo VII}

$$
\text { Referências }
$$

Bibliográficas 


\section{7 - REFERÊNCIAS BIBLIOGRÁFICAS}

1. F. C. Anson. Accounts of Chemical Research. 8 (1975) 400.

2. R. F. Lane and A. T. Hubbard. The Journal of Physical Chemistry. 77 (1973) 1401.

3. R. F. Lane and A. T. Hubbard. The Journal of Physical Chemistry. 77 (1973) 1411.

4. P. R. Moses, L. Wler and R. W. Murray. Analytical Chemistry. 47 (1975) 1882.

5. K. D. Snell and A. G. Keenan. Chemical Society Reviews. 8 (1979) 259.

6. J. Zak and T. Kuwana. Journal of Electroanalytical Chemistry. 150 (1983) 645.

7. R. W. Murray. Electroanalytical Chemistry: A Series of Advances. A. J. Bard - Ed. M. Dekker: New York, 1984, Vol. 13, p. 191.

8. R. W. Murray, A. G. Ewing and R. A. Durst. Analytical Chemistry. 59 (1987) 379A.

9. H. D. Abruña. Coordination Chemistry Reviews. 86 (1988) 135.

10. L. R. Faulkner. Electrochimica Acta. 34 (1989) 1699. 
11. D. W. M. Arrigan. The Analyst. 119 (1994) 1953.

12. M. A. T. Gilmartin and J. P. Hart. The Analyst. 120 (1995) 1029.

13. R. W. Murray. Accounts of Chemical Research. 13 (1980) 135.

14. A. J. Bard. Journal of Chemical Education. 60 (1983) 302.

15. J. A. Cox, R. K. Jaworski and P. J. Kulesza. Electroanalysis. 3 (1991) 869.

16. J. Wang, A. Brennsteiner, L. Angnes and N. Bitsh. Analytical Chemistry. 64 (1992) 151.

17. N. D. Popovic, J. A. Cox and D. C. Johnson. Journal of Electroanalytical Chemistry. 455 (1998) 153.

18. J. R. C. da Rocha, L. Kosminsky, T. R. L. C. Paixão and M. Bertotti. Electroanalysis. 13 (2001) 155.

19. S. I. Córdoba de Torresi, A. Gorenstein, R. M. Torresi and M. V. Vázquez. Journal of Electroanalytical Chemistry. 318 (1991) 131.

20. P. J. Kulesza and L. R. Faulkner. Journal of Electroanalytical Chemistry. 248 (1988) 305.

21. E. Lust, A. Jänes, K. Lust and R. Pullerits. Journal of Electroanalytical Chemistry. 431 (1997) 183. 
22. K. Araki, L. Angnes, C. M. N. Azevedo and H. E. Toma. Journal of Electroanalytical Chemistry. 397 (1997) 205.

23. J. R. C. da Rocha, K. Araki, L. Angnes, H. E. Toma and M. Bertotti. Analytica Chimica Acta. 452 (2002) 23.

24. J. R. C. da Rocha, G. J. F. Demets, M. Bertotti, K. Araki and H. E. Toma. Journal of Electroanalytical Chemistry. 526 (2002) 69.

25. P. Bertocchi, D. Compagnone and G. Palleschi. Biosensors \& Bioelectronics. 11 (1996) 1.

26. A. M. O. Brett, S. H. P. Serrano, I. G. Gutz and M. A. La-Scalea. Bioelectrochemistry and Bioenergetics. 42 (1997) 175.

27. A. M. O. Brett, T. R. A. Macedo, D. Raimundo, M. H. Marques and S. H. P. Serrano. Biosensors \& Bioelectronics. 13 (1998) 861.

28. Jing-Na Ni, Huang-Xian Ju, Hong-Yuan Chen and Dónal Leech. Analytica Chimica Acta. 378 (1999) 151.

29. W. W. Kubiak and J. Wang. Analytica Chimica Acta. 329 (1996) 181.

30. R. A. Durst, A. J. Bäumner, R. W. Murray, R. P. Buck and C. P. Andrieux. Pure \& Applications Chemistry. 69 (1997) 1317.

31. B. Reichman and A. J. Bard. Journal of The Electrochemical Society. 126 (1979) 2133. 
32. A. Al Mohammad and M. Gillet. Thin Solid Films. 408 (2002) 302.

33. S. M. A. Durrani, E. E. Khawaja, M. A. Salim, M. F. Al-Kuhaili and A. M. Al-Shukri. Solar Energy Materials \& Solar Cells. 71 (2002) 313.

34. M. Regragui, M. Addou, A. Outzourhit, J. C. Bernéde, Elb. El Idrissi, E. Benseddik and A. Kachouane. Thin Solids Films. 358 (2000) 40.

35. O. Savadogo and P. Beck. Journal of The Electrochemical Society. 143 (1996) 3842.

36. Z. Chen and P. W Alexander. Analytica Chimica Acta. 332 (1996) 187.

37. P. J. Kulesza and L. R. Faulkner. Journal of The American Chemical Society. 110 (1988) 4905.

38. B. Karwowska and P. J. Kulesza. Electroanalysis. 7 (1995) 1005.

39. P. J. Kulesza, B. Grzybowska, M. A. Malik, M. Chojak and K. Miecznikowski. Journal of Electroanalytical Chemistry. 512 (2001) 110.

40. A. Guerfi and L. H. Dao. Journal of The Electrochemical Society. 136 (1989) 2435.

41. P. K. Shen, J. Syed-Bokkari and C. C. Tseung. Journal of The Electrochemical Society. 138 (1991) 2778. 
42. P. M. S. Monk and S. L. Chester. Electrochimica Acta. 38 (1993) 1521.

43. P. K. Shen and C. C. Tseung. Journal of The Electrochemical Society. 141 (1994) 3083.

44. C. Bock and B. MacDougall. Electrochimica Acta. 47 (2002) 3361.

45. C. Bock, A. Smith and B. MacDougall. Electrochimica Acta. 48 (2002) 57.

46. O. Lev, Z. Wu, S. Bharathi, V. Glezer, A. Modestov, J. Gun, L. Rabinovich and S. Sampath. Chemistry of Materials. 9 (1997) 2354.

47. Z. Yu, X. Jia, J. Du and J. Zhang. Solar Energy Materials \& Solar Cells. 64 (2000) 55.

48. S. C. de Oliveira, R. M. Torresi a S. I. C. de Torresi. Química Nova. $23(2000) 79$.

49. P. J. Kulesza and L. R. Faulkner. Colloids and Surfaces. 41 (1989) 123.

50. P. J. Kulesza and L. R. Faulkner. Journal of Electroanalytical Chemistry. 259 (1989) 81.

51. P. J. Kulesza and L. R. Faulkner. Journal of Electroanalytical Chemistry. 280 (1990) 233. 
52. P. J. Kulesza, W. Lu and L. R. Faulkner. Journal of Electroanalytical Chemistry. 336 (1992) 35.

53. L. M. S. Dusse, L. M. Vieira e M. G. Carvalho. Jornal Brasileiro de Patologia e Medicina Laboratorial. 39 (2003) 343.

54. E. Bechara. Informativo CRQ-IV. Maio/Junho de 2003.

55. D. E. Koshland Jr. Science. 258 (1992) 1861.

56. S. M. Shishido, A. B. Seabra, W. Loh and M. G. de Oliveira. Biomaterials. 24 (2003) 3543.

57. Agência Nacional de Vigilância Sanitária (ANVISA). Portaria $n^{0}$ 218, de 24 de março de 1999.

58. A. Settle (Ed.). Handbook of Instrumental Techniques for Analytical Chemistry. $1^{\text {st }}$ Edition. Prentice Hall PTR: New Jersey, 1997, p. 694.

59. A. M. O. Brett and C. M. A. Brett, Electrochemistry: Principles, Methods and Applications, $1^{\text {st }}$ Edition, Oxford University Press: New York, 1993, p. 339-340.

60. V. S. Bagotzky, Fundamentals of Electrochemistry, $1^{\text {st }}$ Edition, Plenum Press: New York, 1993, p. 503.

61. J. Ruzicka and E. H. Hansen, Analytica Chimica Acta, 78 (1975) 145. 
62. J. Ruzicka and E. H. Hansen, Analytica Chimica Acta. 179 (1986) 1.

63. J. Ruzicka and E. H. Hansen, Flow Injection Analysis (Chemical Analysis), v. 62, $2^{\text {nd }}$ Edition, John Wiley \& Sons, Inc: New York, 1988, p. 20.

64. J. Ruzicka and E. H. Hansen, Analytica Chimica Acta, 99 (1978) 37.

65. Z. Fang, Flow Injection Separation and Preconcentration, $1^{\text {st }}$ Edition, VCH Publishers, Inc.: New York, 1993.

66. J. Ruzicka, E. H. Hansen and H. Mosbaek, Analytica Chimica Acta, 92 (1977) 235.

67. E. H. Hansen, Analytica Chimica Acta, 308 (1995) 3.

68. B. Karlberg and G. E. Pacey, Flow Injection Analysis - A Practical Guide, $1^{\text {st }}$ Edition. Elsevier Science Publishing Company Inc.: New York, 1989.

69. J. I. Goldstein, D. E. Newbury, P. Echlin, D. C. Joy, A. D. Roming, C. E. Lyman, C. Fiori and E. Lifshin. Scanning Electron Microscopy and XRay Microanalysis: A Text for Biologists, Materials Scientists, and Geologists. $2^{\text {nd }}$ Ed. Plenum Press., New York, 1992, p. 1.

70. D. A. Skoog, F. J. Holler e T. A Nieman. Princípios de Análise Instrumental. $5^{a}$ Edição. Artmed Editora S. A.: Porto Alegre, 2002, p. 265267. 
71. D. A. Skoog, F. J. Holler e T. A Nieman. Princípios de Análise Instrumental. 5a Edição. Artmed Editora S. A.: Porto Alegre, 2002, p. 478, 483.

72. K. W. Jones and B. M. Gordon. Analytical Chemistry. 61 (1989) $341 \mathrm{~A}$.

73. D. A. Skoog, F. J. Holler e T. A Nieman. Princípios de Análise Instrumental. $5^{\text {a }}$ Edição. Artmed Editora S. A.: Porto Alegre, 2002, p. 252.

74. R. W. Cattrall. Chemical Sensors. Oxford Chemistry Primers. Series Sponsor Zeneca. Oxford University Press: Great Britain, 1997, p. 61-62.

75. M. D. Ward, in I. Rubinstein (Ed.). Physical Electrochemistry: Principles, Methods and Applications. $1^{\text {st }}$ Edition, Marcel Dekker, Inc: New York, 1984, pp. 294.

76. C. H. Hamann, A. Hamnett and W. Vielstich. Electrochemistry. $1^{\text {st }}$ Edition. WILEY-VCH: Weinheim, 1998, p. 265, 401.

77. A. J. Bard and L. R. Faulkner. Electrochemical Methods Fundamentals and Applications. $2^{\text {nd }}$ Edition, John Wiley \& Sons, Inc.: Phoenix, 2001, p. 725-726.

78. J. J. Pedrotti, L. Angnes and I. G. R. Gutz. Electroanalysis. 8 (1996) 673. 
79. J. Basset, R. C. Denney, G. H. Jeffery, J. Mendham. Vogel Análise Inorgânica Quantitativa. $4^{\mathrm{a}}$ Edição, Editora Guanabara Dois: Rio de Janeiro, 1981, p. 276.

80. L. Kosminsky and M. Bertotti. Journal of Electroanalytical Chemistry. 471 (1999) 37.

81. A J. Bard and L.R. Faulkner, Electrochemical Methods Fundamentals and Applications, $2^{\text {nd }}$ Edition, John Wiley \& Sons, Inc.: Phoenix, 2001, p.151- 292.

82. A. M. O. Brett e C. M. A. Brett. Eletroquímica: Princípios, Métodos e Aplicações. Livraria Almedina: Coimbra, 1996, p. 111-113.

83. A. J. Bard and L. R. Faulkner. Electrochemical Methods Fundamentals and Applications. $2^{\text {nd }}$ Edition, John Wiley \& Sons, Inc.: Phoenix, 2001, p. 331.

84. J. C. Miller and J. N. Miller. Statistics for Analytical Chemistry. $2^{\text {nd }}$ Edition. John Wiley \& Sons: England, 1988, p. 115.

85. C. Gabrielli, M. Keddam and R. M. Torresi. Journal of The Electrochemical Society. 138 (1991) 2657.

86. A. J. Bard and L. R. Faulkner. Electrochemical Methods Fundamentals and Applications. $2^{\text {nd }}$ Edition. John Wiley \& Sons, Inc.: New York, 2001, p. 606. 
87. J. R. C. da Rocha, T. L. Ferreira, R. M. Torresi and M. Bertotti. Talanta, 69 (2006) 148.

88. L. Kosminsky and M. Bertotti. Electroanalysis. 11 (1999) 623.

89. J. B. Russell. Química Geral. Editora McGraw-Hill do Brasil Ltda, São Paulo: 1982, p. 288-289.

90. P. Atkins e L. Jones. Princípios de Química: Questionando a vida moderna e o meio ambiente. $1^{a}$ Edição. Bookman Editora: Porto Alegre, 2001, p. 692.

91. L. Kosminsky, V. Mori and M. Bertotti. Journal of Electroanalytical Chemistry. 499 (2001) 176.

92. S. L. Queiroz e A. A. Batista. Química Nova. 22 (1999) 584.

93. V. Mori and M. Bertotti. Analyst. 125 (2000) 1629. 


\section{8 - Curriculum Vitae -118}

\section{Capítulo VIII}

\section{Curriculum}

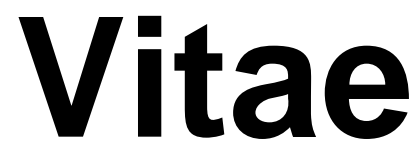




\section{Dados Pessoais}

\section{CURRICULUM VITAE}

8 - Curriculum Vitae -119

Nome: José Roberto Caetano da Rocha.

Data de nascimento: 24/01/1959.

Naturalidade: Bálsamo - SP.

Estado Civil: Casado.

\section{Endereço Profissional}

Universidade Estadual de Ponta Grossa - UEPG

Departamento de Química - Sala 88 - Bloco M

Av. Carlos Cavalcanti, 4748

Campus Uvaranas - Ponta Grossa - PR - CEP 84030-900

e-mail: jrcrocha@quim.iq.usp.br.

jircrocha@uepg.br.

\section{Formação Acadêmica}

$\leftrightarrow$ Técnico em Química.

Colégio Dr. Clóvis Bevilacqua - Santo André - SP.

Período: 1976 a 1979.

$\stackrel{\leftrightarrow}{\star}$ Bacharel e Licenciado em Ciências com Habilitação em Química.

Faculdades Oswaldo Cruz - São Paulo - SP.

Período: 1990 a 1994.

$\stackrel{\leftrightarrow}{\rightarrow}$ Mestre em Ciências - Área Química Analítica

Título da Dissertação: Estudos Eletroquímicos Envolvendo Eletrodos Modificados por Metaloporfirinas e Aplicação na Determinação de Nitrato $\left(\mathrm{NO}_{3}^{-}\right)$e Nitrito $\left(\mathrm{NO}_{2}^{-}\right)$.

Instituto de Química - USP - São Paulo - SP.

Período: março/1998 a fevereiro/2001. 
$\stackrel{\leftrightarrow}{\star}$ Doutor em Química - Área Química Analítica

Título da Tese: Eletrodos Modificados por Óxido de Tungstênio: Métodos de Preparação e Aplicações Analíticas

Instituto de Química - USP - São Paulo - SP.

Período: março/2001 a janeiro/2006.

\section{Experiência Profissional}

$\stackrel{\leftrightarrow}{\rightarrow}$ Universidade Estadual de Ponta Grossa

Professor Colaborador

Período: abril/2005 a dezembro/2005.

Renovação de Contrato: até dezembro/2006

$\stackrel{\leftrightarrow}{\leftrightarrow}$ Secretaria da Educação do Estado de São Paulo.

Professor Efetivo

Período: 2000 a março/2005.

Professor OFA

Período: 1995 a julho/1998.

$\Leftrightarrow$ Bolsista CNPq

Doutorado

Período: março/2001 a fevereiro/2005

Mestrado

Período: 08/1998 a 07/2000.

$\stackrel{4}{\rightarrow}$ Rhodia S/A. - São Paulo-SP.

Chefe de Seção - Laboratório Químico.

Período: julho/1990 a agosto/1995. 
Técnico de Laboratório

8 - Curriculum Vitae -121

Período: abril/1989 a julho/1990

$\stackrel{\leftrightarrow}{4}$ Laboratórios Anakol Ltda. - São Paulo - SP.

Controlador de Qualidade.

Período: 10/1979 a 07/1987.

\section{Participação em Congressos}

$\stackrel{4}{4}$ FERREIRA, Tiago Luiz; ROCHA, José Roberto Caetano da; TORRESI, Roberto Manuel; BERTOTTI, Mauro. Influência do pH na solubilização de filmes de óxidos de tungstênio: uso de microbalança eletroquímica de cristal de quartzo. In: 28${ }^{a}$. REUNIÃO ANUAL DA SOCIEDADE BRASILEIRA DE QUÍMICA, Juiz de Fora. 2005.

$\Leftrightarrow$ ROCHA, José Roberto Caetano da; FERREIRA, Tiago Luiz; BERTOTTI, Mauro. Comparação da redução catódica de oxiânions em eletrodo de carbono vítreo modificado com óxidos de molibdênio ou com óxidos de tungstênio. In: XIV SIMPÓSIO BRASILEIRO DE ELETROQUÍMICA E ELETROANALÍTICA, 2004, Teresópolis - RJ. A Eletroquímica na interface da nanociência e nanotecnologia. Teresópolis: Instituto de Química - UFRJ, 2004. p. $75-75$.

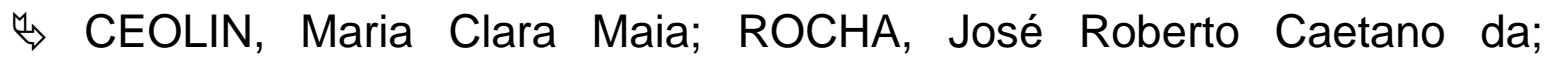
TORRES, Bayardo Baptista. Atividades Motivadoras para a Aprendizagem. In: $26^{\mathrm{a}}$. REUNIÃO ANUAL DA SOCIEDADE BRASILEIRA DE QUÍMICA, 2003, Poços de Caldas. Atividades Motivadoras para a Aprendizagem. Poços de Caldas: Sociedade Brasileira de Química, 2003. p. ED-65. 
$\stackrel{4}{4}$ ROCHA, José Roberto Caetano da; CEOLIN, Maria Clara Maia; SOUTO, Sônia Maria Guedes Do. Comparação do Nível de Apropriação de Conceitos Químicos utilizando Diferentes Abordagens no Ensino Médio Parte I. In: $26^{\mathrm{a}}$. REUNIÃO ANUAL DA SOCIEDADE BRASILEIRA DE QUÍMICA, 2003, Poços de Caldas. São Paulo: Sociedade Brasileira de Química, 2003. p. ED-64.

$\stackrel{4}{4}$ ROCHA, José Roberto Caetano da; CEOLIN, Maria Clara Maia; SOUTO, Sônia Maria Guedes Do. Comparação do Nível de Apropriação de Conceitos Químicos utilizando Diferentes Abordagens no Ensino Médio Parte II. In: 26․ REUNIÃO ANUAL DA SOCIEDADE BRASILEIRA DE QUÍMICA, 2003, Poços de Caldas: Sociedade Brasileira de Química, 2003. p. ED-62.

$\Leftrightarrow$ ROCHA, José Roberto Caetano da; CEOLIN, Maria Clara Maia; SOUTO, Sônia Maria Guedes Do. Comparação do Nível de Apropriação de Conceitos Químicos utilizando Diferentes Abordagens no Ensino Médio Parte III. In: 26․ REUNIÃO ANUAL DA SOCIEDADE BRASILEIRA DE QUÍMICA, 2003, Poços de Caldas: Sociedade Brasileira de Química, 2003. p. ED-64.

$\stackrel{\leftrightarrow}{\leftrightarrow}$ ROCHA, José Roberto Caetano da; PEREIRA, Audrei Conti; BERTOTTI, Mauro. Determinação Amperométrica de $\mathrm{IO}_{3}{ }^{-}$Utilizando Eletrodo de Carbono Vítreo Modificado com $\mathrm{WO}_{3}$. In: $12^{\circ}$. ENCONTRO NACIONAL DE QUÍMICA ANALÍTICA, 2003, São Luis - MA. 2003. 
$\Leftrightarrow$ ROCHA, José Roberto Caetano da; KOSMINSKY, Luís; BERTOTTI, Mauro. Electrocatalytic Reduction of Iodate at Glassy Carbon Electrodes Modified by Tungsten Oxides. In: $54^{\text {th }}$ ANNUAL MEETING OF THE INTERNATIONAL SOCIETY OF ELECTROCHEMISTRY, 2003, São Pedro. Book of Abstracts. International Society of Electrochemistry, 2003. p. 77.

$\Leftrightarrow$ ROCHA, José Roberto Caetano da; BERTOTTI, Mauro. Estudo Preliminar sobre a Eletrodeposição de Óxido de Tungstênio (VI, V) em Eletrodo de Carbono Vítreo. In: XIII - SIMPÓSIO BRASILEIRO DE ELETROQUÍMICA E ELETROANALÍTICA, 2002, Araraquara: Cultura Acadêmica Editora, 2002. p. 145-147.

$\Leftrightarrow$ ROCHA, José Roberto Caetano da; DEMETS, Gregoire Jean François; BERTOTTI, Mauro; ARAKI, Koiti; TOMA, Henrique Eisi. Transferência de carga em eletrodos modificados com porfirinas tetrarutenadas eletrostaticamente montadas. In: XXV - REUNIÃO ANUAL DA SOCIEDADE BRASILEIRA DE QUÍMICA, 2002, Poços de Caldas. Livro de Resumos. São paulo: SBQ, 2002.

$\Leftrightarrow$ ROCHA, José Roberto Caetano da; ANGNES, Lúcio; ARAKI, Koiti; TOMA, Henrique Eisi; BERTOTTI, Mauro. Catálise da oxidação do nitrito em superfície modificada com depósitos alternados de porfirinas de cobalto e zinco. In: XII - SIMPÓSIO BRASILEIRO DE ELETROQUÍMICA E ELETROANALítICA, 2001, Gramado. Anais. Gramado, 2001.. Gramado: UFRS, 2001. p. 454-456. 
(4) ROCHA, José Roberto Caetano da; NATIVIDADE, Maria Auxiliadora Efrem; GALHARDO, Cristiane Xavier; MASINI, Jorge Cesar. Determinação espectrofotométrica de cloridrato de fenilefrina em fármacos através de análise por injeção em fluxo. In: XXIII - REUNIÃO ANUAL DA SOCIEDADE BRASILEIRA DE QUÍMICA, 2000, Poços de Caldas. Livro de Resumos. São Paulo: SBQ, 2000. v. 3.

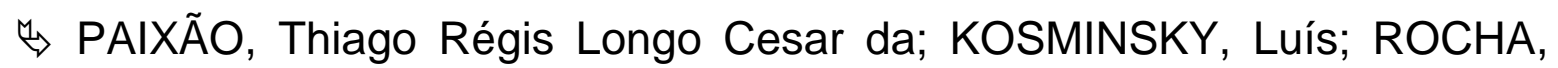
José Roberto Caetano da; BERTOTTI, Mauro. Oxidação do nitrito em eletrodo modificado: Desenvolvimento de método analítico para determinação em embutidos. In: XXIII - REUNIÃO ANUAL DA SOCIEDADE BRASILEIRA DE QUÍMICA, 2000, Poços de Caldas - MG. Livro de Resumos. São Paulo: SBQ, 2000. v. 3.

$\Leftrightarrow$ ROCHA, José Roberto Caetano da; BERTOTTI, Mauro; ANGNES, Lucio; ARAKI, Koiti; TOMA, Henrique Eisi. Sensor Amperométrico para análise de nitrato e nitrito: Uso de porfirinas metálicas. In: X - ENCONTRO NACIONAL DE QUÍMICA ANALÍTICA, 1999, Santa Maria - RS. Livro de Resumos UFSM. Santa Maria: UFSM, 1999.

\section{Publicações}

$\stackrel{\leftrightarrow}{\hookrightarrow}$ J. R. C. da Rocha, T. L. Ferreira, R. M. Torresi and M. Bertotti. An Analytical Application of the Electrocatalysis of the lodate Reduction at Tungsten Oxide Films. Talanta. 69 (2006) 148.. 
4 $>$ J. R. C. da Rocha e A. CAVICCHIOLI. Uma abordagem alternativa para o aprendizado dos conceitos de átomo, molécula, elemento químico, substância simples e substância composta, nos Ensinos Fundamental e Médio. Química Nova na Escola. 21 (2005) 29.

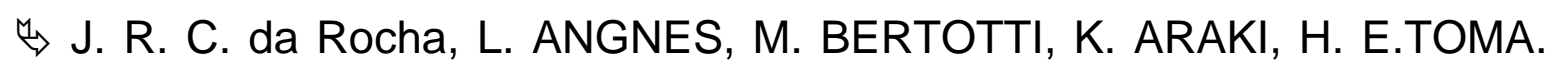
Amperometric Detection of Nitrite and Nitrate at Tetraruthenated PorphyrinModified Electrodes in a Continuous-Flow Assemby. Analytica Chimica Acta. 452 (2002) 23.

$\Leftrightarrow$ J. R. C. da Rocha, C. X. GAlhaRdo, M. A. E. NATIVIDADE, J. C. MASINI. Spectrophotometric Determination of Phenylephrine Hidrochloride in Pharmaceuticals by Flow Injection Analysis Explointing the Reaction with Potassium Ferricyanide and 4-Aminoantipyrine. Journal Of AOAC International. 85 (2002) 875.

$\stackrel{\leftrightarrow}{\rightarrow}$ J. R. C. da Rocha, G. J. F. DEMETS, M. BERTOTTI, K. ARAKI, H. E. TOMA. Charge Transfer at Electrostatically Assembled Tetraruthenated Porphyrin Modified Electrodes. Journal of Electroanalytical Chemistry. 526 (2001) 69.

$\stackrel{\leftrightarrow}{\hookrightarrow}$ J. R. C. da Rocha, L. KOSMINSKY, T. R. L. C. da PAIXÃO, M. BERTOTTI. Anodic Oxidation of Nitrite at a Molybdenum Oxide Layer. Electroanalysis. 13 (2001) 155. 